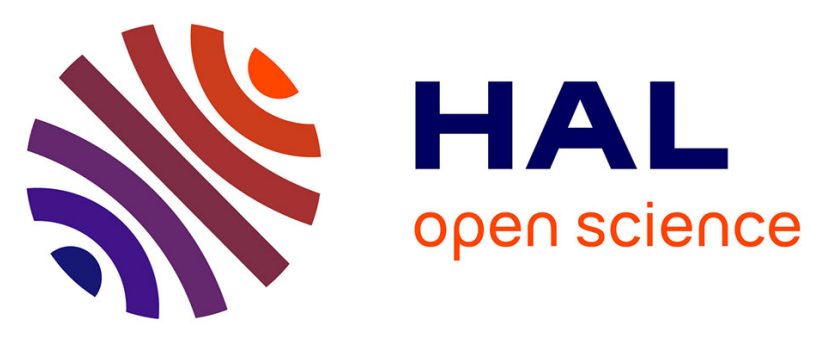

\title{
Deux moulins hydrauliques du Haut-Empire romain en Narbonnaise: villae des Mesclans à La Crau et de Saint-Pierre/Les Laurons aux Arcs (Var) Jean-Pierre Brun, Marc Borréani
}

\section{- To cite this version:}

Jean-Pierre Brun, Marc Borréani. Deux moulins hydrauliques du Haut-Empire romain en Narbonnaise: villae des Mesclans à La Crau et de Saint-Pierre/Les Laurons aux Arcs (Var). Gallia - Archéologie de la France antique, 1998, 55, pp.279-326. 10.3406/galia.1998.3004 hal-01901602

\section{HAL Id: hal-01901602 https://hal.science/hal-01901602}

Submitted on 16 Jan 2020

HAL is a multi-disciplinary open access archive for the deposit and dissemination of scientific research documents, whether they are published or not. The documents may come from teaching and research institutions in France or abroad, or from public or private research centers.
L'archive ouverte pluridisciplinaire HAL, est destinée au dépôt et à la diffusion de documents scientifiques de niveau recherche, publiés ou non, émanant des établissements d'enseignement et de recherche français ou étrangers, des laboratoires publics ou privés.

\section{(1) (1) $\$$}

Distributed under a Creative Commons Attribution - NonCommercial - NoDerivatives $\mid 4.0$ 


\title{
DEUX MOULINS HYDRAULIQUES DU HAUT-EMPIRE ROMAIN EN NARBONNAISE
}

\author{
Villae des Mesclans à La Crau \\ et de Saint-Pierre/Les Laurons aux Arcs (Var)
}

\section{Jean-Pierre BRUN" et Marc BORRÉANI*}

À la mémoire de Pascal Lecacheur qui nous a quittés durant la fouille des Mesclans ${ }^{1}$.

Mots-clés. Narbonnaise, moulin hydraulique, huilerie, installation vinicole, Haut-Empire, aqueduc.

Key-words. Gallia Narbonensis, water-mill, oil press, wine press, Early Roman Empire, aquaduct.

Résumé. Deux moulins hydrauliques d'époque romaine ont été mis au jour en 1984 et en 1996 lors de fouilles d'urgence dans le département du Var : villa de Saint-Pierre/Les Laurons aux Arcs et villa des Mesclans à La Crau. Tous deux sont datés du Haut-Empire (probablement du II s.) et ils ont fonctionné jusqu'au milieu du III s. environ. Ils faisaient partie de villae produisant, outre des céréales, $d u$ vin et de l'huile. Ces moulins pourraient avoir été utilisés pour couvrir les besoins des habitants el des travailleurs du domaine. Leur existence pose le problème de la fréquence de l'utilisation de l'énergie hydraulique car ces moulins étaient relativement courants non seulement dans les villes et à leurs abords, mais aussi dans les campagnes : les exemples se multiplient dans l'ensemble du bassin méditerranéen (notamment en Italie, en Afrique), en Gaule et en Brelagne.

Abstract. Two hydraulic mills from the Roman era have been uncovered in 1984 and 1996 during rescue excavations carried out in the department of Var, one in the villa of Saint-Pierre/Les Laurons (Les Arcs), one in the villa of Les Mesclans (La Crau). They were both dated from the Early Roman Empire (probably from the $2^{\text {nd }}$ century AD) and have been in use until about the middle of the $3^{\text {rl }}$ century $A D$. They were parts of villae producing wine, oil, as well as cereals. These mills could have been used by the estate inhabitants and workers for their own needs. Their discovery rises a question : how frequently was hydraulic energy used at that time ? These mills were in fact relatively common not only in cities and their surroundings but also in the country; many examples have been found in all the Mediterranean countries (particularly in Italy and Africa), Gaul and Germany.

* UMR 6573 du CNRS, Centre Camille Jullian, Archéologie méditerranéenne et africaine, MMSH, 5 rue du Château de l'Horloge, BP 647 , F-13094 Aix-en-Provence cedex 2 et Centre archéologique du Var.

** Conseil général du Var, Centre archéologique du Var, 14 boulevard Bazeilles, F-83000 Toulon.

1. La fouille des Mesclans a été conduite par Marc Borréani et Jean-Pierre Brun avec la collaboration des salariés et des bénévoles du Centre archéologique du Var : Philippe Aycard, Gabriel Cazalas, Michel Cruciani, Jean-I ur. Demontès, Jean-Pierre Dewert, Françnise I.aurier, Nicole I e. Tiec, Pierre. Saliceti et Luc Severs. Les plans sont de Françoise Laurier, topographe du Centre archéologique du Var. 
La question de la diffusion réelle des moulins hydrauliques durant l'Antiquité a stagné longtemps à la suite de l'article célèbre de Marc Bloch qui avait avancé que le moulin à eau, " invention antique, est médiéval par l'époque de sa véritable expansion " (Bloch, 1935, rééd. 1983 , p. 806). À partir des années 1980 , un meilleur recensement des textes, le réexamen ou la reprise de fouilles anciennes (en Bretagne, à Barbegal dans les Bouches-du-Rhône, aux Thermes de Caracalla et au Janicule à Rome, à l'Agora d'Athènes ${ }^{2}$ ), ainsi que des recherches nouvelles (à Chemtou en Tunisie, à Ickham en Angleterre, etc. ${ }^{3}$ ) ont apporté une documentation qui montre que les moulins à eau étaient bien mieux diffusés qu'on ne le pensait jusqu'alors, notamment dans les villes, les vici, les camps militaires ${ }^{4}$. Mais les moulins hydrauliques, demandant un savoir-faire certain, étaientils fréquents dans les campagnes et depuis quelle époque ? Était-ce un équipement courant au point que chaque villa ou presque ait pu en être dotée, comme, dans certaines régions, elles étaient équipées de pressoirs à vin ou à huile?

Ces questions commencent à recevoir des réponses grâce à des fouilles d'urgence dont il faut répéter combien elles permettent de renouveler les problématiques ${ }^{5}$. Après les exemples signalés dans le Centre de la Gaule, en Bretagne et en Germanie ${ }^{6}$, la fouille préventive et la publication rapide de deux moulins ruraux en Suisse ont apporté des éléments décisifs, notamment sur leur chronologie et sur la modestie de leurs vestiges. Le plus ancien a été découvert au lieu-dit En Chaplix à Avenches, Suisse (Castella, 1994). La construction de ce moulin est précisément datée de 54 de notre ère, grâce à la dendrochronologie, et ses vestiges se réduisent à des meules brisées et à quelques planches et pieux qui, dans un autre

2. Bretagne : voir la mise au point de Spain, 1984a; Barbegal : Benoit, 1940 et Leveau, 1995; Thermes de Caracalla : Schiøler, Wikander, 1984 ; Janicule : Bell, 1992, 1994 ; Agora d'Athènes : Parsons, 1936 ; Spain, 1987.

3. Chemtou : Rakob, Röder, 1989; Röder, Röder, 1993; Ickham : Spain, 1984b.

4. Des mises au point historiographiques complètes ont été réalisées par Ö. Wikander, 1984, 1985, 1990 ; par M.-C. Amouretti, 1986, p. 241249, 1992 et par A. Wilson, 1995.

5. Sur l'heuristique des fouilles d'urgence en Provence voir : Brun $e t$ al., 1993-1994.

6. À Gannes, commune de Beaulieu dans le Loiret : Boisvillette, 1840 ; aux Martres-de-Veyre dans le Puy-de-Dôme : Komeut, 1978; à Lōsnich : terrain, ne se fussent pas conservés. De nombreuses installations de ce type ont dû échapper à l'attention des archéologues, d'autant plus que, pour profiter d'un ruisseau ou d'une chute d'eau, le moulin peut être situé à quelque distance de la villa, comme c'est le cas à Avenches où les vestiges ont été découverts à l'occasion de travaux autoroutiers à $200 \mathrm{~m}$ environ des bâtiments de la villa suburbaine du Russalet ${ }^{7}$. Le second moulin a été fouillé à Hagendorn dans le canton de Zoug (Gähwiler, 1984 ; Gähwiler, Speck, 1991). Il est daté des alentours de 200 après J.-C. et a livré des fragments de trois roues à aubes alimentées par le côté, des fragments de pignons et des meules.

En Narbonnaise, mis à part le cas exceptionnel de «l'usine " de Barbegal (Fontvieille, Bouches-duRhône) ${ }^{8}$, on ne connaissait jusqu'ici guère de moulins comparables à ceux mis au jour en Italie, en Allemagne, en Angleterre, en Suisse et dans le Centre de la France ${ }^{9}$. C'est la fouille d'une villa promise à la destruction qui offre aujourd'hui un nouvel exemple. La commune de La Crau dans le département du Var a fait l'objet d'une opération de prospection-inventaire en 1995 conduite par l'un de nous (M.B.). Le site des Mesclans a été découvert quelques jours seulement avant que le propriétaire de la parcelle ne la fasse défoncer pour planter une nouvelle vigne (fig. 1). Une rapide entente a permis de repousser le défonçage à l'automne 1996 et de procéder à la fouille au printemps de la même année. Le site était déjà très détérioré par les labours anciens. Les vestiges dégagés comportent essentiellement une installation viticole, une huilerie, quelques pièces d'habitation et des bassins. En fin de campagne, dans un secteur très arasé, sont apparues les ruines caractéristiques d'un moulin à eau.

7. Nous tenons à remercier Daniel Castella, François Eschbach et toute l'équipe d'Archéodunum à Gollion dans le canton de Vaud de nous avoir chaleureusement accueillis et d'avoir généreusement mis à notre disposition toute la documentation qu'ils avaient accumulée pour préparer leur publication. Il nous est agréable de remercier de leur aide nos collègues aixois Marie-Claire Amouretti et Henri Amouric.

8. Les grandes meuneries urbaines à plusieurs chambres de mouture sont attestées dans plusieurs cas, notamment à Rome, Janicule (Bell, 1992, 1994) et à Chemtou, Tunisie (Röder, Röder, 1993).

9. Il faut toutefois signaler que les vestiges d'un coursier de roue à aubes a été découvert à Lattes et publié en 1989 (Amouric et al., 1989) et que les fouilles de La Bourse à Marseille ont probablement mis au jour un moulin hydraulique (cf. infra, p. 316). 


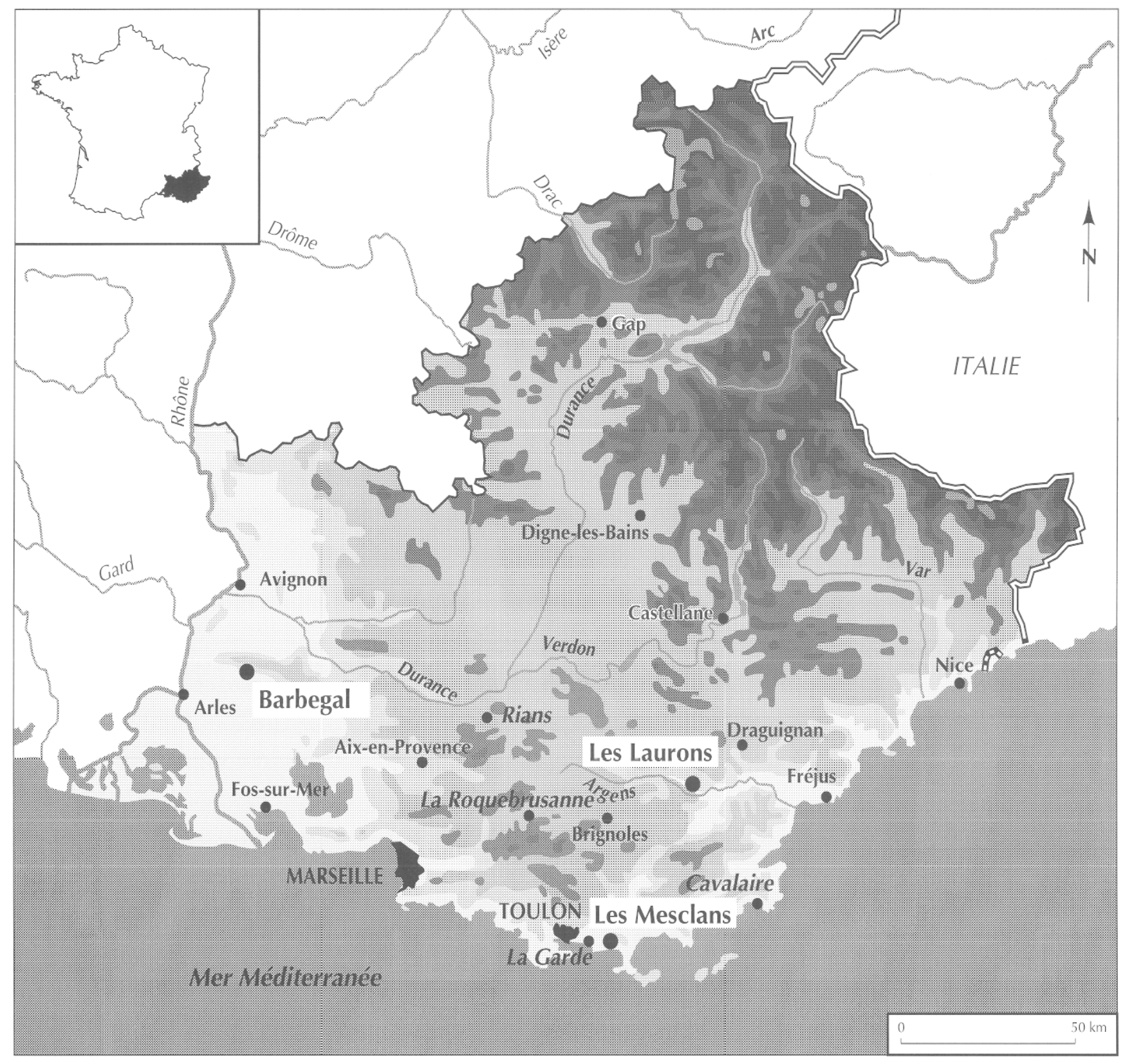

Fig. 1 - Carte de situation.

Cette découverte a attiré notre attention sur des structures similaires que Marc Borréani et Michel Pasqualini avaient fouillées en 1984 au lieu-dit Saint-Pierre/Les Laurons sur la commune des Arcs (Var), lors de la construction d'un lotissement (Bérato et al., 1990). Les plans des deux moulins sont très proches et leur étude mérite une publication conjointe.

\section{LA VIILIA DES MESCLANS À LA CRAU}

\section{LE CONTEXTE ARCHÉOLOGIQUE}

La villa des Mesclans est située dans la basse vallée du Gapeau, à l'est de Toulon, sur la commune de La Crau (fig. $2, n^{\circ} 1$ ). Le Gapeau est une rivière côtière qui prend sa source à Signes et se jette dans la Méditerranée à hau- 
teur des Salins-d'Hyères, après avoir reçu l'apport du RéalMartin. La basse vallée du Gapeau et la vallée du RéalMartin (communes de La Crau et de Hyères) sont bien connues grâce à des prospections systématiques. À la fin de l'Âge du Fer, plusieurs habitats de hauteur étaient occupés, notamment à La Bouisse sur la commune de Cuers (fig. 2, $n^{\circ}$ 2). De l'autre côté de la vallée du Réal-Martin, au lieu-dit Saint-Michel de Valbonne (fig. 2, $n^{\circ} 8$ ), un habitat fortifié occupe une croupe rocheuse. Des fouilles récentes ont permis de dater le rempart du $\mathrm{II}^{\mathrm{e}} \mathrm{s}$. avant J.-C. et de dégager une case d'habitation (Brun, 1994) ; l'habi-

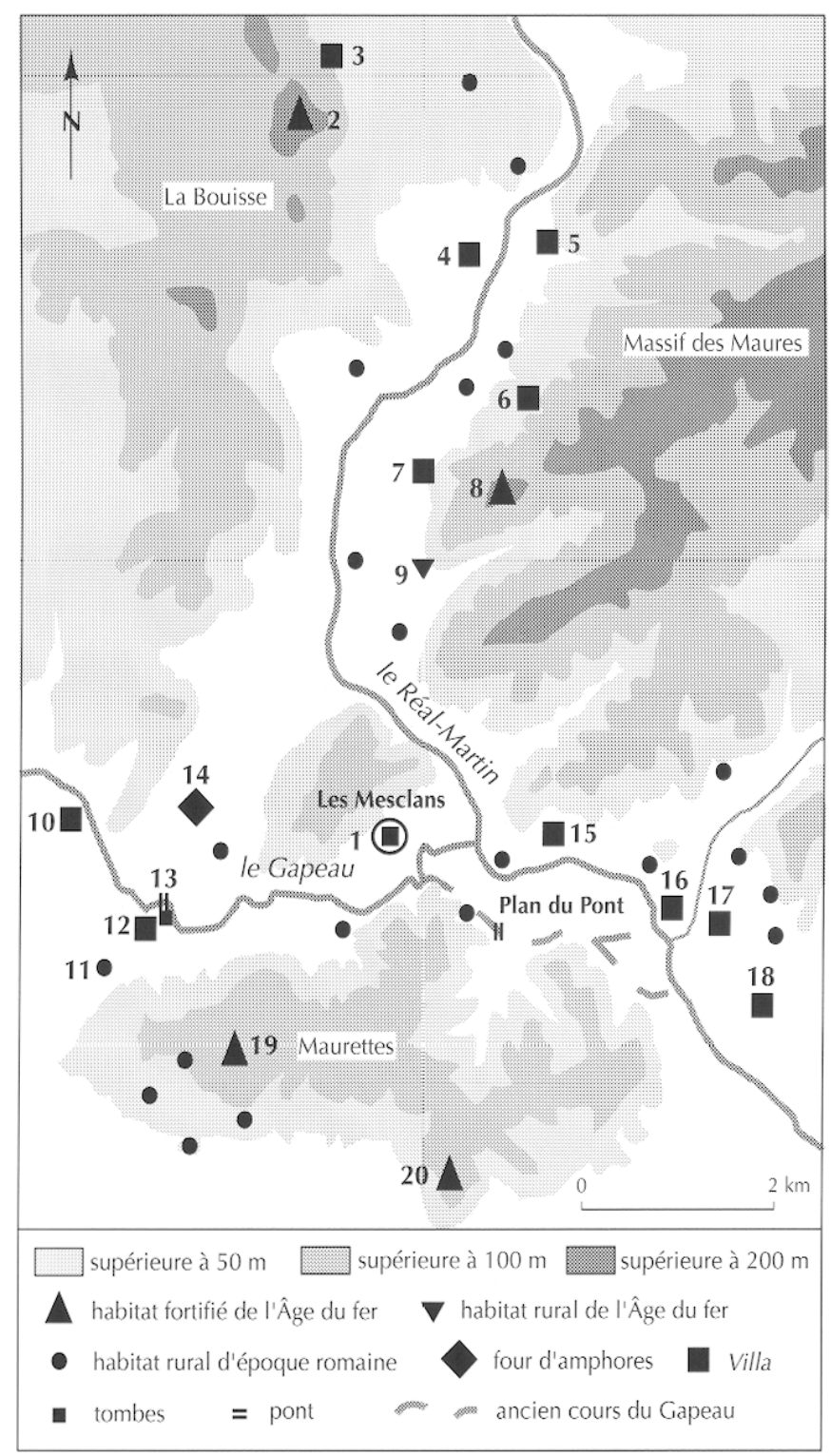

Fig. 2 - Carte archéologique des environs de la villa des Mesclans à La Crau (M. Borréani). tat était associé à un sanctuaire guerrier qui a livré des stèles portant des représentations gravées de têtes coupées (Benoit, 1955, p. 31 et pl. 26). La divinité a continué d'être adorée à l'époque romaine sous le nom de Mars Rudianus dont on a retrouvé deux inscriptions (CIL XII, 381 et 382). Ce sanctuaire marquait probablement la limite entre les cités de Fréjus et d'Arles puisqu'une borne de territoire y a été découverte (Gascou, 1992). Au sud du Gapeau, la chaine de collines des Maurettes, qui domine la vallée des Mesclans, culmine au Fenouillet où se trouve un habitat fortifié occupé au Ve puis aux II ${ }^{\mathrm{e}}$ et I $\mathrm{I}^{\mathrm{er}}$ s. avant J.-C. et au cours de l'Antiquité tardive (fig. 2, $\mathrm{n}^{\circ} 19$ ). Dans ce même petit massif, la colline du château d'Hyères (fig. 2, $\mathrm{n}^{\circ}$ 20) est également occupée à l'Âge du Fer, aux II ${ }^{\text {e-Ier }} \mathrm{s}$. avant J.-C., mais les constructions médiévales ont ici occulté toute fortification de cette période.

Dès la fin de l'Âge du Fer, un habitat indigène de plaine s'est implanté à Valbonne (fig. 2, n 9), au pied même de l'habitat fortifié de Saint-Michel. Dans la seconde moitié du Ir s. avant J.-C., les sites de hauteur furent progressivement abandonnés, et la plaine, qui semble avoir été centuriée ${ }^{10}$, se couvrit de nouvelles cultures et d'habitats dispersés dont plusieurs prirent de l'importance au cours du Haut-Empire et devinrent de grandes tillae: aux Mesclans, à Notre-Dame (fig. 2, $\mathrm{n}^{\circ} 11$ ) et aux Meissonniers (fig. 2, $\mathrm{n}^{\circ} 10{ }^{11}$, dans la vallée du Gapeau, à La Philippe (fig. 2, ${ }^{\circ}$ 3), à Sigaloux (fig. 2, $\mathrm{n}^{\circ} 4$ ), au Maupas (fig. 2, $\mathrm{n}^{\circ} 5$ ), à La Grande Bastide (fig. 2, $\mathrm{n}^{\circ} 6$ ) et à La Décapris (fig. 2, $\left.\mathrm{n}^{\circ} 7\right)^{12}$, dans la

10. G. Chouquer et F. Favory (1992, p. 148-149) ont décelé des traces de deux réseaux. L'un dénommé Toulon A, orienté N26 $10^{\prime} \mathrm{E}$, correspondrait au cadastre mis en place lors de la déduction de la colonie d'Arles; l'autre, Toulon B, est orienté $\mathrm{N1}^{\circ} 45^{\prime} \mathrm{E}$ et serait attribuable au Haut-Empire. Aucune trace de limite n'a été repérée dans le bassin même des Mesclans, les limites les plus denses étant au nord de La Crau, dans le secteur du Collet-Long.

11. La villa de $\mathrm{N}$ otre-Dame a livré des dolia et un forum de pressoir à levier et celle des Meissonniers des briques d'hypocauste et des moellons de grès.

12. La villa de La Philippe, occupée durant tout l'Empire, comportait une installation de pressurage qui a été fouillée (Brun, 1985). Sur la villa de Sigaloux, trois cuves accolées ont été détruites lors de défonçages agricoles. À la villa du Maupas un sol bétonné a été arraché lors de défonçages et le site a livré des pilettes circulaires d'hypocauste et une tuile cheminée (Coudert, Pasqualini, 1982, site $n^{\circ} 11$, p. 43). La villa de La Grande Bastide, occupée du I Ier au Ve $s$. après J.-C., possède des sols de béton de tuileau et des enduits muraux en place et a livré des fragments de marbre gris-blanc, des tubuli et des moellons avec traces de chaux. Dans la villa de La Décapris, on a anciennement trouvé 
vallée de Sauvebonne (vallée du Réal-Martin) et à La Tuilerie (fig. 2, $\mathrm{n}^{\circ} 15$ ), à La Clapière (fig. $2, \mathrm{n}^{\circ} 16$ ), à La Jeannette (fig. 2, $\mathrm{n}^{\circ} 17$ ) et à Sainte-Eulalie (fig. 2, $\left.\mathrm{n}^{\circ} 18\right)^{13}$, dans la vallée du Gapeau, en aval des Mesclans. Plusieurs de ces villae étaient équipées de pressoirs à huile ou à vin, et leur implantation le long du Gapeau et du Réal-Martin devait faciliter les expéditions vers la côte. Il est significatif qu'un important atelier d'amphores gauloises soit situé à $1 \mathrm{~km}$ du Gapeau, au lieu-dit Le ColletLong (fig. 2, $\mathrm{n}^{\circ} 14$ ). Des prospections électromagnétiques menées en 1980 ont montré qu'il existait vraisemblablement deux fours ayant produit des amphores gauloises 4 durant les $\mathrm{I}^{\mathrm{er}}$ et $\mathrm{II}^{\mathrm{e}}$ s. de notre ère (Gruel, Leblanc, 1981 ; Laubenheimer, 1985, p. 203206).

Le Gapeau, axe nord-sud de circulation des marchandises, était franchissable d'est en ouest à hauteur de la villa de Notre-Dame : la culée d'un pont en épaisse maçonnerie est encore visible sur la rive gauche du fleuve au lieu-dit Les Abattoirs (fig. 2, $n^{\circ} 13$ ). Il devait donc exister une voie joignant la côte (en fait Olbia) à la vallée du Réal-Martin par Le Collet-Long. Cet axe a attiré des sépultures, notamment à hauteur du hameau Notre-Dame (fig. 2, $\mathrm{n}^{\circ}$ 12) où des tombes du III ${ }^{\mathrm{e}}$ ct du IVe s. ont ćté fouillćcs cn 1980 (Gćbara, Pasqualini, 1993).

une statue en ronde bosse (Silène), un bas-relief (rinceau) et de nombreuses tuiles marquées I. Herennius ; un sauvetage effectué en 1993 par M. Borréani et Fr. Laurier a mis au jour un four de tuilier du Bas-Empire (inédit).

13. Au domaine de I a Tuilerie, situé à $1 \mathrm{~km}$ des Mesclans, sur l'autre rive du Réal-Martin, un gisement occupé durant tout l'Empire a livré du béton de tuileau, des tuiles timbrées (L. Herennius), ainsi qu'un fragment de carneau (prospection Jean-Marie Michel). Un site proche a également livré du béton de tuileau et des tuiles timbrées (Mari). À $1,5 \mathrm{~km}$ plus au sud, la villa de La Clapière était ornée de mosaĩques. L'une d'elle, datable du $\mathrm{I}^{\mathrm{er}} \mathrm{s}$. de notre ère, représente un dauphin et un vase (Garcin, 1835, p. 591 ; Denis, 1882, p. 505-506) ; les prospections récentes y ont trouvé des dolia, du béton de tuileau et des tuiles marquées L. Herennius. À $500 \mathrm{~m}$ de là, au sud du ruisseau des Borels, le domaine de La Jeannette possède une villa dotée de pressoirs à huile ou à vin (Brun, 1986, p. 174, n 51). À $900 \mathrm{~m}$ au sud, le domaine de Sainte-Eulalie est partiellement bâti sur une villa romaine équipée de pressoirs (Brun, 1986, p. 175, n53). Des sondages, effectués dans le cadre d'une opération d'urgence par Annick De Fenoyl-Leducq et Françoise Brien en 1990, ont permis de préciser la chronologie qui $s^{\prime}$ 'étend du $\mathrm{I}^{\mathrm{er}} \mathrm{au} \mathrm{V}^{\mathrm{e}} \mathrm{s}$. de notre ère et déceler la présence probable d'un lieu de culte et d'ateliers de métallurgistes (Centre archéologique du Var, 1990, p. 231-232).

\section{LA VILLA}

Le quartier des Mesclans tire son nom du confluent entre le Gapeau et le Réal-Martin (mescla $=$ mélange). Entre la colline du Mont Redon au nord et celle du Fenouillet au sud, le Gapeau a formé un petit bassin dont l'entrée est marquée par un resserrement (fig. 2). Le domaine de la villa des Mesclans ne devait pas être limité, comme aujourd'hui, par le confluent des deux rivières, car, jusqu'au Moyen Âge, le Gapeau coulait au pied des Maurettes et un pont permettait de le franchir au lieu-dit Plan du Pont. Là, dans les riches terres alluviales humides, on devait entretenir des pâturages et planter des céréales tandis que les coteaux devaient porter, comme aujourd'hui, des vignes et des oliviers. Les bâtiments de la villa sont implantés en piémont sud de la colline de schiste du Mont Redon. Les constructions, étagées sur la pente de la colline à l'altitude moyenne de $30 \mathrm{~m}$, dominent la rive gauche du Gapeau distante de $500 \mathrm{~m}$ environ.

En 1982, des prospections menées par J.-P. Coudert et M. Pasqualini sur la commune de La Crau avaient localisé au pied de la colline du Mont Redon quatre sites, considérés comme restreints, et datés des $\mathrm{I}^{\text {er }}$ II $^{\mathrm{c}}$ s. aprc̀s J.-C. (Coudcrt, Pasqualini, 1982, sitcs 9a, $9 \mathrm{~b}, 9 \mathrm{c}$ et $9 \mathrm{~d}$, p. 43). Celui qui nous intéresse (site 9c) avait livré un fond de dolium et une monnaie lors d'un défonçage. Depuis lors, le site n'ayant plus été visité, son intérêt restait largement sous-estimé. Les recherches systématiques entamées en octobre 1995 afin de réactualiser la carte archéologique de la commune de La Crau furent l'occasion d'une nouvelle prospection qui rêvéla l'ampleur du site ${ }^{14}$. D'abondants matériaux de construction et du mobilier archéologique étaient éparpillés dans les vignes et dans un champ en friche situé sur la pente de la colline, sur environ $5000 \mathrm{~m}^{2}$. Le champ de vignes au sud, dans la vallée, au contact de la colline, a également livré des vestiges datables entre le $\mathrm{I}^{\mathrm{er}}$ et le $\mathrm{V}^{\mathrm{e}} \mathrm{s}$. de notre ère, ainsi que des matériaux (tuiles marquées L. Her(ennii) Opt(ati), Mari, L. Fabi, briques en portion de cylindre, plaques de marbre) qui permettent d'y situer la pars urbana (site $9 \mathrm{~d}$ de 1982) (fig. 3).

14. L'opération de prospection a été financée par le Ministère de la Culture, Service régional de l'Archéologie. 


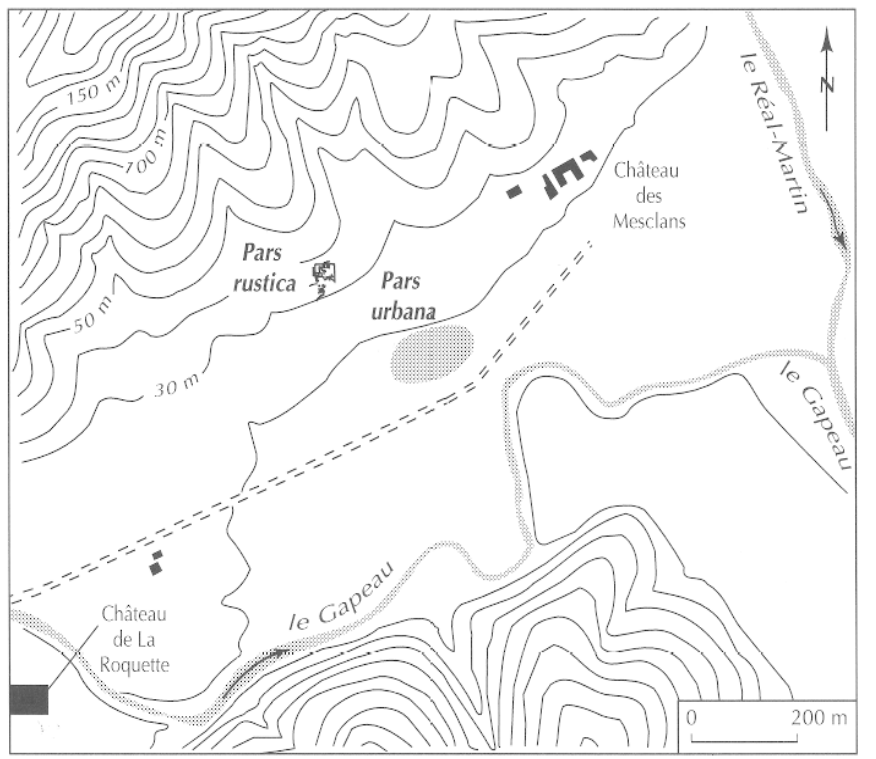

Fig. 3 - Les Mesclans : plan de masse (Fr. Laurier).

Une parcelle en friche, sur les pentes de la colline, était jonchée de débris de tuiles et de dolium. Ce terrain devant être défoncé en vue de la plantation de vignes, il fut décidé par le Service régional de l'Archéologie, en accord avec le propriétaire, M. Xavier de Villeneuve-Bargemon, de procéder à des sondages afin d'évaluer l'état de conservation des vestiges et leur risque de destruction lors du défonçage. Ces sondages, réalisés en décembre 1995, mirent au jour, sur une superficie d'environ $2000 \mathrm{~m}^{2}$, plusieurs structures appartenant à la pars rustica de la villa. Les vestiges étant souvent très proches de la surface, il existait un risque important de destruction lors du défonçage. Il fut donc décidé d'organiser une fouille préventive qui eut lieu aux mois de mai et juin 1996 et permit de déga-

15. La fouille a été cofinancée par le Ministère de la Culture, Service régional de l'Archéologie et le Conseil général du Var, Centre archéologique du Var. ger $2500 \mathrm{~m}^{2}$ de la pars rustica de la villa ${ }^{15}$. Les vestiges, recouverts par 30 à $50 \mathrm{~cm}$ de terre arable, sont apparus très arasés, sous l'action conjuguée de l'érosion des pentes et des travaux agricoles, notamment des défonçages au treuil à vapeur effectués dans l'entre-deuxguerres. Seules les parties enterrées et, dans une moindre mesure, les sols bétonnés de certaines pièces étaient préservés. Des murs eux-mêmes, hormis ceux du cellier semi-enterré, ne subsistent que les fondations, et celles-ci ont même totalement disparu à l'est et au sud.

Cette occultation du bâti et l'absence de raccord stratigraphique entre les divers secteurs rendent délicate toute approche globale des installations et de leurs évolutions. Nous n'évoquerons donc que quelques changements perceptibles en certaines zones ${ }^{16}$.

\section{LES BÂTIMENTS DE LA PARS RUSTICA}

L'ensemble dégagé est de forme rectangulaire, le plus grand côté s'orientant sud-nord. La largeur des bâtiments est de 37,50 m d'est en ouest. La longueur dégagée, environ $70 \mathrm{~m}$, est incomplète, la limite sud des

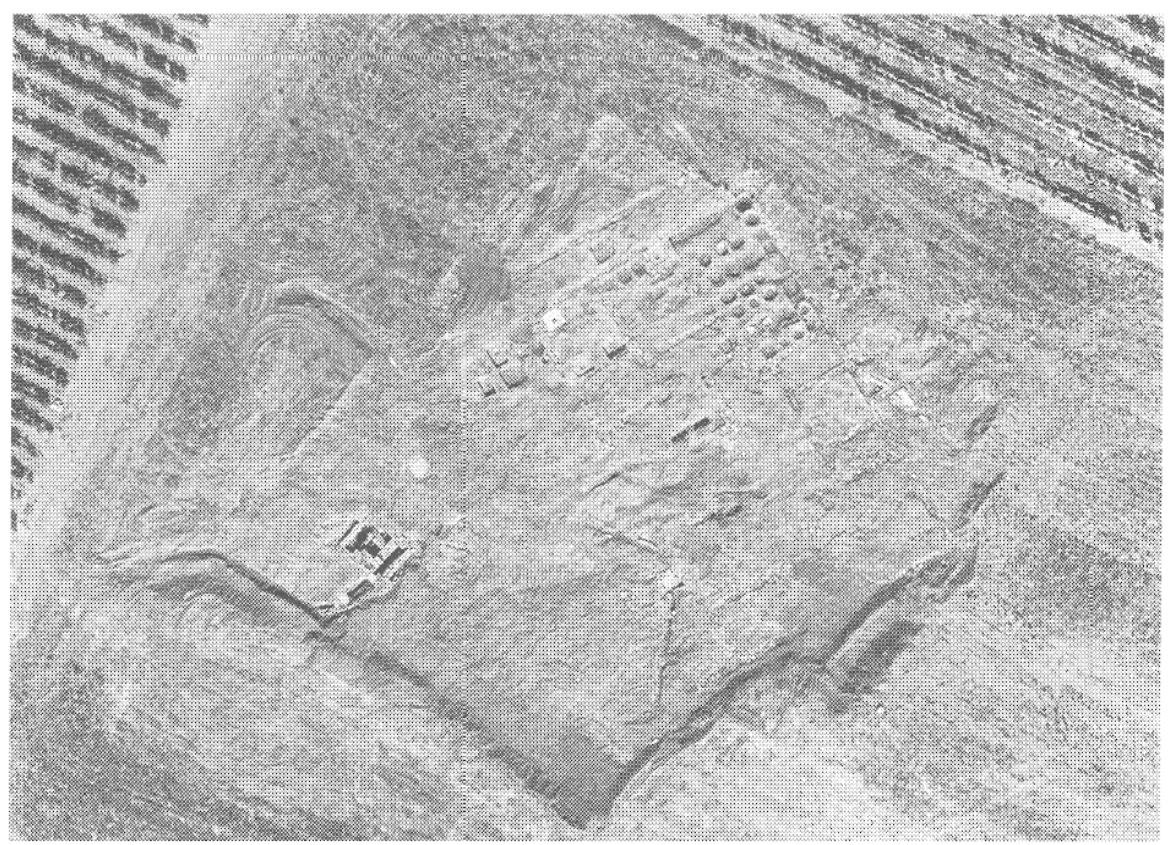

Fig. 4 - Les Mesclans : vue aérienne de la pars rustica.

16. Les données de fouille dépassant le cadre de cet article ont été publiées dans Travaux du Centre archéologique du Var 1996-1997, Hommage à P'ascal Lecacheur, Toulon, 1998, p. 201-255. 


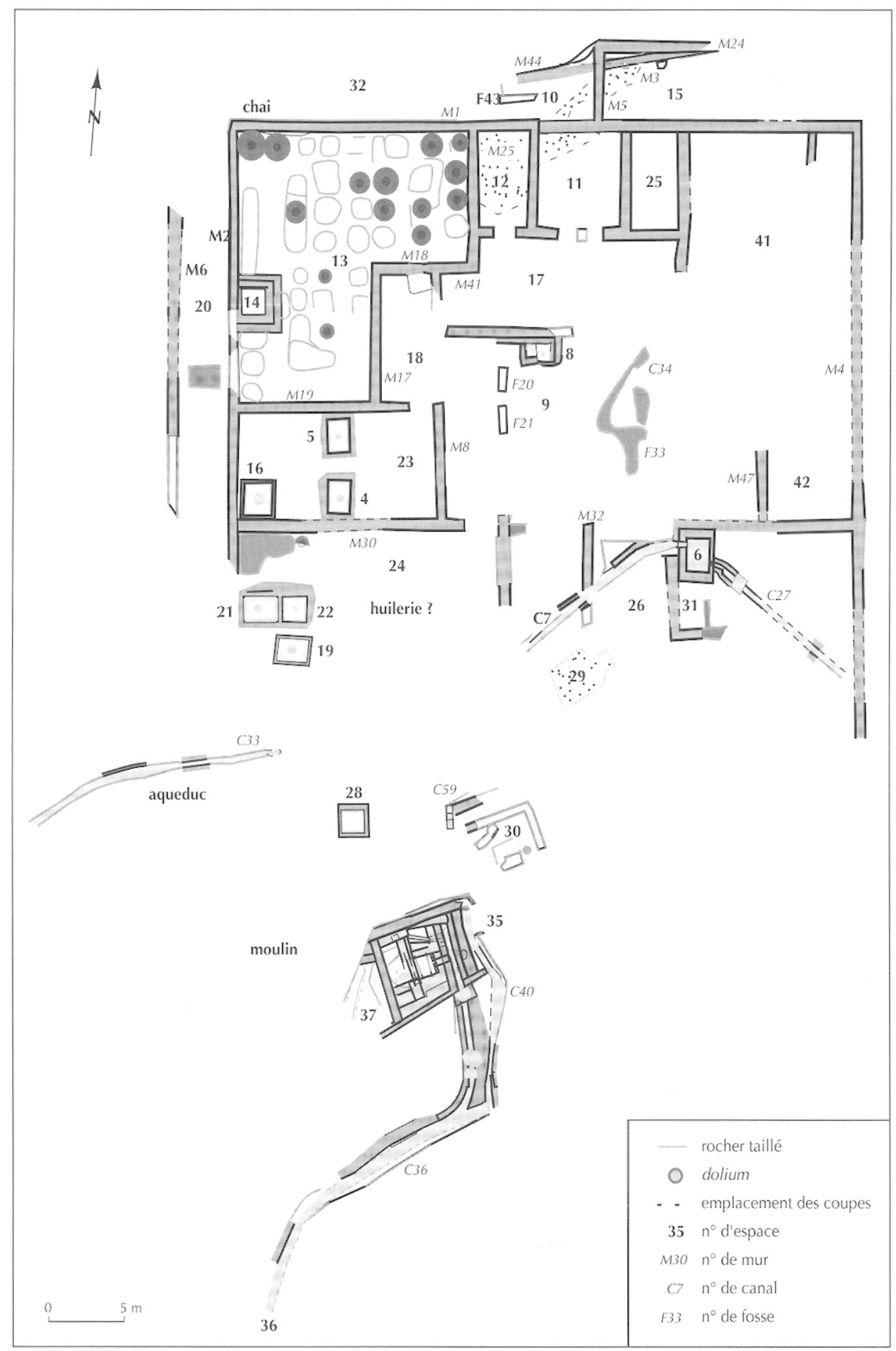

Fig. 5 - Les Mesclans : plan général du site avec indication des numéros d'espaces el des structures (Fr. Laurier). 


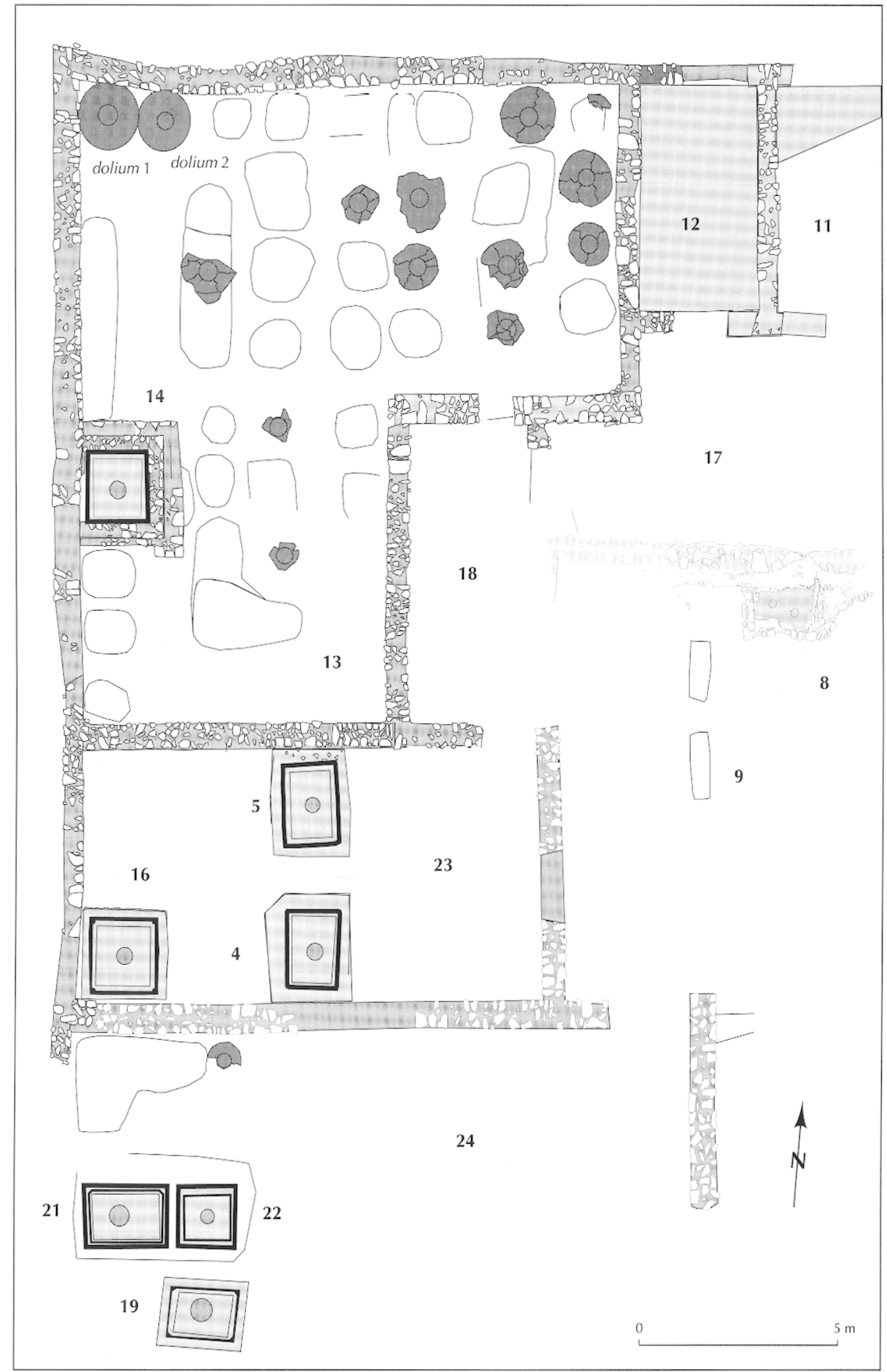

Fig. 6 - Les Mesclans : plan détaillé de l'installation viticole (Ph. Aycard et M. Cruciani). 
constructions, vers l'emplacement de la pars urbana, ayant disparu (fig. 4).

La pars rustica comprend plusieurs installations qui s'ordonnent en partie autour de la cour intérieure 9 (fig. 5). Dans l'angle nord-ouest se situe le chai à vin (salles 13 et 23) qui communique vers l'est, par la galerie 18 , soit avec la cour intérieure 9, soit avec l'espace de circulation 17 , limitrophe à la cour au nord. Sur cet espace 17 s'ouvrent trois pièces $(11,12$ et 25$)$ aménagées dans l'angle nord-est de la pars rustica. Au sud du chai, la pièce 24 pourrait correspondre à une huilerie. Au sud-est de la cour 9 se trouve le bassin 6 , abrité dans la salle 31 . Ce bassin est alimenté par l'aqueduc 7 et possède un système de vidange par le canal 27 , qui traverse le mur de clôture M4.

Dans la partie sud de la pars rustica, détruite jusqu'au substrat rocheux, on ne retrouve que quelques structures isolées dont un tronçon de l'aqueduc 7 et le moulin hydraulique. Ce dernier comporte un coursier (fig. 13, $\mathrm{n}^{\circ} 34$ ), un puits d'engrenage (fig. 13, $\mathrm{n}^{\circ} 2$ ) et deux réduits attenant à celui-ci (fig. $13, n^{\text {os }} 1$ et 3 ). Le coursier s'évacue dans le canal de fuite 36 qui récupère les eaux d'un canal de dérivation ou d'un égout 40. Après avoir bifurqué vers l'ouest, puis vers le sud, le canal 36 disparaît.

\section{LES INSTALLATIONS VITICOLE ET OLÉICOLE}

\section{LES VESTIGES}

Les installations de production de vin et d'huile occupent le quart nord-ouest de la pars rustica (fig. 6 et 7). Elles comprennent au nord un entrepôt où étaient enterrées des jarres (salle 13), au sud deux salles (23 et 24) que la présence de cuves permet d'identifier comme des fouloirs et des pressoirs, et à l'est une petite cuve isolée (8). Seul l'entrepôt est relativement bien conservé ; la nécessité de disposer d'un sol de départ à peu près horizontal a conduit les constructeurs à entailler profondément le rocher au nord et à édifier un mur de soutènement $\mathrm{n}^{\circ} 1$ qui a protégé une partie des dolia. Dans la partie sud de la salle, où le substrat se rapproche du sol, les dolia ont été arrachés par les labours et il ne reste plus que les alvéoles creusées dans le roc. Les salles 23 et 24 sont encore plus détruites ; quant à la cuve 8 , elle est arasée au niveau du fond.

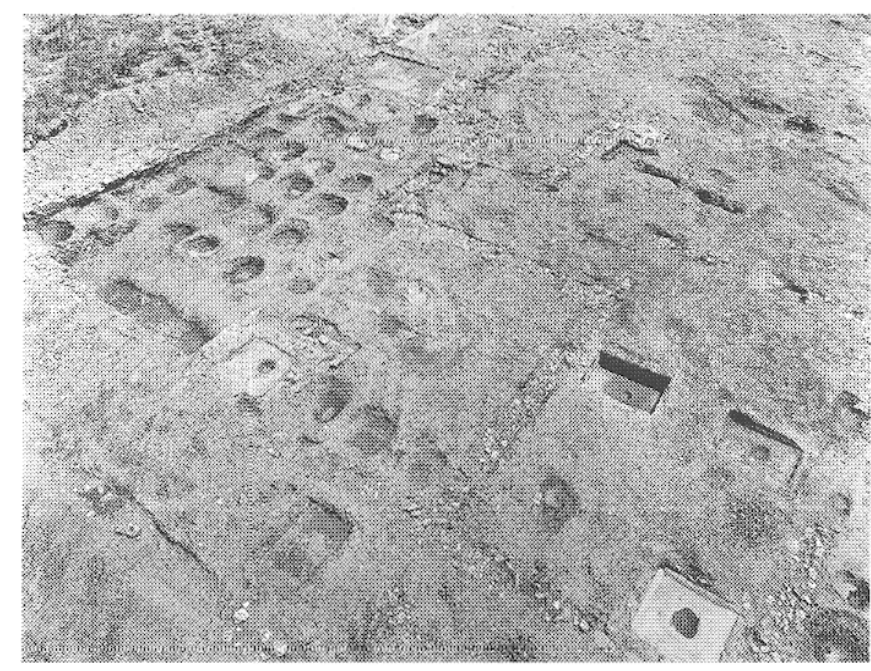

Fig. 7 - Les Mesclans : vue d'ensemble de l'installation viticole prise de l'ouest (J.-P. Brun).

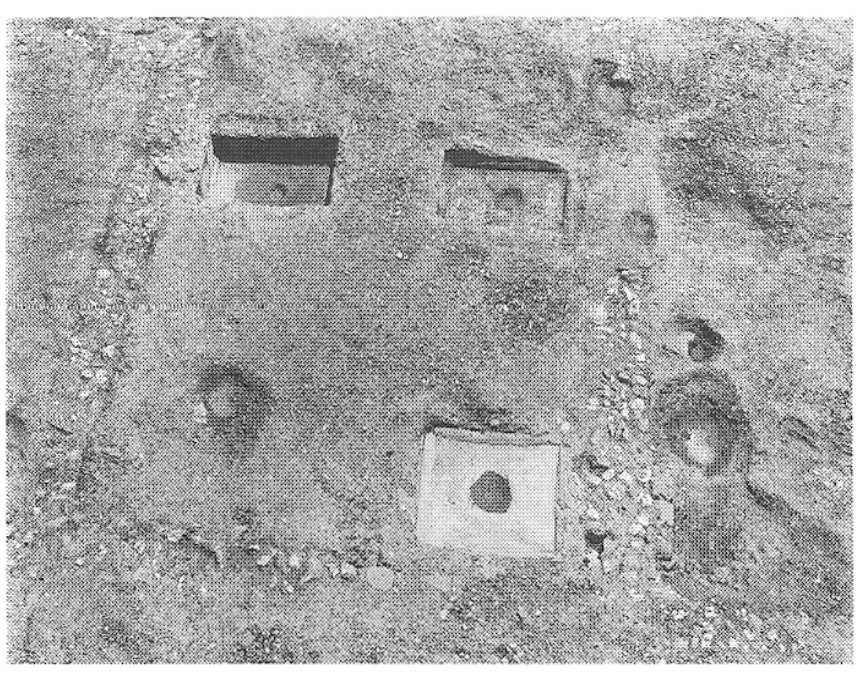

Fig. 8 - Les Mesclans : vue d'ensemble de la salle 23 (J.P. Brun).

On accédait à la salle 23 par une porte ouvrant au nord dans le passage 18 (fig. 8). Le substrat rocheux est présent partout sauf au niveau des trois cuves 4,5 et 16 . Les cuves 4 et 5 , visiblement construites en même temps, présentent des dimensions identiques : $1,89 \mathrm{~m} \times 1,32 \mathrm{~m}$. La cuve 16 diffère des deux autres : $1,80 \mathrm{~m} \times 1,67 \mathrm{~m}$. Il faut restituer le sol d'utilisation à une hauteur de $1 \mathrm{~m}$ à $1,50 \mathrm{~m}$ au moins au-dessus du niveau du fond des cuves.

La salle 13 qui couvrait une surface de $159 \mathrm{~m}^{2}$ a connu deux phases (fig. 9). Au départ, la totalité de l'espace interne était occupé par des dolia. Les 14 dolia encore en 


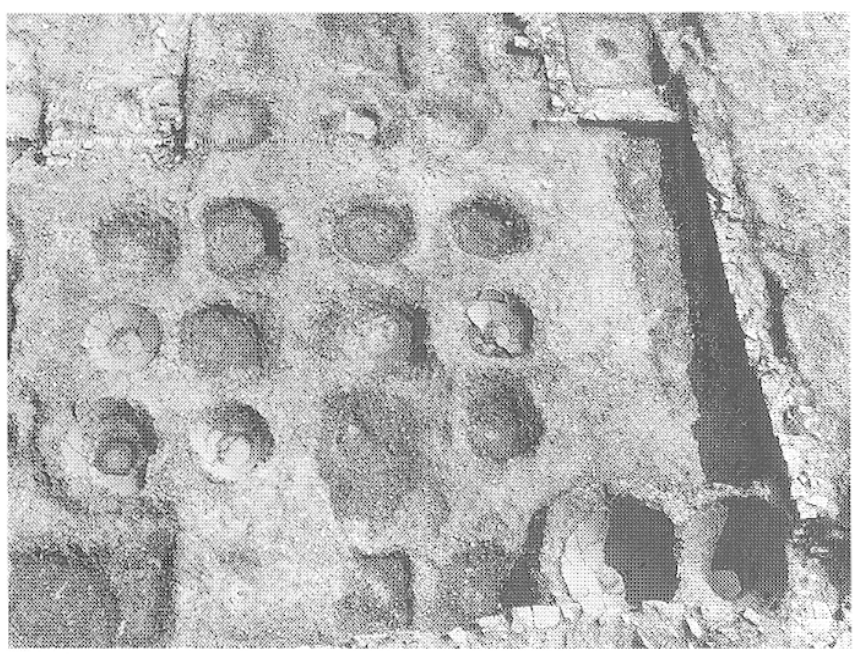

Fig. 9 - Les Mesclans : vue d'ensemble de la salle 13 (J.-P. Brun).

place étaient enterrés dans des tranchées longitudinales ou des alvéoles circulaires. Lors de la phase primitive, le chai devait abriter au total une cinquantaine de dolia. Grâce aux dolia 1 et 2 qui étaient conservés jusqu'à mihauteur et qui ont livré des éléments substantiels de leurs bords, on peut calculer approximativement leur contenance qui se situe autour de 1900 litres. Le matćricl trouvé dans le remblai des dolia a livré de la sigillée sudgauloise, notamment des fragments de deux bols Dragendorff 37 datables de la fin du $\mathrm{I}^{\mathrm{er}}$ ou du début du II" s., ce qui donne un terminus pour la construction du chai et probablement de l'ensemble de la pars rustica. La phase 2 est marquée par la construction de la cuve 14 accolée au mur 2 et mesurant $1,60 \mathrm{~m} \times 1,55 \mathrm{~m}$ (fig. 6). Son mur périmétral empiète sur des tranchées et des fosses à dolia circulaires creusées dans le roc. L'état d'abandon est matérialisé par une couche de gravats contenant essentiellement des moellons, des tuiles et des fragments de dolia. Le mobilier, assez pauvre, comprenait de la vaisselle à pâte claire, des amphores gauloises et des tuiles portant la marque L. Fabi, provenant de l'effondrement de la toiture.

La salle 24 compte trois cuves creusées dans le substrat et disposées à angle droit (fig. 10). Étant donné le niveau d'arasement, leur profondeur n'est pas significative, mais on note que la cuve 19 est creusée plus profondément dans le roc que les deux autres. Leurs fonds et leurs parois sont recouverts d'enduit de mortier de tuileau et elles sont dotées de puisards circulaires.

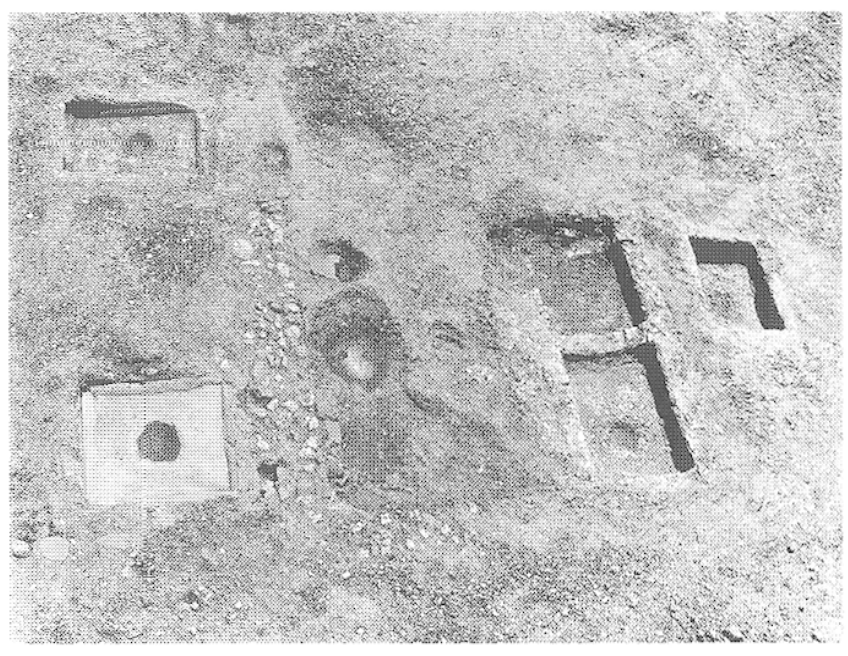

Fig. 10 - Les Mesclans : vue d'ensemble de la salle 24 (J.-P. Brun).

Au nord de la pièce entre les cuves et le mur 30 , une tranchée creusée dans le substrat était destinée à recevoir des dolia. Un fond est encore en place et on peut déceler trois logements de dolia arrachés par les labours.

La cuve 19, qui avait été utilisée comme dépotoir à la fin de l'occupation, a livré un mobilier en place datable dc la promic̀rc moitié du III $^{e}$ s. (sigillée claire B, amphore africaine).

\section{Orbis de trapetum}

La présence d'une huilerie sur le site est attestée par la découverte d'une meule de trapetum trouvée dans le

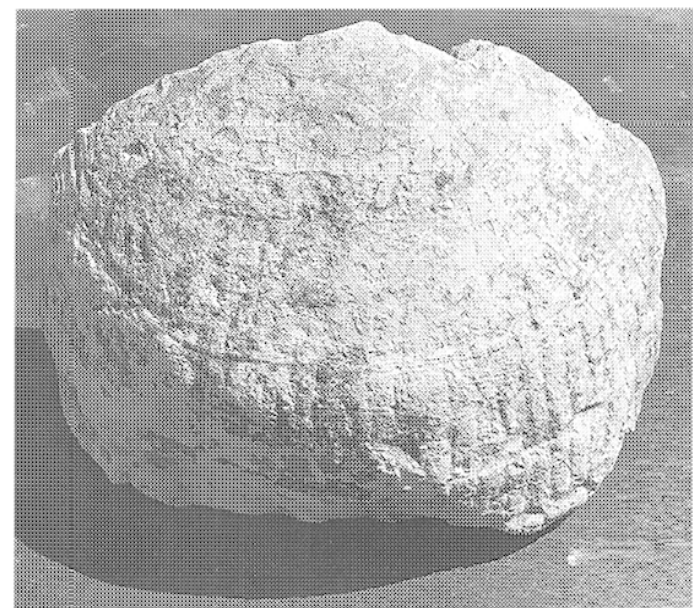

Fig. 11 - Les Mesclans : meule de trapetum (M. Borréani). 
canal du moulin à farine (fig. 11). Taillée dans un bloc de calcaire blanc, elle présente une forme grossièrement hémisphérique d'un diamètre de $0,42 \mathrm{~m}$ et d'une épaisseur de $0,32 \mathrm{~m}$. La surface est creusée de stries radiales destinées à assurer une meilleure trituration de la pâte, comme c'est généralement le cas dans les meules à huile provençales d'époque romaine (Valrose à La I.onde, Saint-Michel à La Garde, etc.). Une autre meule de trapetum en grès est aujourd'hui conservée au château de La Roquette. Elle ne pouvait pas fonctionner dans le même moulin car le matériau, le diamètre et la forme de la meule diffèrent. Elle peut provenir soit d'un autre site, soit d'un autre moulin ayant fonctionné sur le site même des Mesclans.

\section{La cour 9}

La surface de la cour, très inégale et en pente du nord vers le sud, est formée par l'affleurement du rocher, qui n'est aplani qu'en de rares endroits. Lors de la dernière phase d'occupation de la pars rustica, la cour servit de dépotoir dont le mobilier est datable pour l'essentiel de la première moitié du III's. (sigillée claire A [Hayes 14B], B, C [Hayes 50A], amphores africaines 1, gauloises 4, de Spello, etc.).

\section{Les pièces situées dans l'angle nord-est de la cour 9}

Ces pièces se répartissent de part et d'autre du prolongement du mur 1, qui limite au nord le cellier, dont seule la fondation en schiste, quartz et galets liés à l'argile est ici conservée, le mur ayant été épierré. Au sud du mur 1 se trouvent trois pièces $(11,12$ et 25$)$ qui s'ouvrent sur la galerie 17 et sont pourvues de sols en opus signinum (fig. 7). Leurs caractéristiques (sols bétonnés, murs enduits) incitent à penser qu'il s'agit de pièces d'habitation probablement occupées par des serviteurs, mais on ne peut exclure que certaines d'entre elles aient eu des fonctions liées à la production du vin ou de l'huile (manutention, stockage, etc.).

\section{INTERPRÉTATION}

Les vestiges retrouvés attestent la production du vin et de l'huile. Le grand nombre de dolia de la salle 13 ne s'explique que par une production de vin et la présence d'une meule à huile implique l'existence d'une huilerie.
Si les vestiges de l'installation viticole sont aisés à localiser et à interpréter, l'état de destruction des autres vestiges ne permet pas de situer avec certitude le pressoir à huile.

L'installation viticole occupait les pièces 13 et 23 . Le traitement de la vendange commençait dans la pièce 23 où se trouvaient les fouloirs et les pressoirs. Ia disposition des trois cuves 4,5 et 16 pose quelques problèmes. Les cuves 4 et 5 , séparées par un passage, ou plutôt un escalier, pourraient avoir fonctionné avec un fouloir et un pressoir, voire deux pressoirs situés dans la partie ouest. Le sol des fouloirs et pressoirs était placé entre 1 et $2 \mathrm{~m}$ en contre-haut du fond des cuves. La partie est de la pièce, nettement en contrebas, aurait servi alors d'espace de manœuvre des machineries des pressoirs. L'accìs depuis le couloir 18 est d'ailleurs conservé dans l'angle nord-est. Dans l'hypothèse où les blocs de pressoirs conservés sur le domaine voisin de La Roquette proviendraient du site des Mesclans, il pourrait s'agir de deux pressoirs à levier et vis.

Cette disposition est toutefois incompatible avec la présence d'une troisième cuve (16) accolée au mur 2 dans l'angle sud-ouest. Mais l'état d'arasement du site ne permet pas de savoir si cette cuve est antérieure, contemporaine ou postérieure aux deux autres.

Dans la pièce 13, la disposition des dolia en files séparées par d'étroits passages n'appelle aucun commentaire, mais l'cstimation des capacités de stockage du chai permet de donner une idée approximative de l'étendue des vignes en culture. Si tous les dolia possédaient la même capacité, la contenance maximale du chai était de $950 \mathrm{hl}$. André Tchernia a étudié récemment la question du stockage du vin dans les dolia et du rendement des vignobles antiques. Il aboutit aux conclusions qu'en " règle générale, le vigneron avait besoin de libérer ses dolia avant la prochaine vendange " ${ }^{17}$ et que les rendements moyens devaient osciller entre 35 hl à l'hectare et pour les meilleures années ou les vignobles les plus productifs $60 \mathrm{hl} / \mathrm{ha}$. Dans le cas de la villa des Mesclans, la surface cultivée en vignes pourrait donc avoir été de l'ordre d'une vingtaine d'hectares (entre 15 ha au minimum et 27 ha au maximum).

17. Cf. Tchernia, 1995, p. 386 qui cite le Digeste, XVIII, 6, 1, 3 et Pline, N.H., XVIII, 320. 


\section{L'huilerie}

Alors que l'installation viticole forme un ensemble cohérent et bien défini, il est difficile de situer l'emplacement de l'huilerie. La salle 24, comportant trois cuves et probablement quatre dolia, serait une bonne candidate. Si elle faisait partie de l'installation viticole, elle ferait double emploi avec la salle 23 clairement reliée au chai dont les capacités de stockage n'exigent pas l'emploi de plus de deux pressoirs ${ }^{18}$. La disposition des cuves, dont une est plus profonde que les autres, ce qui est utile dans le cas d'un produit à décanter comme l'huile, est compatible avec une huilerie. Par ailleurs, la présence de trois ou quatre dolia peut s'expliquer par la nécessité de stocker de l'eau, de l'huile et des margines, cette amurca dont les anciens faisaient un grand usage (Brun, 1986, p. $57-58)^{19}$.

\section{LES INSTALLATIONS HYDRAULIQUES}

\section{L'ALIMENTATION : Le BASSIN 6, LeS CANAUX 7, 27 ET 33}

Un aqueduc, dont deux tronçons 7 et 33 ont été retrouvés, est totalement détruit dans sa partie ouest et fortement abîmé ailleurs. Provenant de l'ouest à flanc de coteau, il alimentait le bassin 6 et le moulin hydraulique, par un système de dérivation qui n'a pas été conservé. Taillé dans le rocher, il possédait un fond de béton de tuileau d'une largeur de $0,30 \mathrm{~m}$. Ses parements présentent des concrétions calcaires relativement terreuses qui semblent indiquer que l'eau était prise dans une rivière (probablement le Gapeau, $c f$. annexe).

Son débouché dans le bassin 6 est marqué par une tegula bâtie dans le mur ouest. Le bassin (largeur : $1,30 \mathrm{~m}$; longueur : 1,80 m) est intérieurement enduit et comporte

18. Dans la villa du Grand Loou à La Roquebrussanne, 1 fouloir et 2 pressoirs suffisent pour 70 dolia environ. Dans celle de Pardigon 1/3 à Cavalaire-sur-Mer, on compte 2 pressoirs au maximum pour une centaine de dolia. C'est au-delà de 100 dolia qu'il faut disposer d'installations comprenant plusieurs fouloirs et quatre presses : Le Molard à Donzères (Dechandol et al., 1983), Les Toulons à Rians (Brun, Congès, 1994).

19. Dans l'huilerie de la villa de Saint-Michel à La Garde, deux dolia étaient enterrés à proximité des cuves (Brun et al., 1989, p. 122); dans celle du Candéou à Peymeinade, les dolia servaient à la fois à la décantation et au stockage de l'huile (Vindry, 1981).

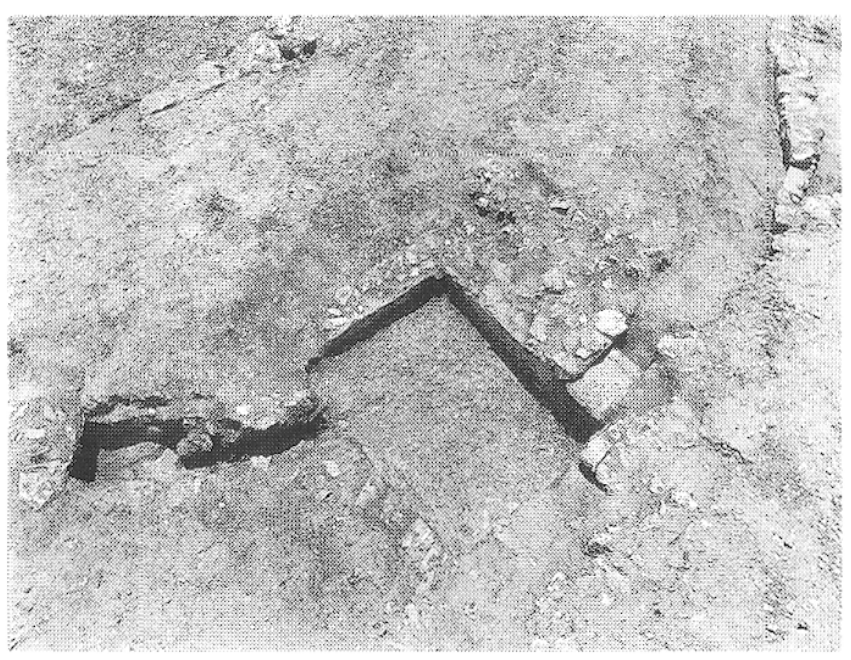

Fig. 12 - Les Mesclans : détail du bassin 6 (J.-P. Brun).

des boudins d'étanchéité dans les angles (fig. 12). Vers l'angle sud-est, une évacuation comporte une feuille de plomb prise dans le mortier qui devait sceller une vanne dont il reste l'empreinte. L'eau s'écoulait ensuite du bassin dans le canal de vidange 27. D'importants dépôts de calcite en aval du mur du bassin ont été formés par des suintements d'eau provenant des parties hautes du bassin. Il parait vraisemblable que la cuve 6 servait de château d'eau alimentant la pars urbana de la villa située en contrebas. De la partie supérieure aujourd'hui détruite devaient partir des tuyaux (de plomb ?) dont les fuites sont probablement à l'origine des concrétions calcaires. La vanne au bas du bassin était utilisée pour vidanger la cuve lors des nettoyages. Le mobilier archéologique trouvé dans le comblement du bassin comprend notamment des vases en sigillées claires $\mathrm{A}, \mathrm{B}$ et $\mathrm{C}$ analogues à ceux trouvés dans le dépotoir de la cour.

Entre l'aqueduc 33 au nord et le moulin au sud, se trouve un fond de bassin carré (28) de $1,30 \mathrm{~m}$ de côté qui pourrait avoir servi de bassin de régulation pour l'alimentation du moulin ou bien au lavage du grain avant la mouture ${ }^{20}$.

20. Le lavage du grain et son hydratation sont souvent nécessaires avant la mouture à cause de la siccité du grain dans les pays méditerranéens (Amouric, 1993, p. 54). Aux Martres-de-Veyre, A.-M. Romeuf a dégagé, à proximité du moulin, un hangar au sol bétonné comportant un bassin qu'elle interprète comme des structures de lavage et séchage du grain (ici fig. 39d). 


\section{LE MOULIN HYDRAULIQUE}

\section{Les vestiges}

Dans la partie sud de la zone fouillée est situé un bâtiment trapézoïdal comprenant plusieurs espaces profondément creusés dans le rocher (fig. 13 à 15). D'est en ouest, on trouve : un tronçon de mur oblique (53), deux canaux parallèles ( 40 et $34-36$ ), deux petites chambres ( 1 et 2), puis un espace plus long (3). Ces structures sont ceinturées de murs bâtis à la chaux ou non qui s'appuient les uns sur les autres. Cinq états doivent être distingués (fig. 16).

\section{État 1}

L'état 1 est marqué par le tronçon de mur 53 clairement coupé par la tranchée de creusement du canal 34 et noyé dans les fondations. Les indices qui auraient permis de le dater et de l'interpréter font défaut (fig. 13).

\section{État 2 : construction du moulin}

À cette phase appartiennent les canaux et les murs périmétraux du moulin $9,48,11,16,49,50,51$. Les murs $9,11,49,50$ et 51 sont faits de moellons de grès et de schiste bâtis à la chaux. Les murs 48 et 16 sont formés de mortier de chaux et gravier coulé dans des banches. L'ordre de construction paraît avoir été le suivant : 9, 16$48,11,49-50-51$; il semble toutefois que tous ces murs appartiennent à une seule phase de construction (fig. 13 et 17).

Le canal 34-36 comprend au nord un coursier quadrangulaire (34) et au sud un canal de fuite (36). Creusé dans le substrat rocheux, il est bordé par les murs 49 et 5051 faits de pierres liées à la chaux. Les parois du puits sont entièrement tapissées de concrétions calcaires qui atteignent par endroits une dizaine de centimètres d'épaisseur. Celles de la paroi ouest présentent des rainures concentriques montrant qu'une roue frottait lors de la dernière phase d'utilisation (état 4). Le canal mesure $0,26 \mathrm{~m}$ au niveau le plus étroit, mais, à l'origine, sa largeur atteignait $0,30 \mathrm{~m}$. Sa profondeur conservée est de $1,70 \mathrm{~m}$. À l'est, le puits est bordé par une banquette (51), large de $0,30 \mathrm{~m}$ et située à $1,05 \mathrm{~m}$ au-dessus du fond du canal ${ }^{21}$. Au

21. Ce type de banquette est connu dans d'autres moulins hydrauliques, par exemple à Athènes (Parsons, 1936, fig. 4). sud, la limite est marquée par un ponceau formé d'une dalle de schiste enjambant le canal. À l'ouest, le logement de l'axe de la roue est encore visible dans le mur 49, à $1,20 \mathrm{~m}$ au-dessus du fond du canal. Le canal de fuite, moins haut que le puits, est bordé de deux murs bâtis à la chaux et couverts de dalles de schiste dont il subsiste deux exemplaires à 3,50 $\mathrm{m}$ au sud du coursier. Un peu au-delà, le canal fait un coude vers l'ouest sur une douzaine de mètres, avant un dernier coude vers le sud-ouest; on le perd $3 \mathrm{~m}$ plus loin. Le tronçon aval, au-delà du premier coude, est creusé dans le rocher sauf en certains endroits où les parois sont consolidées par des maçonneries.

Au niveau du coude vers l'ouest, le canal de fuite est rejoint par le canal 40 qui n'est bien conservé que dans la partie basse. Plus au nord, on ne trouve que les traces de son fond matérialisé par une dépression longitudinale dans le rocher contenant de nombreux tessons de céramique. Au nord du ponceau, on perd sa trace. Dans le canal 40 , dont la pente est très forte, on ne trouve aucune concrétion calcaire.

À l'ouest du puits 34, l'intérieur de la chambre basse de la meunerie mesurait $3,50 \mathrm{~m}$ d'est en ouest et $4,20 \mathrm{~m}$ du nord au sud. Ses aménagements internes sont rendus peu lisibles par les constructions de l'état 3. Ils comportaient à l'est une excavation rectangulaire (54) large de $1,10 \mathrm{~m}$ et limitée par une paroi (55) ménagée lors du creusement du rocher et servant d'assise à un muret dont une pierre a été conservée en soubassement du mur 13 (fig. 18). Le mur 55, ultérieurement arasé, mesurait $0,70 \mathrm{~m}$ d'épaisseur et séparait le puits rectangulaire d'une excavation ovoïde 42 située à l'ouest. Cette dernière, d'un diamètre maximum de $1,55 \mathrm{~m}$, était profonde de 1,25 m par rapport au niveau primitif de l'axe du moulin et ne comportait pas d'évacuation.

L'espace 1 devait être limité au sud par un retour à angle droit de la paroi rocheuse 55 et comportait un drain (52) joignant en diagonale l'angle du mur 10 et le coursier 34. Ce drain, construit en tuiles rondes, aboutissait dans le coursier par un orifice quadrangulaire percé dans le mur 49 (fig. 19). Son extrémité ouest a été bouchée par un fragment de tuile verticale lors de la construction du mur 38 (état 4). Ce drain recueillait les eaux suintant le long des parements sud des murs 9 et 48 où elles ont laissé des concrétions calcaires.

Les seuls éléments de datation trouvés dans les tranchées de fondation du mur 11 sont une assiette (Drag. 18/31 ?) et un bol Drag. 33 en céramique sigillée 


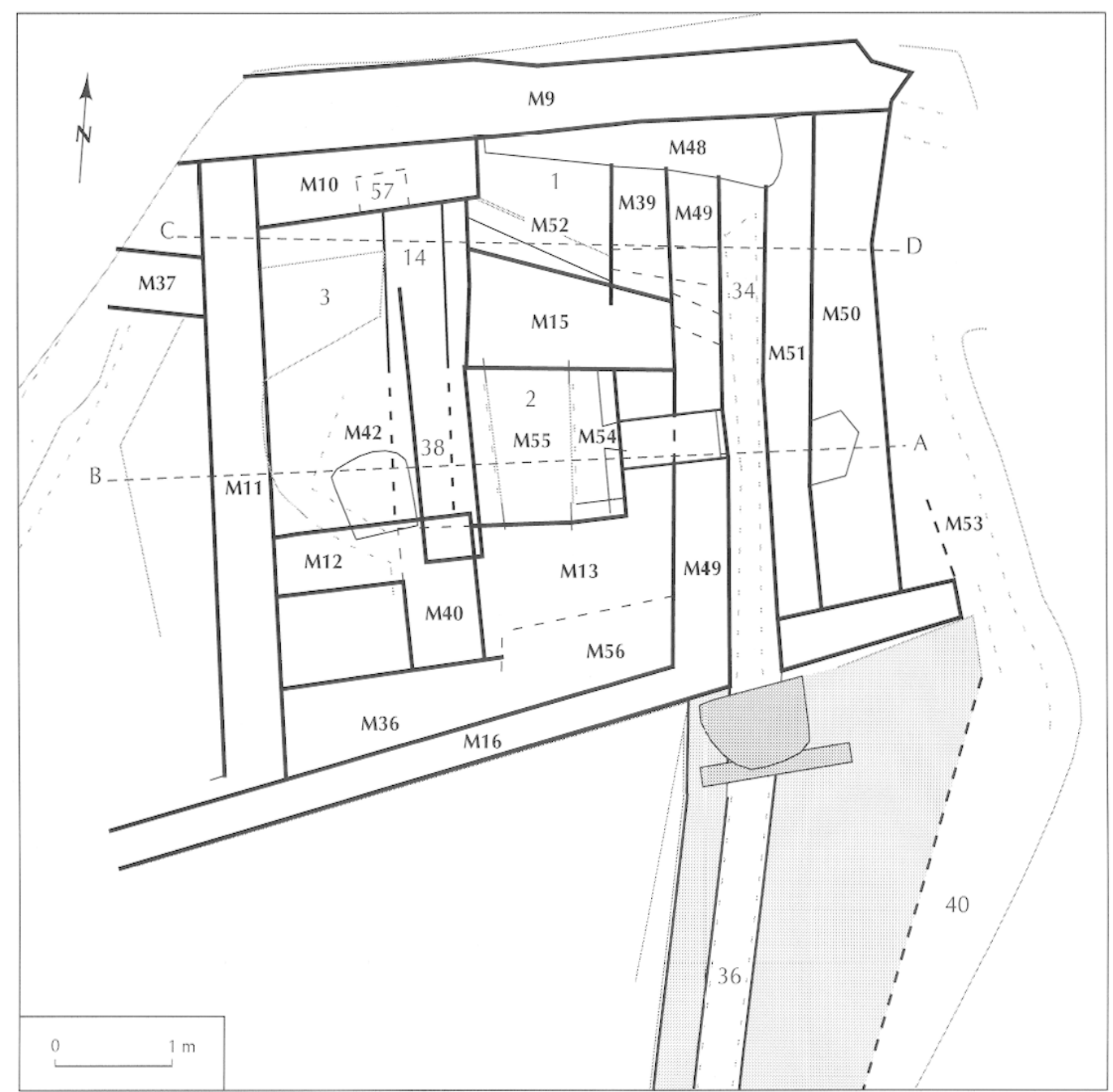

Fig. 13 - Les Mesclans : plan du moulin (Fr. Laurier).

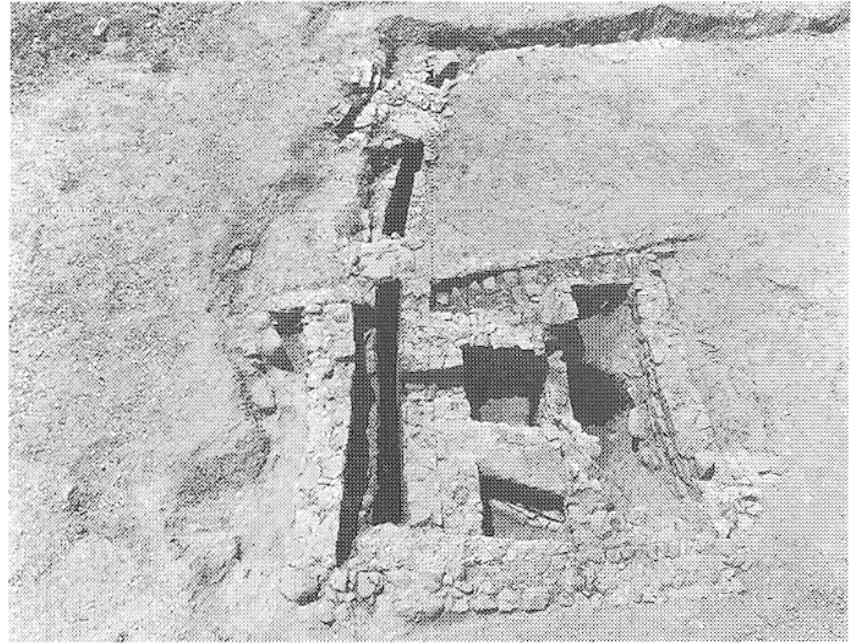

Fig. 14 - Les Mesclans : vue générale du moulin prise du nord (J.-P. Brun).

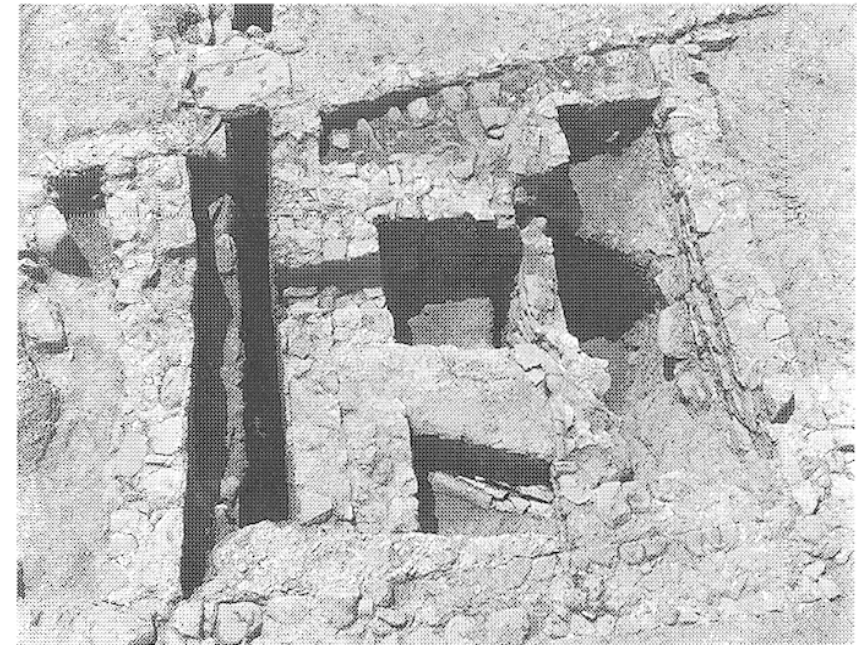

Fig. 15 - Les Mesclans : détail du moulin (J.-P. Brun). 

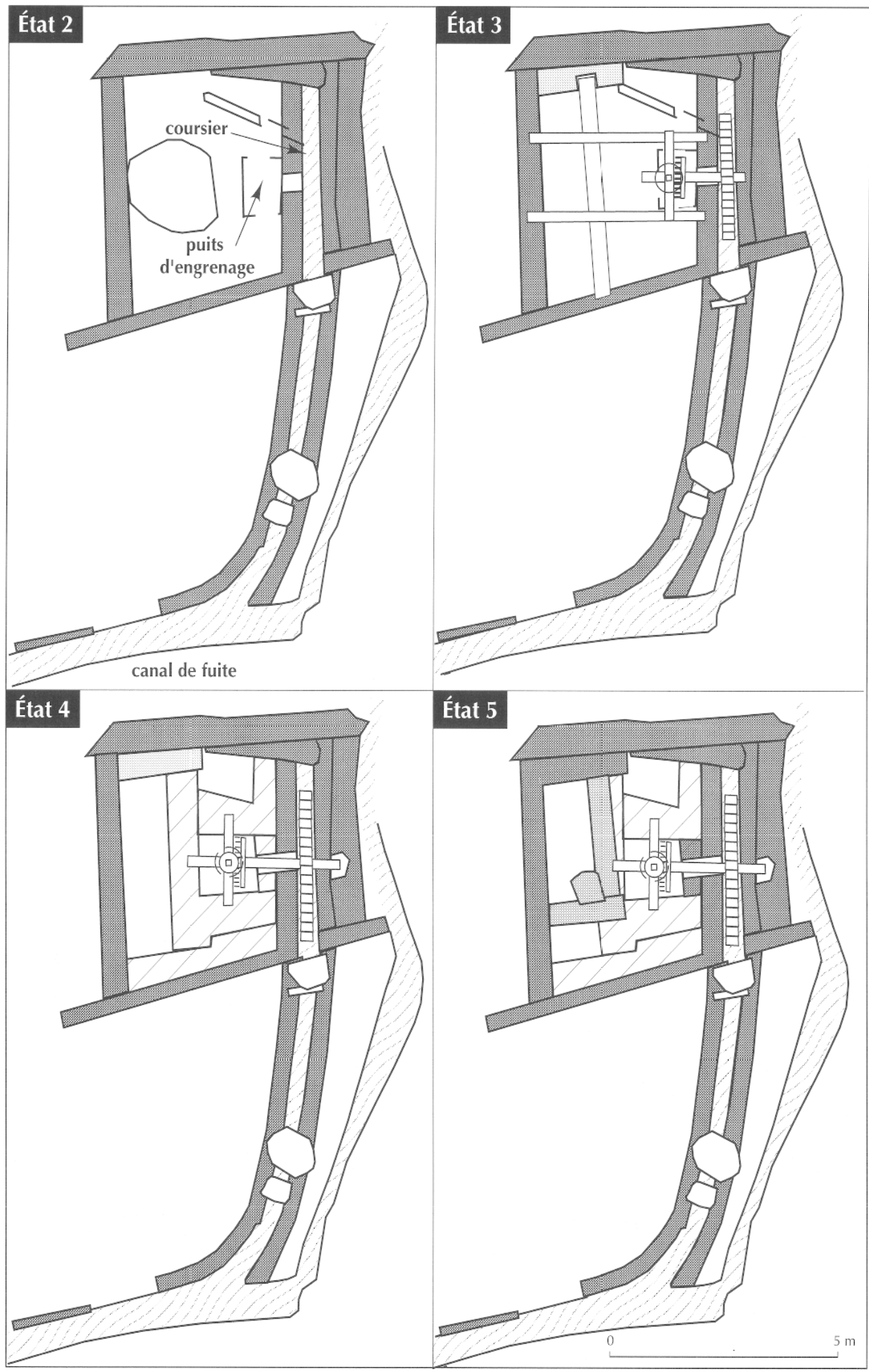

Fig. 16 - Les Mesclans : évolution du bâtiment du moulin (M. Borréani et J.-P. Brun). 


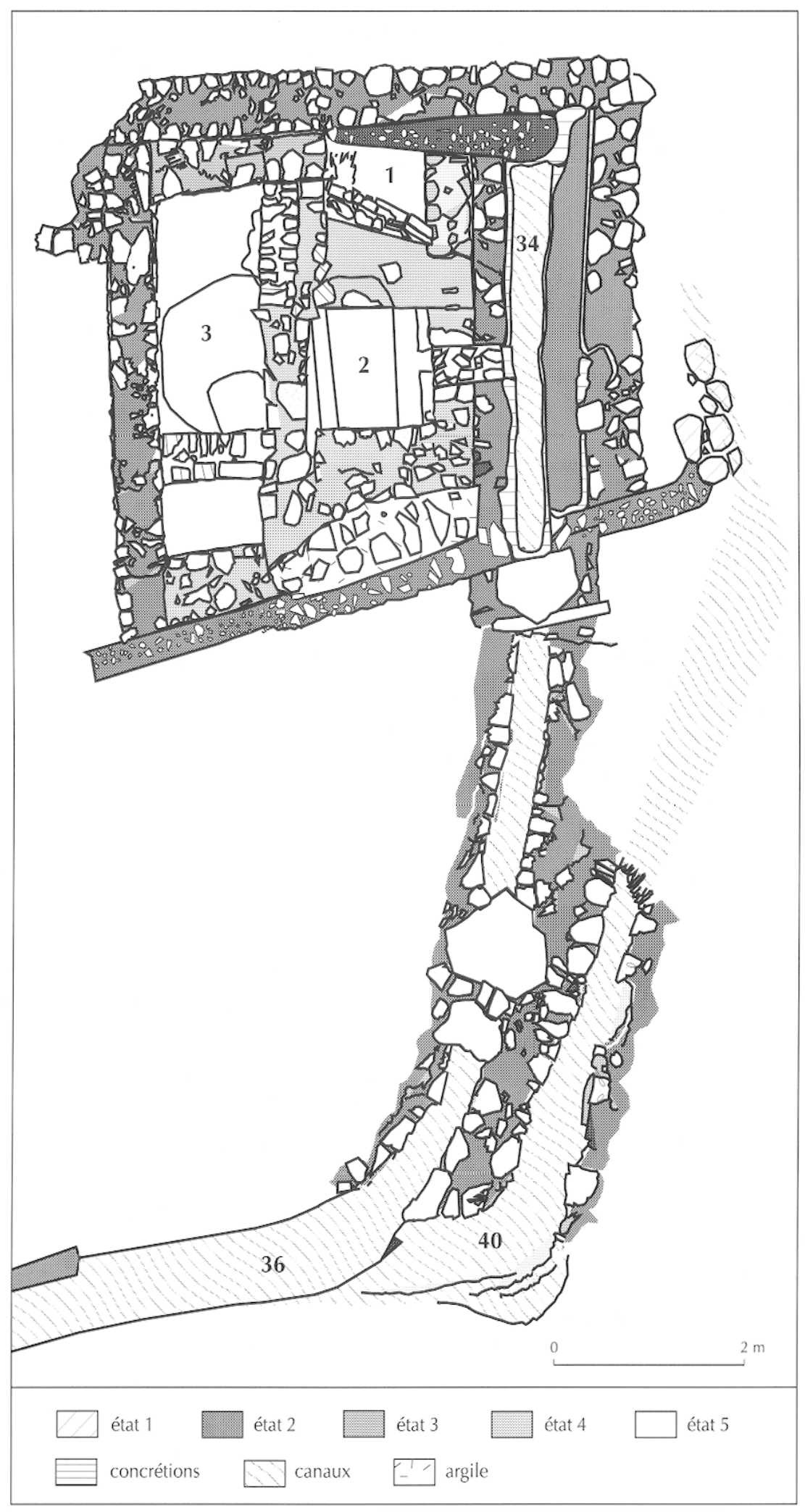

Fig. 17 - Les Mesclans : plan détaillé du moulin (M. Cruciani). 


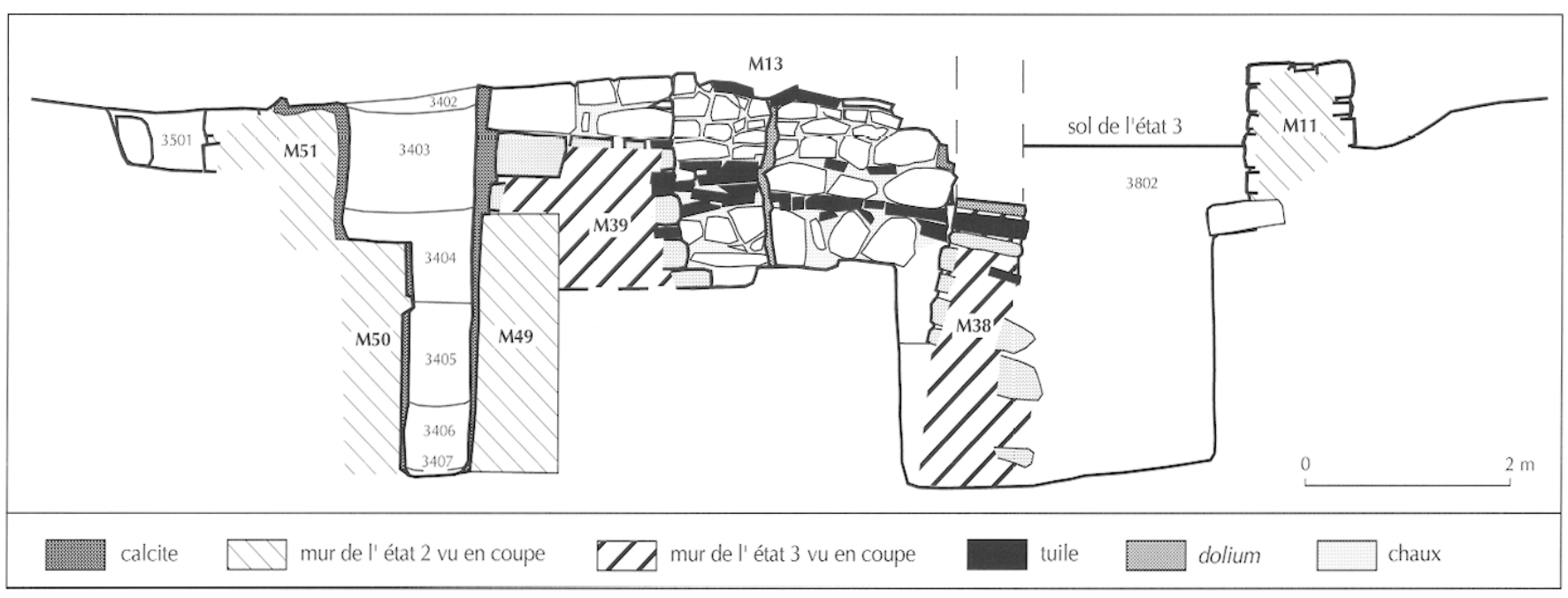

Fig. 18 - Les Mesclans : coupe est-ouest AB (M. Cruciani).

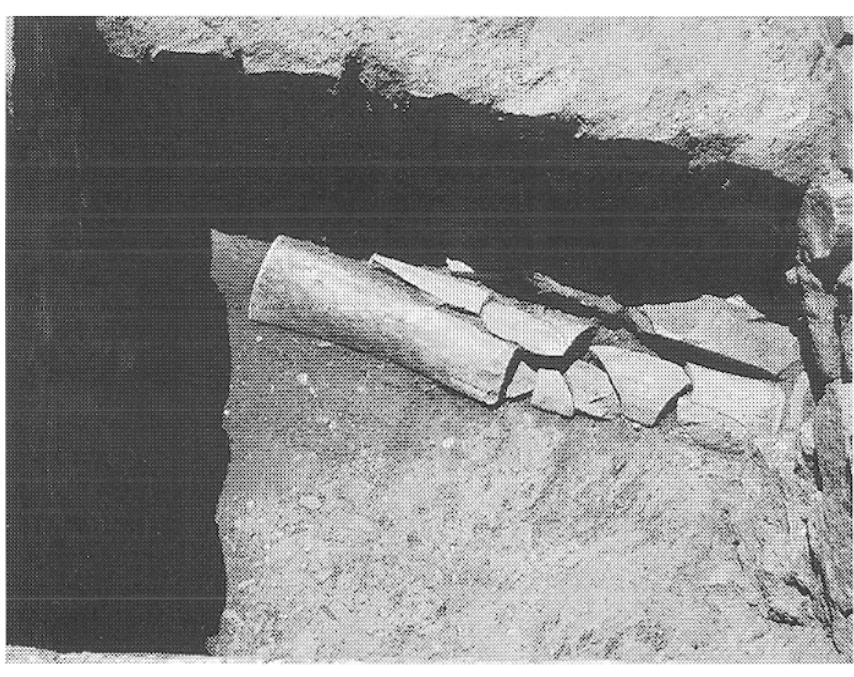

Fig. 19 - Les Mesclans : détail du drain 52 (J.-P. Brun).

de La Graufesenque. Leur présence interdit de dater le premier moulin avant la période flavienne. On rapprochera ces quelques tessons de ceux trouvés dans le remblai de calage des dolia de la salle 13 , et on peut penser que les deux constructions sont à peu près contemporaines.

\section{État 3}

Le mur 10 a été construit dans une phase ultérieure car il s'appuie sur de fines concrétions déposées contre le mur 9. Il doit correspondre à un réaménagement du moulin : on décèle, à la base du mur 10 au contact du rocher, un logement rectangulaire, large de $0,30 \mathrm{~m}$, haut de $0,10 \mathrm{~m}$ et profond d'une quinzaine de centimètres, qui semble correspondre à l'encastrement d'une poutre en bois (57) (fig. 20).

\section{État 4}

Une troisième phase correspond à un réaménagement complet de la chambre basse de la meunerie. Une nouvelle roue, dont le diamètre était de l'ordre de $3 \mathrm{~m}$, fut alors mise en place : les traces concentriques laissées dans les concrétions calcaires permettent de préciser la position de l'axe, situé à une quarantaine de centimètres au-dessus du précédent (fig. 21 et 22). La nouvelle roue, comme la précédente, était fort étroite (seulement $0,25 \mathrm{~m}$ de largeur). Comme auparavant, elle devait être alimentée par un canon en bois fixé sur le mur 48. Un écoulement secondaire passait entre l'extrémité du mur 48 et la banquette 51 : à son emplacement, des concrétions calcaires ont emprisonné des branches et un fragment de col d'amphore gauloise 4 encore reconnaissable.

Le mur 49 fut doublé par le mur 39 bâti à la chaux. À la base du mur 39, dans le puits 2 , se trouve une barbacane faite de deux pierres de chant et d'un linteau : elle traverse les deux murs et débouche dans le coursier par des orifices rectangulaires étroits. Elle drainait probablement les eaux qui pouvaient entrer dans le puits d'engrenage par l'axe de la roue. 


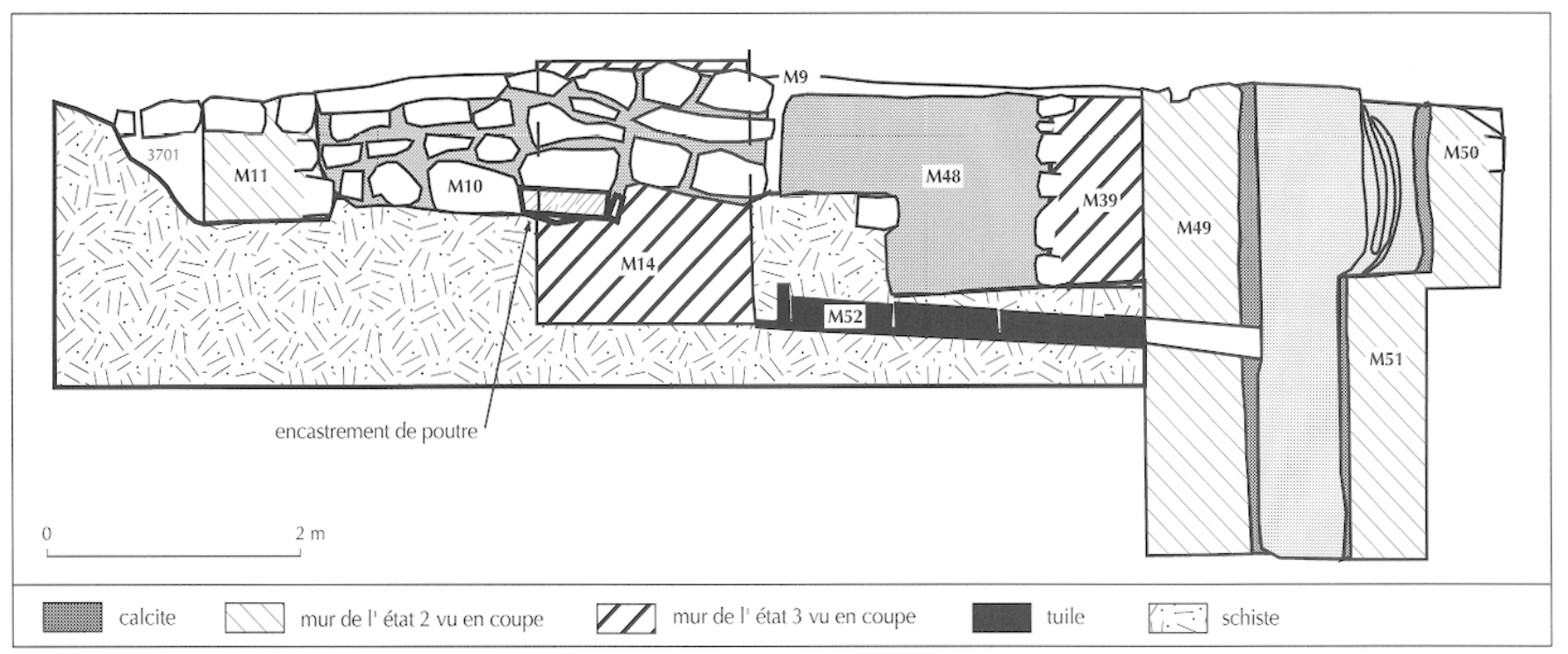

Fig. 20 - Ies Mesclans : coupe ouest-est CD (M. Cruciani).

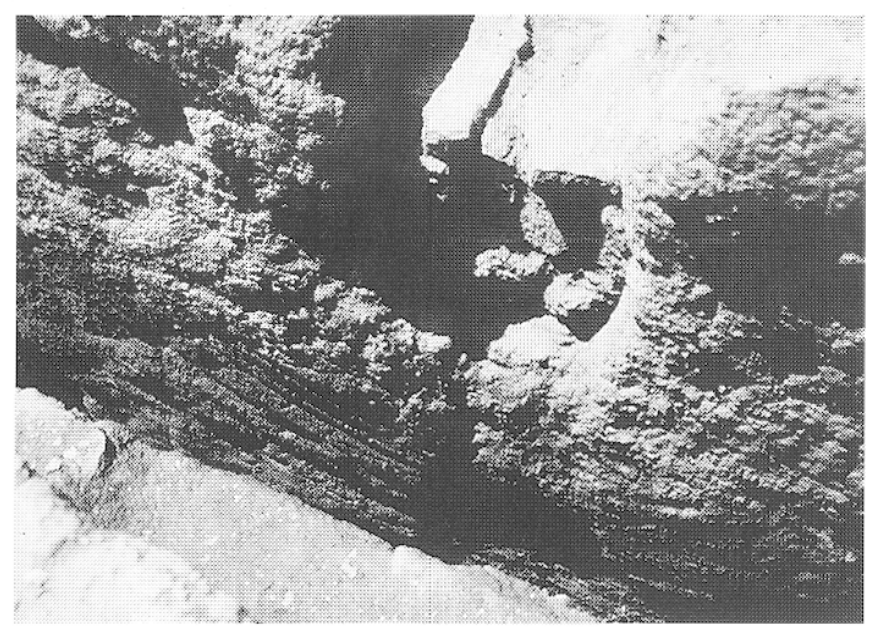

Fig. 21 - Les Mesclans : détail des concrétions calcaires portant les traces du frottement de la roue à aubes (J.-P. Brun).

Le déplacement vers l'ouest de l'ensemble de la machinerie obligea à détruire l'ancienne installation taillée dans le roc et à en créer une nouvelle, maçonnée (fig. 23). Le nouveau puits du rouet (2), approximativement carré, mesurait $1,20 \mathrm{~m}$ de côté environ. La paroi de rocher, qui à la phase 2 limitait le logement 54 , fut arasée et l'excavation circulaire 42 comblée. Le puits 2 était bordé par des massifs maçonnés construits à cette occasion. Au sud, les murs 13 et 40 contiennent un blocage de pierres liées à l'argile (56). Au nord, le massif trapézoïdal

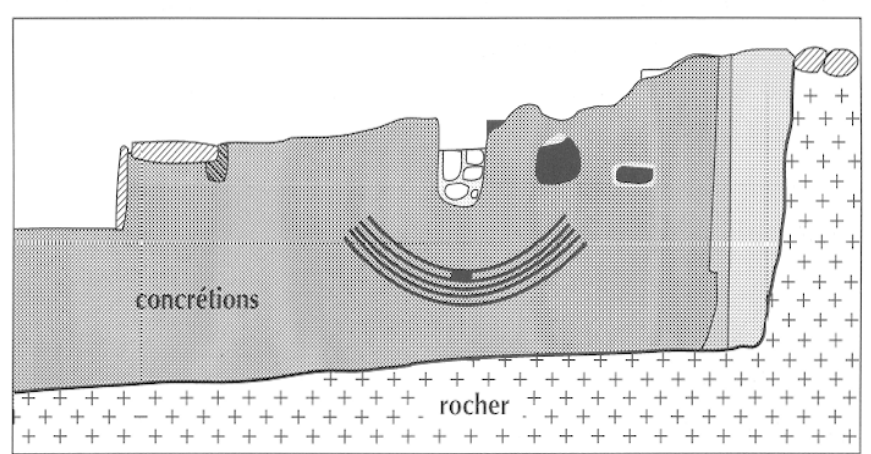

Fig. 22 - Les Mesclans : géométral du coursier montrant les traces de frottement de la roue à aubes (J.-P. Brun).

15, fait de pierres, de tuiles et de fragments de dolia bâtis à la chaux, est lié au mur 39. Les deux massifs (13 et 15) présentent deux lézardes verticales au niveau du point dur formé par l'arasement de la paroi rocheuse et du mur 54 (fig. 18). Le mur 38, très mal fondé dans le remblai du comblement de la fosse 42 , s'est déversé vers l'ouest. Construit en pierres et en fragments de dolia, notamment des bords, il s'appuie contre le massif 15 et semble lié au mur 40, à moins qu'il ne s'agisse du même mur fracturé par le déversement du mur 38.

Dans le puits 1, la face nord du massif 15 fut alignée sur la bordure du caniveau 52 qui fut obturé à ses deux extrémités. Il fut remplacé par une nouvelle barbacane, 


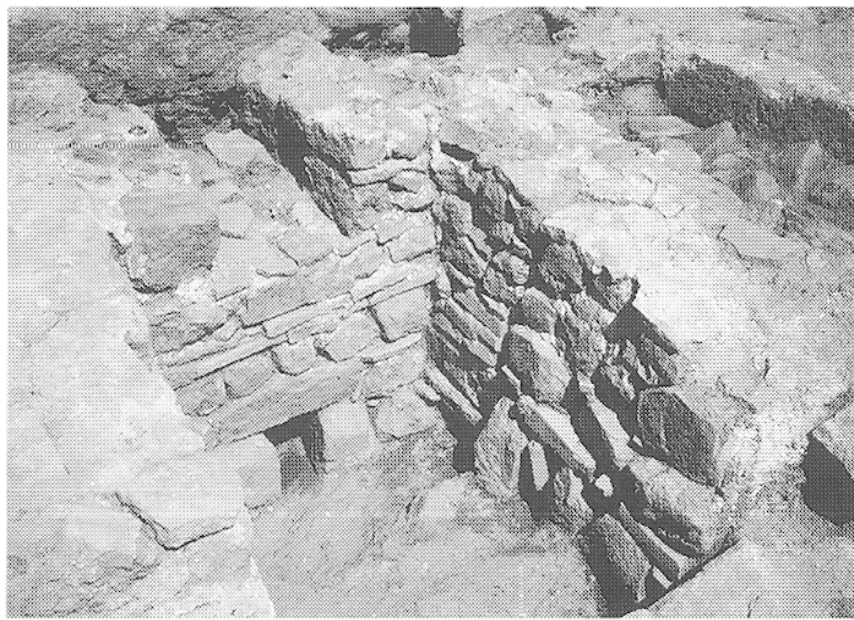

Fig. 23 - Les Mesclans : détail du puits d'engrenage $n^{\circ} 2$ (M. Borréani).

construite à l'identique de celle du puits 2 et traversant les murs 39 et 49 en amont de la précédente. Il semble qu'elle ait servi à évacuer les eaux de ruissellement ou de suintement du canal d'amenée.

Dans la partie ouest, un nouvel espace (3) fut créé par l'édification des murs $38-40$ et 36 et la fosse 42 fut comblée de terre, de pierres, de fragments de tuiles et de dolia.

Au cours de cette phase et de la suivante, le canal de fuite et le canal de dérivation ont été progressivement remplis de détritus, essentiellement des tessons d'amphores et de vaisselle, mais aussi des fragments de meules à grains et à huile. Les meules à grains sont au nombre de quatre. Une meta et un catillus, en rhyolite amarante, proviennent des carrières de l'Estérel largement exploitées à l'époque antique (Palausi, 1965 ; Désirat, 1980), puis au Moyen Âge et jusqu'au XIX' s. (Amouric, 1990, p. 445). La meta, d'un diamètre de $0,59 \mathrm{~m}$, mesure $7,5 \mathrm{~cm}$ d'épaisseur à la périphérie; le catillus, de même diamètre, présente une épaisseur de $12 \mathrm{~cm}$ (fig. 24). Une autre meta est taillée dans du basalte (diamètre : $0,55 \mathrm{~m}$; épaisseur : $0,10 \mathrm{~m} c f$. fig. 24). La quatrième meule, un catillus en basalte conservé à moitié, ne semble pas avoir fonctionné avec la meule dormante précédente (fig. 25). Son diamètre est de $0,58 \mathrm{~m}$ et son épaisseur moyenne de $11 \mathrm{~cm}$. Son œillard n'est pas circulaire mais carré $(11 \mathrm{~cm}$ de côté). La face inférieure est creusée de deux encoches rectangulaires opposées servant de logement à l'anille, pièce de fer rectangulaire fixée à l'axe vertical et transmettant à la meule le mouvement rotatif. La face supé-

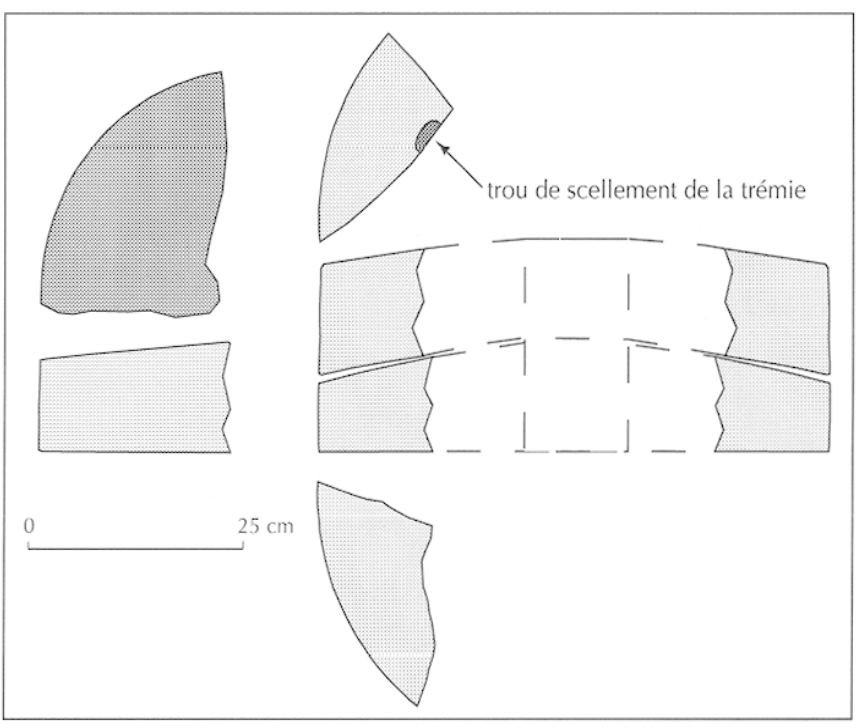

Fig. 24 - Les Mesclans : meules à grain en rhyolite (J.P. Brun).

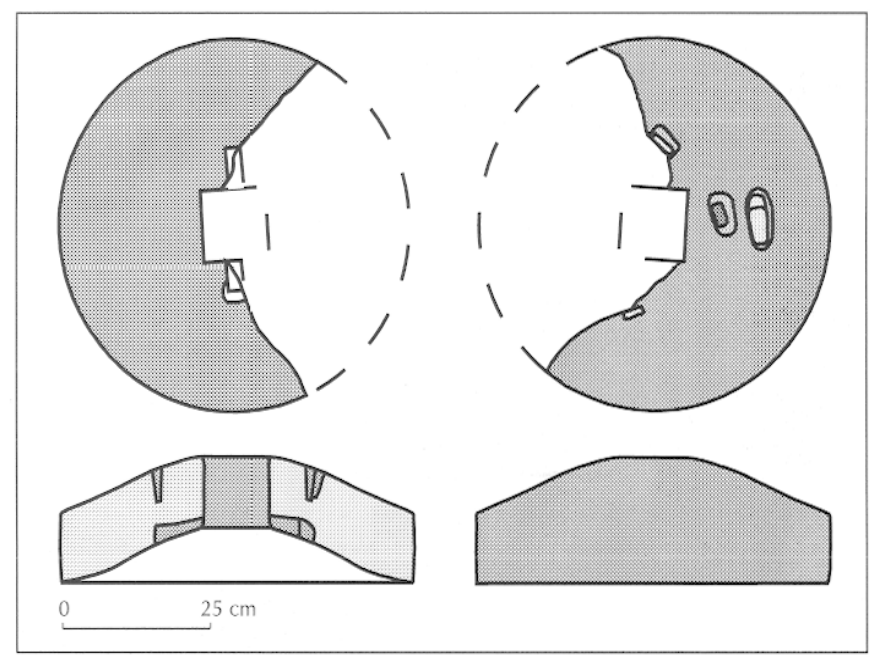

Fig. 25 - Les Mesclans : meule à grain en basalte (J.-P. Brun).

rieure comportait quatre trous disposés en croix dont deux contiennent encore du plomb. Un autre trou est décalé vers la périphérie. La nature du basalte permet de situer sa carrière d'extraction dans la coulée Le BeaussetOllioules.

Les rares objets contenus dans les remblais ne permettent pas de préciser la date de la construction de l'état 4 . Le remblai de la fosse 42 contenait de la céramique sigillée sud-gauloise, des fragments d'une amphore Dressel 20 et un couvercle Hayes 196 en céramique culinaire africaine qui imposent de repousser la 
datation de l'état 4 après le début du II ${ }^{e}$ s., mais on ne peut mieux préciser. Les objets rejetés dans les canaux, plus abondants, sont majoritairement datables de la première moitié du $\mathrm{III}^{\mathrm{e}} \mathrm{s}$. (sigillée claire $\mathrm{A}$ [Hayes $6 \mathrm{~A}$, $9 A / B]$, sigillée claire $B$, culinaire africaine, amphores africaines 1, Dressel 20, gauloises 4 et 5); ils doivent dater l'époque du fonctionnement du moulin lors de l'état 4.

\section{État 5}

Un dernier remaniement est décelable dans l'espace 3 : la construction du mur 12 fait de remplois, dont un gros bloc de calcaire équarri, et la reprise du mur 40 surmonté du mur 14. On ne sait s'il s'agit d'une réparation du moulin ou des traces d'une réaffectation. Sa datation est incertaine (courant III $\mathrm{s}$. ?).

Après la fin de l'occupation, l'ensemble des structures a été recouvert par une couche de gravats conservée dans les zones en creux. Elle contenait un mobilier comparable à celui jeté dans les canaux et globalement attribuable à la première moitié du III' $\mathrm{s}$.

\section{Interprétation}

\section{État 2}

Le moulin avait été implanté en contrebas de l'aqueduc de façon à bénéficier d'un dénivelé de $4 \mathrm{~m}$ entre le fond de l'aqueduc et le fond du coursier. Cette situation s'explique par la volonté d'alimenter la roue par en haut, système le plus efficace lorsqu'on ne dispose pas de grandes quantités d'eau ni d'un courant fort ${ }^{22}$. Il faut donc restituer une roue à augets : l'eau remplit les augets et son poids entraîne la roue vers le bas. Étant donné la hauteur du passage de l'axe dans le mur 49 , la roue devait mesurer environ 2,50 $\mathrm{m}$ de diamètre (base de l'axe à $1,20 \mathrm{~m} \mathrm{du}$ fond + rayon de l'axe, environ $0,10 \mathrm{~m},-0,05$ à 0,10 entre la roue et le fond). Ce diamètre laisse donc

22. L.a faiblesse du débit d'eau explique, d'une part, que l'on ait utilisé une roue très étroite et, d'autre part, que l'on ait choisi une roue verticale plutôt qu'horizontale pourtant plus simple à construire. Les moulins à roue horizontale demandent généralement un fort débit d'eau que, dans les moulins modernes, on obtenait en aménageant des " écluses" en amont. H. Amouric (1983, p. 159) cite à ce propos cette phrase d'Alphonse Jouven, constructeur de moulin au XIX" s. "les moulins à rodet volant prennent pour leur action un volume de fluide considérablement plus fort que ceux mus d'après le système des roues hydrauliques à poids " (Jouven, 1848, p. 16). un dénivelé de $1,50 \mathrm{~m}$ entre le fond de l'aqueduc et le sommet de la roue. La largeur de la roue avoisinait $0,30 \mathrm{~m}$. Le rapport entre la faible largeur et le diamètre relativement grand pose des problèmes de rigidité de la structure et ne s'explique que par le souci de ne pas prélever de trop grandes quantités d'eau sur l'alimentation de la villa qui devait être prioritaire. D'autres exemples de roues étroites sont connus : celle retrouvée à Vénafre mesurait $0,29 \mathrm{~m}$ de largeur pour un diamètre de $1,85 \mathrm{~m}$ (Jacono, 1938) et dans les fouilles de La Bourse à Marseille, où la roue à augets retrouvée dans le bassin du port mesurait $0,20 \mathrm{~m}$ de largeur pour un diamètre de $3 \mathrm{~m}$ (Euzennat, Salviat, 1968, p. 40-41 ; Guéry, Hallier, 1987, p. 272).

Le canal d'amenée d'eau devait être supporté par le mur 48 et prolongé par un canon en bois conduisant l'eau jusqu'aux augets. Les suintements sur les faces sud des murs 48 et, dans une moindre mesure, 9 ont provoqué les dépôts de calcite décrits plus haut.

Le moyeu de la roue devait reposer à l'est sur un bloc de pierre ou de bois scellé sur la banquette 51. Dans les moulins de Saepinum (Italie, Molise), du Janicule à Rome et de l'Agora d'Athènes, l'axe est posé sur un bloc de pierre présentant une gorge (Parsons, 1936, p. 84 ; Bell, 1994, fig. 6 ct 9).

À l'ouest du mur 49 se trouvait un logement approximativement carré, taillé dans le roc et limité à l'est par une paroi (55) ménagée dans le rocher et complétée par une élévation en pierre. Ce mur devait comporter un second bloc support où tournait l'autre extrémité du moyeu de la roue. Le fond de l'excavation est situé à $0,45 \mathrm{~m}$ en dessous de l'axe de la roue. C'est dans cet espace que tournait la roue dentée verticale, le rouet. $\mathrm{La}$ largeur du puits oblige à restituer un petit rouet dont le diamètre devait atteindre $0,80 \mathrm{~m}$ environ. Il était doté de dents (les " aluchons ") qui entraînaient soit un autre rouet horizontal, soit une "lanterne ", étroite cage de forme cylindrique formée de fuseaux verticaux chevillés entre deux disques de bois.

L'engrenage horizontal était fixé à un axe vertical en fer ${ }^{23}$ qui, traversant par dessous la meule dormante, transmettait le mouvement circulaire à la meule tournante. Toute la partie supérieure du moulin pourrait

23. Grâce aux fouilles de Zugmantel (Germanie), de Great Chesterford et de Silchester (Grande-Bretagne), on connaît quatre exemplaires de " gros fer " pourvus de leur anille et dans un cas d'une lanterne en bois (Jacobi, 1912 ; Spain, 1984a, p. 124-125). 
avoir été assemblée en bois. On n'a des traces d'un tel aménagement qu'à l'état suivant qui n'est probablement qu'une réfection ou une consolidation. Le dispositif semble se rapprocher de celui de l'Agora d'Athènes : quatre poutres disposées de façon à former un cadre étaient encastrées dans les murs latéraux du moulin et soutenaient l'assemblage portant le plancher du moulin lui-même (fig. 26) (Parsons, 1936, fig. 10). On est donc tenté de restituer un cadre de bois dont une entretoise supportait la crapaudine dans laquelle tournait l'axe de la lanterne et de la meule. Cette crapaudine peut avoir été en métal, mais également en pierre comme à Ickham et à Haltwhistle, Grande-Bretagne (Spain, 1984a, p. 126), à Avenches, Suisse (Castella, 1994, p. 40, fig. 20) et probablement à Saepinum, Italie (fig. $37, \mathbf{n}^{\circ} 4$ ). Toutefois, aucun galet ou pierre présentant des traces d'usure circulaire n'a été découvert ; quant au métal, il a pu être récupéré.

Un point reste obscur : la fonction de la fosse 42 , grossièrement cylindrique et taillée dans le roc. Son emplacement et ses dimensions auraient permis d'y installer une roue horizontale, un "rodet volant ", mais l'absence de canal d'évacuation des eaux élimine cette hypothèse, à moins que cette fosse ait correspondu à un premier projet abandonné. L'emploi de moulins de ce type est attcsté en Afrique du Nord (Chemtou, Testour, moulins de la région de Cherchell) et en Orient (Césarée de Palestine), mais pour une époque plus tardive (IV s.) ${ }^{24}$ et rien n'assure qu'ils aient été connus en Gaule auparavant.

\section{État 3}

L'état 3 est marqué par la construction du mur 10 qui comporte un logement d'encastrement de poutre nordsud. Cette phase pourrait donc correspondre à une modification du plancher de la chambre haute de la meunerie selon le schëma connu à l'Agora d'Athènes (fig. 26).

\footnotetext{
24. Les moulins horizontaux sont très répandus en Provence au Moyen Âge. Un bel exemple de ce type a été fouillé en 1996 et identifié par Mireille Vacca-Goutoulli et Henri Amouric au lieu-dit La Calade du Castellet (Fontvielle, Bouches-du-Rhône, voir Bilan scientifique du SRA de Provence-Alpes-Côte d'Azur, 1996, p. 85). Le moulin, aménagé dans une ancienne carrière, semble postérieur à l'Antiquité et antérieur à l'An Mil (communication personnelle des découvreurs). À l'époque moderne, et jusqu'au début du XIX' s., la grande majorité des moulins hydrauliques étaient mus par des roues horizontales (Amouric, 1983, 1984).
}

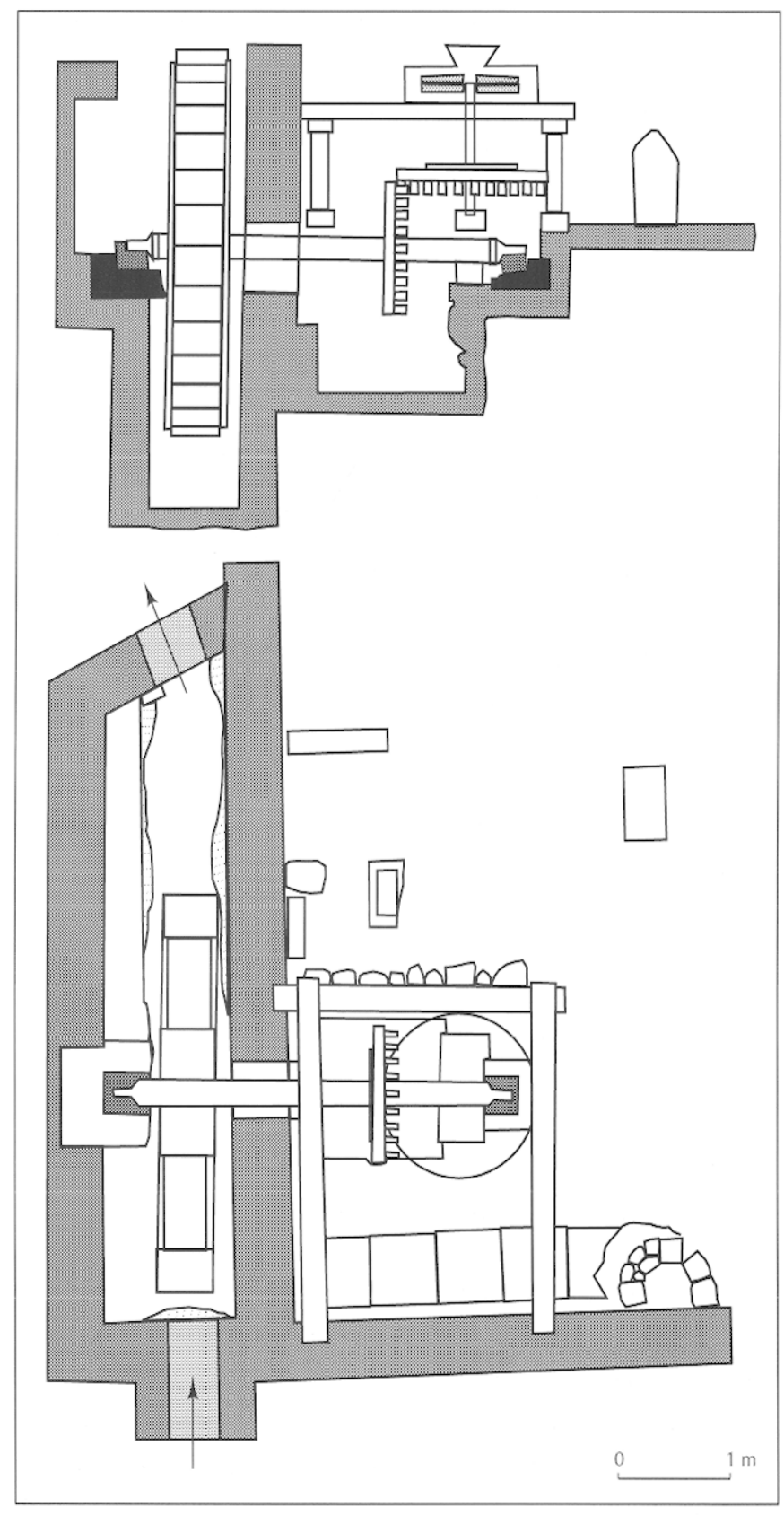

Fig. 26 - Moulin de l'Agora d'Athènes (d'après Parsons, 1936).

\section{État 4}

Les aménagements de l'état 4 sont plus aisés à interpréter. Tout se passe comme si on avait à la fois augmenté la puissance du moulin en accroissant le diamètre de la roue à augets et remplacé les assemblages en bois par de solides murs bâtis à la chaux (fig. 27). Le rehaussement de l'axe du moulin a dû avoir pour corollaire un changement de roue peut-être devenue trop vieille et 


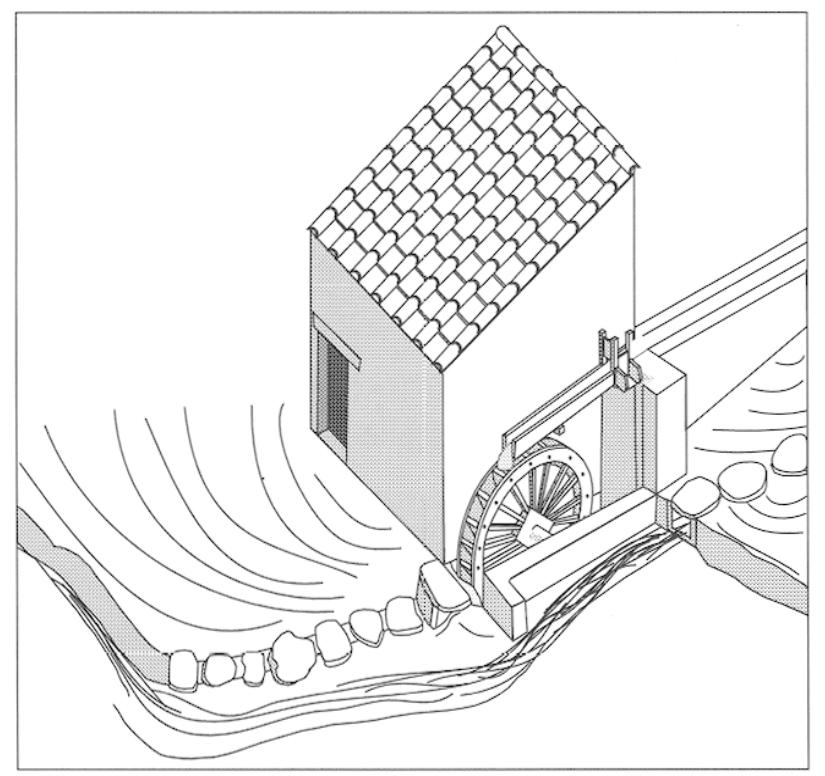

Fig. 27 - Les Mesclans, essai de restitution du moulin : axonométrie (J.-P. Brun).

irréparable ${ }^{25}$. Les cercles laissés par le frottement de la roue sur les concrétions calcaires permettent de déterminer que le moyeu de la roue reposait juste au-dessus de la maçonnerie subsistante. En laissant un espace de 0,10 m au fond du coursier, le diamètre de la roue serait de 3,00 m environ et son sommet serait situé à $1 \mathrm{~m}$ au-dessous du fond de l'aqueduc. Vers l'est, le moyeu devait prendre appui non plus sur la banquette primitive, désormais trop basse, mais directement dans une niche ménagée dans le mur 50 dont il subsiste la trace moulée par les concrétions (fig. 17). Cette niche n'était pas située exactement dans l'axe du passage du moyeu, mais légèrement au sud car, pour être perpendiculaire au plan de la roue à augets, le moyeu devait traverser obliquement le logement ménagé dans les murs 49 et 39 (fig. 16 et 17). Par ailleurs, le diamètre et la position de la roue donnés par les rainures dans les dépôts calcaires interdisent de faire porter directement le moyeu sur un palier en pierre par exemple, car, dans cette hypothèse, le moyeu eût été trop haut. On doit donc plutôt restituer un axe de fer de moindre diamètre

25. I.es comptes des chanoines de Sens remontant au $X V^{e}$ s. montrent la fréquence des réparations nécessitées par les moulins. La roue, notamment, demande des soins constants, des changements de pièces de bois, des renforts en fer, voire une réfection complète (Rouillard, 1996 , p. 49-57). enfoncé dans le moyeu et tournant sur un palier de même métal pris dans la maçonnerie. À l'ouest de la chambre basse, le moyeu était encastré probablement de la même manière dans une niche du mur 38 (fig. 28).

Le gain de hauteur permettait d'obtenir un rouet de l'ordre de $1 \mathrm{~m}$ de diamètre environ (le diamètre maximal est donné par la largeur du puits : $1,15 \mathrm{~m}$ ), ce qui ne permettait pas une forte multiplication de la vitesse, même avec une lanterne de petit diamètre.

Les maçonneries, très puissantes, formaient une masse compacte susceptible de résister aux vibrations et aux mouvements centrifuges provoqués par la rotation de la roue à augets. Sont-elles les fondations d'une voûte supportant la chambre haute ? On manque d'éléments de réponse. L'axe vertical, le " gros fer ", devait prendre appui sur un sommier transversal fixé dans les murs 15 et 13. Le comblement de la fosse 42 , devenue inutile, permit d'établir un sol dans l'espace 3, et il paraît logique de restituer à cet emplacement un escalier permettant de monter à la chambre haute de la meunerie (fig. 28).

Il est probable que la meule en basalte relativement bien conservée et jetée dans le comblement du canal de fuite appartenait à cet ensemble dont on peut tenter une reconstitution. La fixation de l'anille est classique, mais

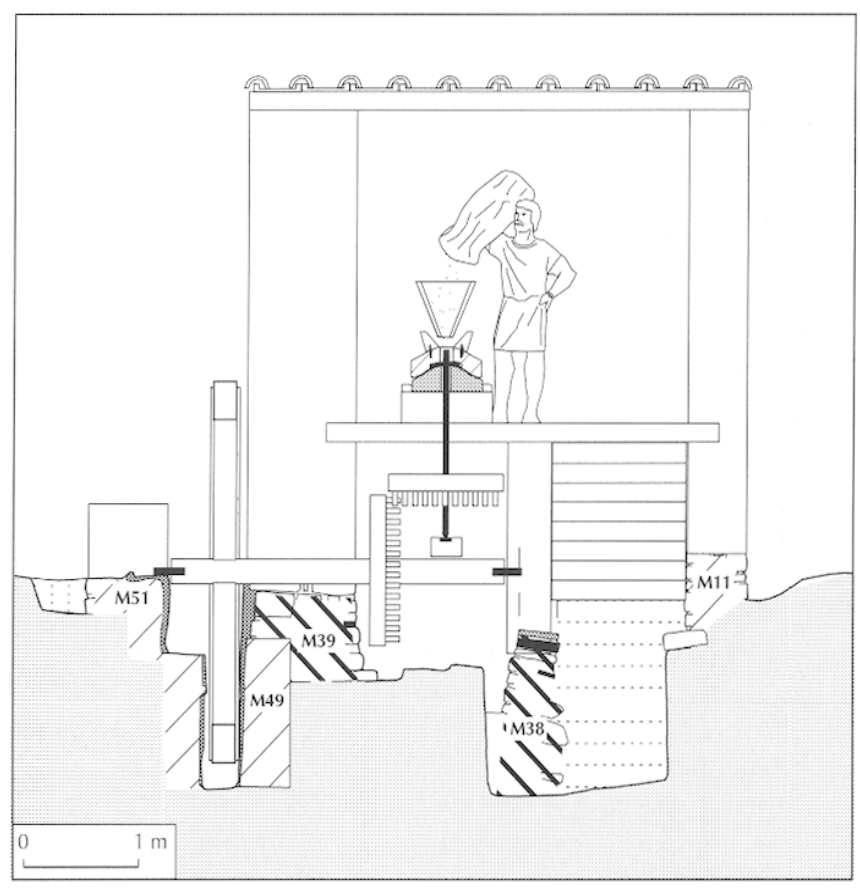

Fig. 28 - Les Mesclans, essai de restitution du moulin : coupe (J.-P. Brun). 
l'œillard carré n'était pas jusqu'ici attesté (fig. 25). Plus hypothétiques sont les fonctions des trous creusés sur la face supérieure. Il peut s'agir soit du scellement de crampons en fer prenant la meule sur le dessus, soit de plombs d'équilibrage, soit de scellements d'anneaux de levage, soit de ceux d'une trémie. Dans la première hypothèse, les crampons feraient double emploi avec l'anille, mais cette association parait attestée au moins dans une meule d'Augst (Castella, 1994, p. 59). Il faut toutefois remarquer que la forme et l'emplacement des trous ne sont pas conformes à ce que l'on connaît ailleurs dans les meules de ce type (ici les trous rectangulaires sont en croix, alors que d'ordinaire ils sont circulaires et disposés en deux files parallèles, $c f$. Castella, 1994, p. 46-62). La deuxième solution suppose une connaissance technique non encore attestée à l'époque romaine : lorsque les meules à grains de fort diamètre tournent à haut régime, entrầnées par un grand rouet et une petite lanterne, la meule tournante doit être équilibrée en coulant du plomb dans des logements judicieusement disposés ; ici les trous sont situés trop près de l'axe pour être utiles à l'équilibrage (sauf le trou isolé situé plus près du bord, mais ce pourrait être une simple réparation). Faut-il voir dans ces logements la trace de la fixation d'anneaux de manutention en fer comme $\mathrm{H}$. Jacobi en restitue sur les meules de Zugmantel (Jacobi, 1912, fig. 38) ? Étant donné la petitesse des meules et leur relative légèreté, de tels anneaux sont inutiles : on pouvait déplacer ces meules à mains nues. En dernière hypothèse, on doit probablement attribuer ces logements à la fixation d'une trémie. En général, les trémies ne sont pas solidaires de la meule tournante : Vitruve (Arch., X, 5, 2) écrit que la trémie est suspendue au-dessus de la meule. Mais il arrive qu'une seconde trémie, solidaire de la meule, soit placée sous la trémie principale pour éviter toute dispersion de grains. Cette hypothèse résout l'anomalie constituée par la forme carrée de l'œillard qui conviendrait à une seconde trémie en forme de tronc de pyramide inversée.

Un dernier point à examiner concerne l'incidence du matériau et de la forme de la meule. Les matériaux volcaniques, basalte et rhyolite, quasi exclusivement utilisés dans l'Antiquité, permettent d'obtenir des farines de plusieurs sortes en repassant plusieurs fois la mouture à une vitesse de rotation lente tant dans les moulins « à sang » ${ }^{26}$

26. Les moulins « à sang » sont actionnés soit par des hommes, soit par des animaux. que dans les moulins hydrauliques (Amouretti, 1986, p. 113-119 et 1987, p. 15-16). Leur usage a été aban-donné en Provence entre la fin de l'Antiquité et le Moyen Âge au profit de meules en roches sédimentaires. L'explication réside peut-être dans le fait que, dans des moulins tournant à des vitesses élevées afin de moudre le grain en un seul passage (mouture à la grosse), le basalte et les roches volcaniques brûlaient la farine. Parallèlement, le diamètre des meules augmenta (supérieur à $1 \mathrm{~m}$ ) et leur profil s'aplatit. Cette évolution, ou plutôt mutation, pourrait traduire une augmentation notable des vitesses de rotation afin d'obtenir des farines panifiables en une seule opération (Amouric, à paraître).

Aux Mesclans, la présence de meules en basalte d'un diamètre de $0,58 \mathrm{~m}$ à profil tronconique assez marqué (pente de $22^{\circ}$ ) serait en faveur d'un moulin hydraulique à vitesse de rotation lente, dans lequel il fallait recommencer au moins deux fois l'opération de mouture. On devrait donc restituer, non pas une lanterne, mais un rouet horizontal d'un diamètre proche du rouet vertical qui tournerait à peu près à la même allure que la roue à augets. C'est un assemblage de ce type que décrit le texte de Vitruve ${ }^{27}$.

A contrario, des vitesses de rotation élevées sont attestées par la découverte de la lanterne en bois jetée dans un puits au début du III $^{e} s$. dans le camp de Zugmantel; formée de deux disques de chêne d'un diamètre de $20 \mathrm{~cm}$ reliés par six fuseaux de fer longs de $16 \mathrm{~cm}$ et d'un diamètre de $3 \mathrm{~cm}$, elle pouvait assurer un pouvoir multiplicateur important $(1: 8$ par exemple, cf. Jacobi, 1912, p. 90, fig. 44 ; Moritz, 1958, p. 125). À l'Agora d'Athènes, où R. J. Spain restitue désormais une lanterne à la place d'un second grand rouet (Spain, 1987 contra Parsons, 1936), les meules ont des diamètres variant de $0,71 \mathrm{~m}$ à $0,82 \mathrm{~m}$ et sont plates (pente de $2^{\circ}$ seulement, mais il faut tenir compte de leur usure). Malgré leur matériau, un basalte, leur profil pourrait bien confirmer que ce moulin avait une vitesse de rotation rapide, proche de 60 tours/mn selon Parsons

27. Vitruve (Arch., X, 5, 2) : "Secundum id, lympanum maius item dentatum planum est conlocatum quo continetur ". Callebat et Fleury (1986, p. 149) ont indiqué que la correction maius en minus traditionnelle n'avait pas lieu d'être. Il en découle que le type de moulin décrit par Vitruve tournait à une vitesse relativement lente, à peu près celle de la roue motrice. Pour les périodes médiévale et moderne, la question a été reprise par G. Comet (1992, p. 415-437). 
(1936) ${ }^{28}$. À Zugmantel, les meules taillées dans du basalte ont un profil relativement conique (16 à $\left.18^{\circ}\right)$ et sont associées à une petite lanterne; toutefois, selon les auteurs de la publication, il s'agirait non d'un moulin hydraulique mais d'un moulin "à sang ", certainement plus lent (Jacobi, 1912; Baatz, 1995). La question reste donc ouverte : aux Mesclans, la conicité de la face d'abrasion, le petit diamètre et l'utilisation du basalte seraient des indices d'une vitesse de rotation lente et donc d'un engrenage horizontal de grand diamètre ${ }^{29}$.

\section{CONCLUSION}

La zone fouillée est trop partielle et l'état de destruction est tel qu'il n'est pas possible de fournir une description cohérente de l'évolution de l'ensemble de la villa. Il parait vraisemblable que le noyau primitif de l'habitat soit situé, comme d'ordinaire, sous la pars urbana dont nous avons vu plus haut qu' elle gît sous le champ de vignes en contrebas de la zone fouillée. Le plus ancien matériel remonté dans les labours date du $\mathrm{I}^{\mathrm{er}} \mathrm{s}$. de notre ère mais, en l'absence de fouille, il serait imprudent d'affirmer que les origines de la villa ne sont pas plus anciennes ${ }^{30}$. En effet, dans le secteur qui a été dégagé, et en particulier dans le remblai qui servait à caler les dolia, on a découvert des fragments d'amphores de l'atelier des Carmes à Marseille qui n'a plus utilisé la pâte micacée très caractéristique après le début du I ${ }^{\mathrm{er}} \mathrm{s}$. de notre ère (Bertucchi, 1992, p. 115).

Le mobilier du remblai des dolia comprend de la vaisselle sigillée produite à La Graufesenque (Dragendorff 15/17 et 37), des fragments d'amphores Dressel 2/4 de Tarraconnaise et gauloise 5 de Narbonnaise. La présence de ces éléments indique que la construction du chai est au plus tôt contcmporainc dc la pćriodc flavicnnc, mais, étant donné la rareté du matériel, on ne peut accorder

28. R. J. Spain (1987, p. 342) évoque la vitesse de 160 tours/mn, certainement beaucoup trop élevée pour le diamètre des meules. Au sujet des vitesses de rotation, voir Comet (1992, p. 425).

29. La position du mur 38 qui soutenait probablement le plancher de l'étage oblige, en tout état de cause, à restituer un engrenage horizontal d'un diamètre inférieur à $1 \mathrm{~m}$.

30. En Provence, dans la majorité des cas, les villae sont fondées dans la seconde moitié du $\mathrm{I}^{\mathrm{er}} \mathrm{s}$. avant J.C. et correspondent à la mise en valeur des terres qui suivit la déduction des colonies d'Arles, d'Orange, de Fréjus, etc. (Brun et al., 1985). de signification à l'absence de sigillée claire A pour tenter de resserrer la chronologie. Toutefois, la couverture des bâtiments a été réalisée avec des tuiles provenant de la région de Fréjus. Pour l'essentiel, elles ont été produites par l'atelier de Lucius Fabius, et un certain nombre par d'autres fabricants tels que Marius, Lucius Herennius et C.H.V, marques largement diffusées sur la côte varoise (Fédière, 1981 ; Brun et al., 1984). Ces productions sont mal datées car rarement découvertes dans des contextes sûrs, mais la marque Mari se retrouve également sur des amphores de l'époque flavienne (Laubenheimer et al., 1991, p. 253). Si les tuiles de Marius ne proviennent pas de remplois, on pourrait dater la construction des bâtiments de la pars urbana de la fin de la période flavienne ou du début du II ${ }^{\mathrm{e}} \mathrm{s}$.

L'aménagement hydraulique pourrait faire exception. Le mobilier découvert dans les niveaux de fondation du moulin ne s'oppose pas à une datation au cours de la même période que le reste de la pars rustica, mais rien n'assure que l'aqueduc et le bassin de décantation ne soient pas plus anciens. On pourrait par exemple imaginer que l'aqueduc a été construit d'abord pour alimenter la villa et fournir de l'eau sous pression dans la pars urbana, et que, dans un second temps, éventuellement lors de l'édification des autres bâtiments de la pars rustica, on ait profité de l'énergie hydraulique pour couvrir les besoins artisanaux. Toutefois, rien ne s'oppose non plus à une construction simultanée de l'aqueduc et du moulin ; la prise du canal du moulin sur l'aqueduc étant détruite, on ne peut discerner si elle est contemporaine de l'aqueduc ou postérieure. Étant donné l'altitude du château d'eau $\mathrm{n}^{\circ} 6(35 \mathrm{~m})$, on doit restituer un canal long de $3 \mathrm{~km} \mathrm{au}$ moins pour prendre l'eau dans le Gapeau, jusqu'au niveau du château de La Monache, où le lit du cours d'eau est à la côte 40 . Le canal devait traverser la légère dépression de La Gensolenne-La Bastidette sur un mur, peut-être en s'appuyant sur l'éminence du Collet-Long. Il devait atteindre ensuite la colline du Mont Redon pour aboutir aux Mesclans; toutefois aucun tronçon n'a été jusqu'à présent repéré le long de ce tracé supposé ${ }^{31}$.

31. Il faut souligner que le Béal d'Hyères, aqueduc long de $8 \mathrm{~km}$, construit entre 1458 et la fin du XVe s., prenait son eau dans le Gapeau à hauteur du château de Ia Castille et traversait la plaine de NotreDame sur un mur haut de $4 \mathrm{~m}$ environ. Ce Béal était destiné à l'arrosage des jardins de la ville d'Hyères et à l'alimentation des moulins hydrauliques (Denis, 1882, p. 444-474). 
Les neuf monnaies trouvées en place ou hors contexte ainsi que le mobilier céramique ou en verre découvert dans les quelques zones en creux préservées des labours sont datables du II ${ }^{\mathrm{e}}$ et des trois premiers quarts du $\mathrm{III}^{\mathrm{e}} \mathrm{s}$. Ce matériel permet de cerner globalement la période d'utilisation de la pars rustica qui paraît abandonnée dans le troisième quart du III' ${ }^{e}$., alors que la pars urbana continue d'être occupée jusqu'au Ve s. au moins.

\section{LA VILLA DE SAINT-PIERRE/ LES LAURONS AUX ARCS}

\section{SITUATION}

La commune des Arcs est située à cheval sur le massif ancien des Maures au sud, la dépression périphérique dans laquelle coule le fleuve Argens, et des massifs calcaires au nord (fig. 29). L'Argens, qui se jette dans la Méditerranée à la hauteur de Fréjus, forme un coude à cet endroit et pénètre pour quelques kilomètres dans le massif des Maures. Depuis la plus haute antiquité, ce lieu a été un point de passage du fleuve et les Romains y avaient établi un pont attesté dès 43 avant J.-C. dans la correspondance de Cicéron (Ad Fam., X, 34a, 34b, $35=$ Correspondance $\mathrm{n}^{\mathrm{os}} 868,876$, éd. Budé).

L'archéologie du terroir des Arcs et de la commune limitrophe de Taradeau est bien connue grâce à des études récentes ${ }^{32}$. À la fin de l'Âge du Fer, plusieurs habitats de hauteur fortifiés ont coexisté dans le massif des Maures : La Cabredor (fig. 29, $\mathrm{n}^{\circ}$ 20), Le Castellas (fig. 29, $\mathrm{n}^{\circ}$ 19), L’Apié de Raybaud (fig. 29, $\mathrm{n}^{\circ} 18$ ) et sur la bordure méridionale des massifs calcaires : Les Arcs (fig. 29, $n^{\circ}$ 9), Le Fort (fig. 29, $n^{\circ} 3$ ) et Le Castellas à Taradeau (fig. 29, $\mathrm{n}^{\circ}$ 2). Tous sont abandonnés dans le courant de la seconde moitié du I ${ }^{\text {cr }}$ s. avant J.-C. au profit d'habitats implantés au pied des collines, dont certains existent dès la fin du $\mathrm{II}^{\mathrm{e}}$ ou le début du $\mathrm{I}^{\mathrm{er}} \mathrm{s}$. avant J.-C. Plusieurs d'entre eux ont été fouillés et montrent des installations modestes au départ (quelques cases ou des baraquements en bois) : La Roquette (fig. $29, \mathrm{n}^{\circ} 10$ ), occupé dès le $\mathrm{II}^{\mathrm{e}} \mathrm{s}$. avant J.-C. sinon aupa-

32. Sur les Arcs : Bérato, Dugas, 1990, 1993 et sur Taradeau : Brun $e t$ al., 1993.

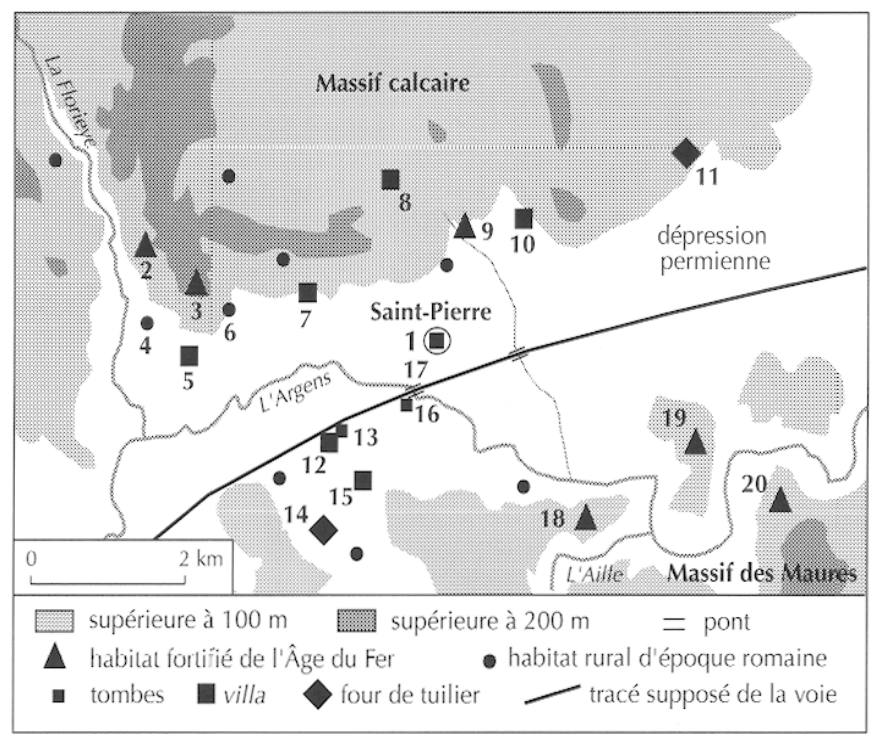

Fig. 29 - Carte archéologique des environs de la villa de SaintPierre/Les Laurons aux Arcs (M. Borréani).

ravant ${ }^{33}$, Saint-Pierre/Les Laurons (fig. $29, \mathrm{n}^{\circ} 1$ ), ToutEgau (fig. 29, $n^{\circ}$ 6), L'Ormeau (fig. 29, $n^{\circ} 4$ ), La Clémensanne (fig. 29, $\mathrm{n}^{\circ} 7$ ). Les terroirs sont densément occupés car fertiles (alluvions de l'Argens), facilement accessibles (en bordure de la voie d'Italie, le long d'un cours d'eau) et situés à proximité de centres urbains naissants : Forum Julii au sud à $26 \mathrm{~km}$ et Forum Voconii à l'ouest à $10 \mathrm{~km}^{34}$. Dans la seconde moitié du ${ }^{\text {er }} \mathrm{s}$., ces habitats ruraux sont embellis, souvent totalement transformés par l'édification de bâtiments en pierre, dotés de thermes et d'installations de production tels que pressoirs à vin et à huile. Ces constructions nécessitent des matériaux et plusieurs fours de tuiliers sont construits à Saint-Jean (fig. $29, \mathrm{n}^{\circ} 14$ ) et à SainteRoseline (fig. 29, $\mathrm{n}^{\circ} 11$ ). Aux II ${ }^{\mathrm{e}}$ et III ${ }^{\mathrm{e}}$ s., de nombreuses villae plus ou moins luxueuses sont attestées : Les Clarettes (fig. 29, $\mathrm{n}^{\circ}$ 8), Le Touar 3 (fig. 29, $\mathrm{n}^{\circ}$ 12), La Magnanière (fig. 29, $\mathrm{n}^{\circ} 15$ ), Saint-Pierre/Les Laurons (fig. $29, \mathrm{n}^{\circ} 1$ ) sur la commune des Arcs, ainsi que La Clémensanne (fig. 29, $n^{\circ} 7$ ) et Saint-Martin (fig. 29, $n^{\circ} 5$ ) sur celle de Taradeau. Nombre de ces sites sont encore

33. Fouille de Marc Borréani (Bilan scientifique du SRA de Provence-AlpesCôte d'Azur, 1994, p. 181-182).

34. Sur Fréjus : Février, 1977 ; Gascou, 1982 ; Gascou, Janon, 1985. Sur la voie de Fréjus à Forum Voconii (aux Blais, Le Cannet-des-Maures) : Boyer, Février, 1959. 


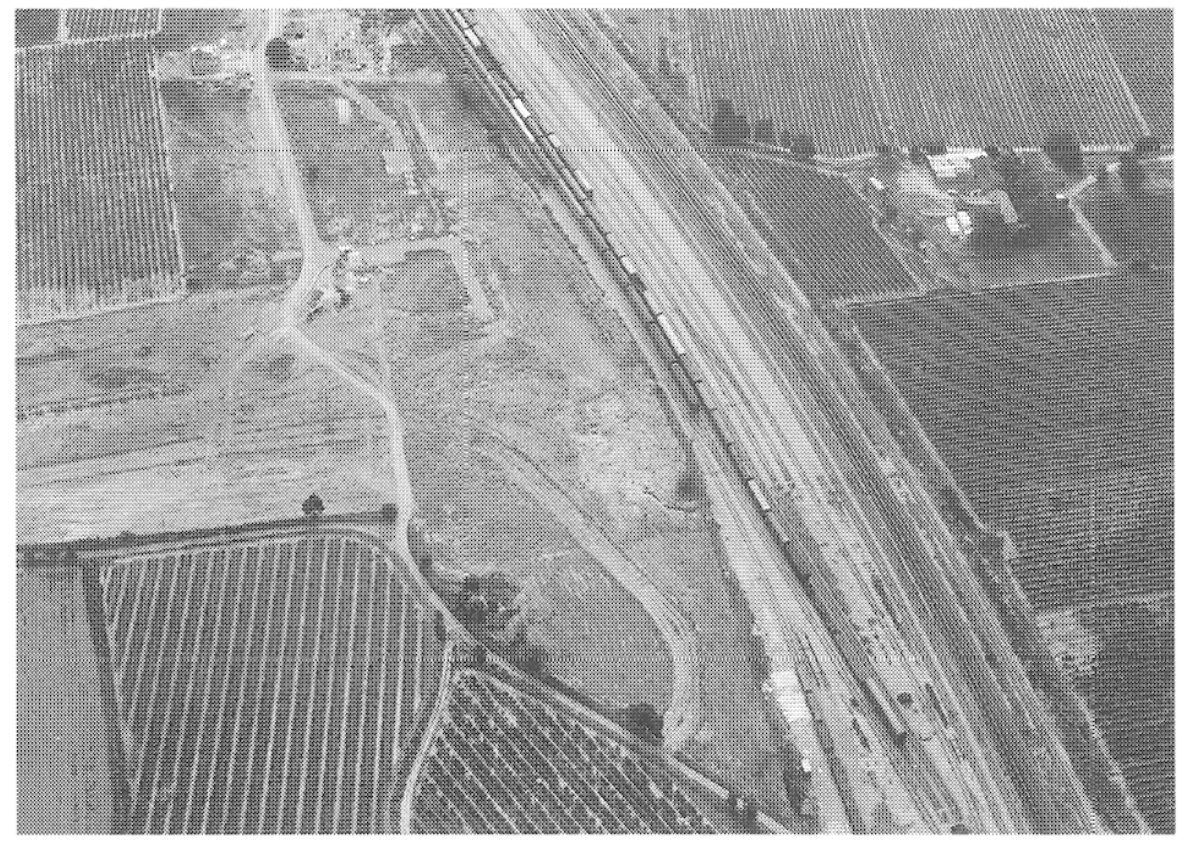

Fig. 30 - Saint-Pierre/Les Laurons: vue aérienne du site (J.-P. Brun). occupés au Bas-Empire, jusqu'au Ve s., voire au VI' s. pour certains. Plusieurs nécropoles sont connues le long de la voie, notamment à La Magdeleine (fig. 29, $\mathrm{n}^{\circ}$ 16), à proximité du pont sur l'Argens (fig. 29, $\mathrm{n}^{\circ} 17$ ) et au Touar (fig. 29, $\left.{ }^{\circ} 13\right)^{35}$.

La villa de Saint-Pierre/Les Laurons est située sur la rive gauche de l'Argens, en amont du pont, à $600 \mathrm{~m}$ du fleuve; ses bâtiments étaient implantés au sud de la cuesta calcaire, à une altitude de $60 \mathrm{~m}$. En 1984, l'aménagement du lotissement des Laurons a entraîné la destruction de la pars rustica de la villa qui nécessita une fouille de sauvetage dirigée par Michel Pasqualini (fig. 30). Les résultats de cette intervention furent publiés (Bérato et al., 1990) sans que l'installation du moulin hydraulique ne fût alors identifiée.

Le site est coupé en deux par la voie ferrée Paris-Nice, très large à cet endroit du fait de la proximité de la gare des Arcs. Au sud, la pars urbana gît encore sous les champs de vignes qui livrent des vestiges d'aménagements luxueux : marbre, tesselles en pierre et en pâte de verre bleue, fragments de peintures murales. Le mobilier trouvé en surface couvre une large période entre le $\mathrm{I}^{\mathrm{er}} \mathrm{s}$. avant J.-C. et l'Antiquité tardive. L'emplacement de la

35. Groupe funéraire du Haut-Empire : Boyer et al., 1986, p. 91-120 et nécropole des III'-IV"s. : Bérato et al., 1996. villa fut occupé au Moyen Âge par le prieuré de SaintPierre dépendant de l'abbaye de Saint-Victor de Marseille (Bérato et al., 1992).

Au nord de la voie ferrée, les vestiges fouillés, très arasés, font partie de la pars fructuaria (fig. 31). Ils montrent trois grandes phases de construction.

La période 1 , datable de la seconde moitié du ${ }^{\mathrm{er}} \mathrm{s}$. avant J.C., correspond au creusement de fosses et de tranchées dans le tuf. Ces aménagements évoquent des fondations de bâtiments en bois implantés lors de la création de l'habitat; ils trouvent des correspondances dans le premier état de la villa du Grand Loou à La Roquebrussanne (Brun, 1986, p. 190).

La période 2, datable de la fin du I $\mathrm{I}^{\mathrm{er}}$-début du $\mathrm{II}^{\mathrm{e}} \mathrm{s}$. après J.-C, est marquée par l'édification de bâtiments construits en pierres liées à la chaux. L'état d'arasement des structures ne permet pas de restituer le plan d'ensemble, mais on reconnait des cuves, appartenant probablement à une huilerie, et des constructions édifiées dans le tuf que l'on interprète désormais comme un moulin hydraulique (fig. 32 et 33 ).

La période 3 correspond à la désaffection de ces installations et à leur utilisation comme dépotoir à la fin du III $\mathrm{s}$. et au IV $\mathrm{s}$. après J.-C. La pars urbana de la villa semble avoir été occupée plus tard, au moins jusqu'au $V^{e}$ s. après J.-C. 


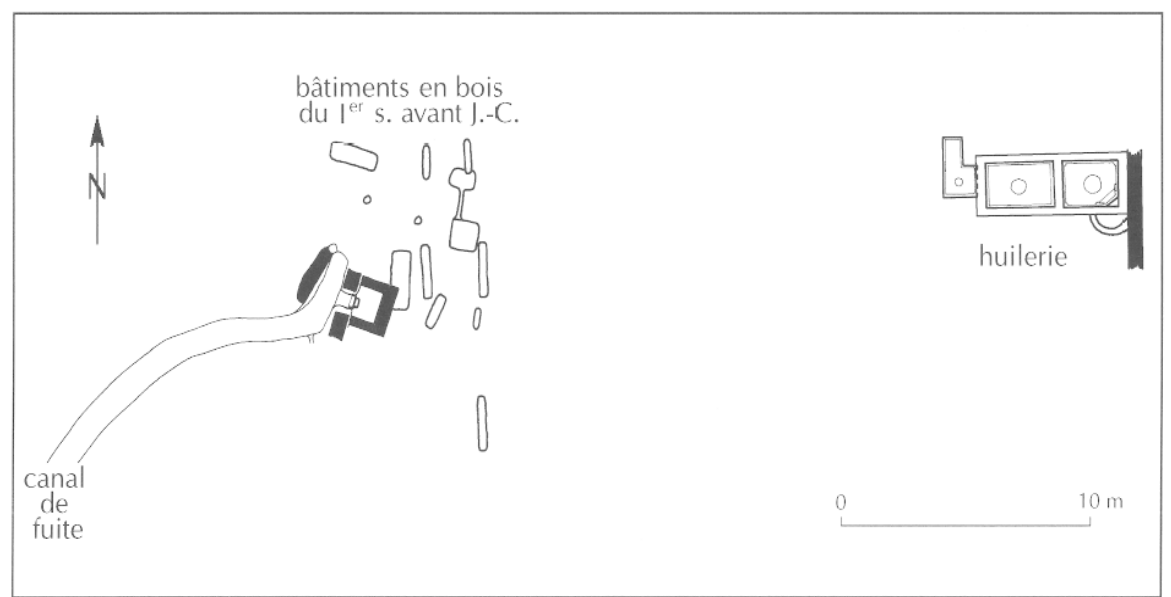

Fig. 31 - Saint-Pierre/Les Laurons: plan général du site (M. Borréani).

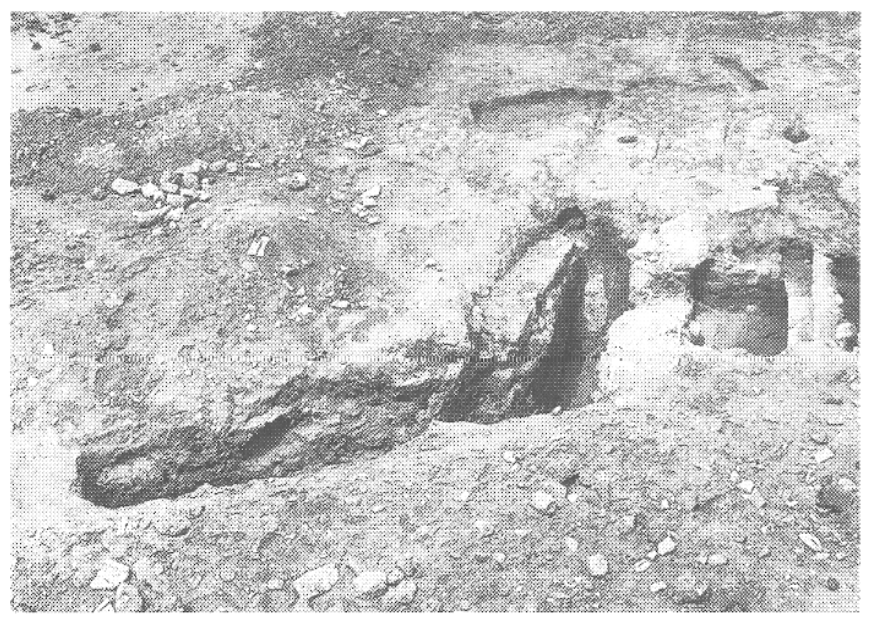

Fig. 32 - Saint-Pierre/Les Laurons : vue du moulin à eau (M. Pasqualini).

\section{LE MOULIN HYDRAULIQUE}

Des structures du moulin, très arasées, ne sont conservées que les parties enterrées, à savoir le coursier et la chambre du rouet. Le bâtiment du moulin, qui était édifié au-dessus de la chambre du rouet, a totalement disparu, excepté deux portions de murs encadrant le logement de l'axe de la roue (fig. 32 et 33). Le mobilier trouvé dans la couche de fondation du moulin comprend de la céramique campanienne et sigillée sud-gauloise (Drag. 37), des amphores de Bétique et gauloises.

\section{LE COURSIER}

Le coursier, d'une longueur de $3 \mathrm{~m}$, était taillé dans le tuf (fig. 33 et 34). La roue était alimentée par un canal d'amenée qui a disparu. Au niveau de la chute se trouve un entaillement bien marqué dans l'angle nord-ouest du canal, mesurant environ $0,30 \mathrm{~m}$ sur $0,30 \mathrm{~m}$. Le coursier, conservé sur une hauteur de $1,70 \mathrm{~m}$, était large de 0,70 à $0,90 \mathrm{~m}$. Son fond, plat au nord, était ensuite surcreusé sur une profondeur de $0,30 \mathrm{~m}$ et une largeur de $0,30 \mathrm{~m}$. L'eau avait laissé d'importantes concrétions calcaires sur les parois. Au-delà du coursier, le canal de fuite obliquait vers le sud-ouest, puis adoptait un tracé curviligne vers le sud qui a été suivi sur environ $13 \mathrm{~m}$ jusqu'à la voie ferrée.

À l'ouest, une banquette, pavée de fragments de tegulae, avait été ménagée en bordure du coursier sur une longueur de 2,00 $\mathrm{m}$ et une largeur de $0,50 \mathrm{~m}$; elle était située à une profondeur de $0,30 \mathrm{~m}$ par rapport au niveau actuel du substrat et servait d'assise au bloc de pierre ou de bois qui supportait le moyeu de la roue à augets.

Le diamètre maximum de la roue est donné par la longueur du coursier $(3,00 \mathrm{~m})$ et par la distance entre le fond et le logement de l'axe de la roue $(1,40 \mathrm{~m})$. Étant donné qu'il convient de laisser au moins une dizaine de centimètres entre la roue et le fond du canal, on estimera que le diamètre de la roue à augets devait mesurer entre 2,50 et $2,80 \mathrm{~m}$. Sa largeur, nécessairement inférieure à celle du coursier $(0,70 \mathrm{~m})$, pouvait avoisiner $0,50 \mathrm{~m}$. 

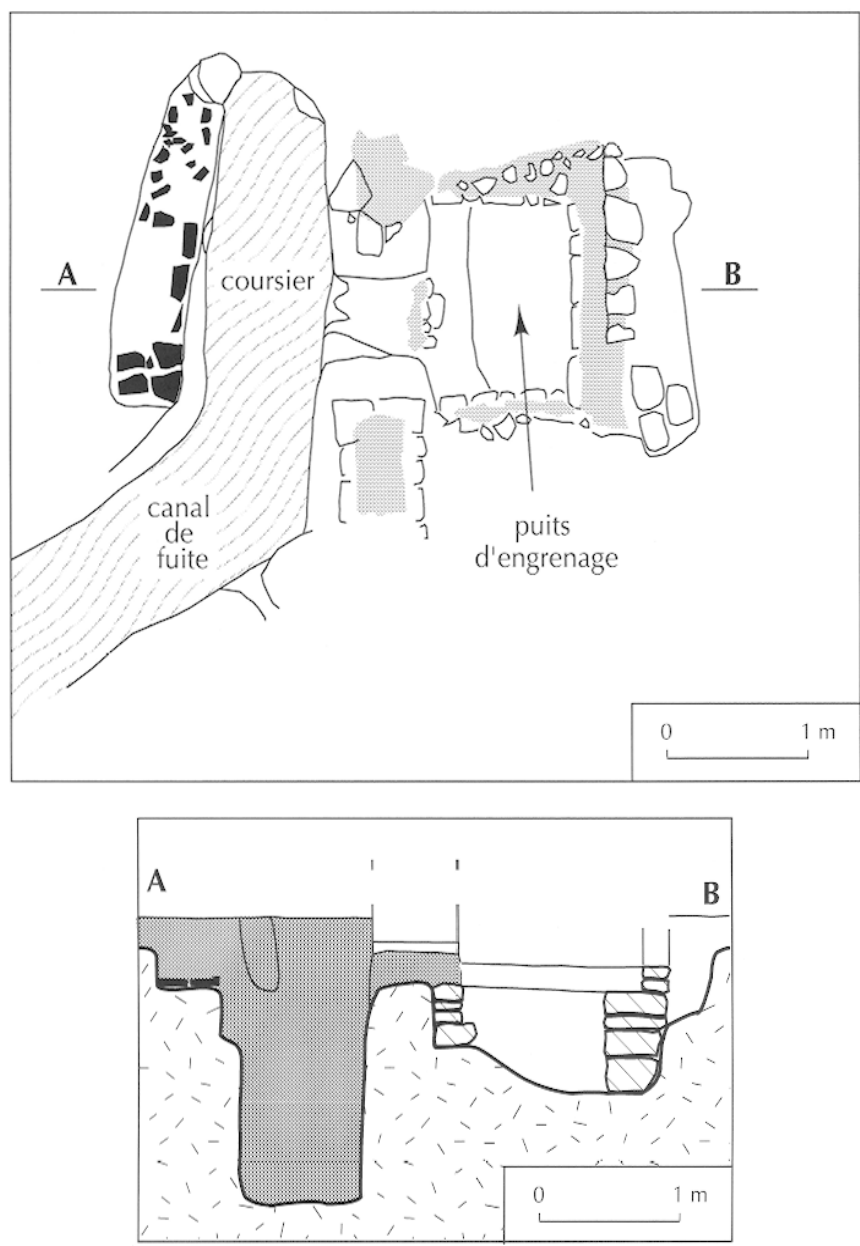

Fig. 33 - Saint-Pierre/Les Laurons : plan et coupe du moulin à eau (M. Borréani).

\section{LE LOGEMENT DU MOYEU DE LA ROUE ET LA CHAMBRE DU ROUET}

Creusé dans le tuf, le passage du moyeu mesurait $0,54 \mathrm{~m}$ de largeur pour une longueur de $0,80 \mathrm{~m}$ et une profondeur conservée de $0,25 \mathrm{~m}$. Il était encadré au nord et au sud par deux lambeaux de murs liés à la chaux, d'une largeur de $0,60 \mathrm{~m}$.

La chambre du rouet était creusée dans le tuf et parementée au nord, à l'est et au sud par des murs bâtis à la chaux. Sa longueur minimale mesurait $1,20 \mathrm{~m}$ pour une largeur de $1,00 \mathrm{~m}$. Le mur oriental présentait un ressaut de $0,24 \mathrm{~m}$ de large, permettant de loger le bloc support de l'axe du moyeu.

Lors de la fouille, la profondeur du puits d'engrenage n'était que de $0,40 \mathrm{~m}$, sauf à l'ouest où un surcreusement

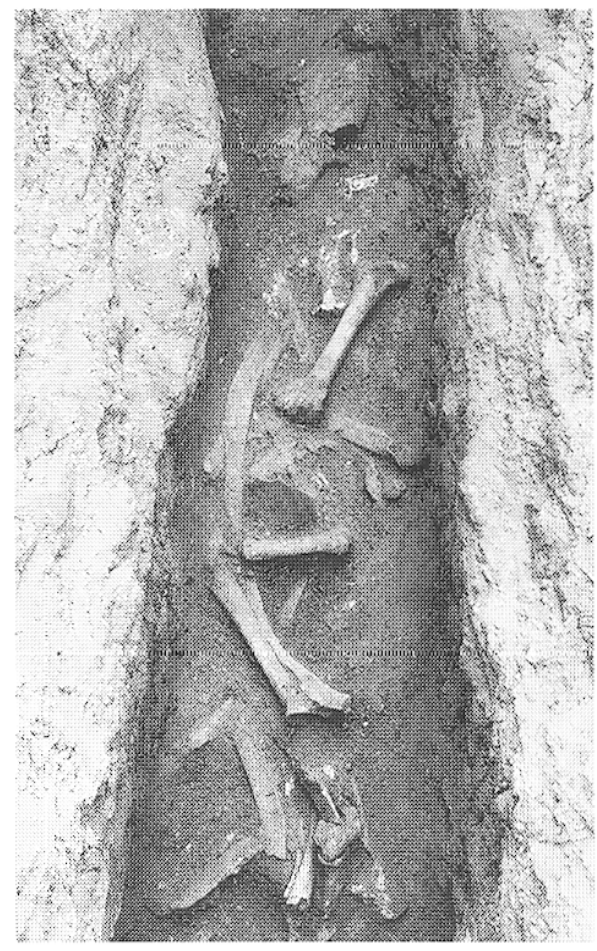

Fig. 34 - Saint-Pierre/Les Laurons : détail du dépotoir comblant le coursier (M. Pasqualini). .

du rocher portait la profondeur à $0,68 \mathrm{~m}$ par rapport à l'arase du mur est. Ce surcreusement marquait l'emplacement du rouet dont le diamètre pouvait avoisiner $1,10 \mathrm{~m}$, la longueur minimale de la chambre étant de $1,20 \mathrm{~m}$. On retrouve ici des valeurs voisines de celles du moulin des Mesclans et il faut imaginer que la vitesse de rotation des meules était, là aussi, relativement lente.

Après la fin de l'utilisation du moulin, le coursier et le canal de fuite servirent de dépotoir où l'on jeta des ossements d'animaux, des gravats, des amphores et de la vaisselle (fig. 34). Le mobilier comprend de la sigillée sudgauloise (Drag. 37 de Banassac), de la sigillée claire $A$ (Hayes 3B, 3C, 8A, 9A, 14B, 31), de la sigillée claire B (Desbat 2 et 67) et de la sigillée claire $C$ (Hayes 50A), des amphores africaines IA, Dressel 20, Beltran 2A, G.5, G.4, mais aussi un cadran solaire, des épingles en os, etc.

\section{L'ALIMENTATION DU MOULIN}

En l'absence d'indice archéologique quant à l'origine de l'alimentation en eau du moulin, on notera l'existence, dès le Moven Âge, de plusieurs moulins implantés au 
sud-ouest du village. Ceux-ci étaient mus par l'eau du vallon de Fantroussière, situé à environ $1500 \mathrm{~m}$ au nord-est de la villa (Sauze, 1993, p. 71), vallon qui pourrait donc également avoir alimenté la villa et son moulin hydraulique.

\section{LES MOULINS HYDRAULIQUES ANTIQUES ET L'HISTOIRE AGRAIRE}

\section{L'ESSOR AGRICOLE DU HAUT-EMPIRE ET LA DIFFUSION DES MOULINS HYDRAULIQUES DANS LES VILLAE}

Que les moulins hydrauliques soient connus depuis le $\mathrm{I}^{\mathrm{cr}}$ s. avant J.-C. et déjà largement diffusés sous l'Empire, les textes l'indiquent clairement ${ }^{36}$. Les vestiges archéologiques, longtemps rares, se multiplient depuis quelques années. À l'occasion de la publication du moulin d'En Chaplix à Avenches (Suisse), Daniel Castella et François Eschbach, poursuivant les efforts de Örjan Wikander

36. Strabon (XII, 3, 30) signale qu'il existait un hydraletès dans le palais de Mithridate à Cabire, donc dès la première moitié du I Ir $s$. avant J.-C. On en trouve également mention chez Lucrèce (De Natura Rerum, V, 514-516), Antipater de Thessalonique (Anthologie Palatine, IX, 418), Vitruve (Arch., V, 2), Pline (N.H., XVIII, 97 qui signale que les moulins hydrauliques sont d'un usage courant). L'Édit sur les Prix de 301 (XV, 52-55) fixe le prix maximum d'un moulin à eau à 2000 deniers, alors que les moulins à bras valent 250 deniers et ceux actionnés par des animaux entre 1250 et 1500 deniers. Dans le Talmud de Jérusalem, le traité du Shabbath proscrit l'utilisation du moulin à eau le samedi (I, 5 , cf. Schwab, 1977, p. 22). Au IVe s., Ausone (Mosella, v. 361-364) évoque les moulins à eau de la Moselle; Palladius (Opus Agriculturae, I, 41) conseille d'utiliser les eaux issues des thermes pour installer des moulins et Libanios (Or, IV, 29) mentionne qu'en 387, les boulangers d'Antioche devaient payer une redevance pour l'utilisation des moulins hydrauliques. Au IV s., Jean Cassien, vers 425 , compare les mouvements de l'âme à ceux des meules que le courant fait tourner sans cesse (Conlatio, I, 18). Au VI ${ }^{e}$ s., Cassiodore (Variae, III, 31, 2) évoque les détournements d'eau pour alimenter des jardins et des moulins (en 510-511) ; Procope (Bell. Goth., I, 19) mentionne, lors du siège de Rome par les Goths en 536, l'arrêt des moulins implantés sur les aqueducs alors coupés et l'installation de moulins flottants sur le Tibre ; Grégoire de Tours (Historia Francorum, III, 19) donne une description de Dijon vers 580 où un cours d'eau fait tourner des moulins " avec une prodigieuse vélocité "; Marius Aventicus en signale en 563 à Genève (Chron. s.a. 563). Pour la Narbonnaise, saint Césaire (Sermon, 8, 4) écrit que " notre esprit ressemble à ces meules qui tournent sans cesse sous l'impulsion de l'eau ". Plus tard, la loi salique prévoit une compensation importante (équivalente à un bœuf) pour le vol du « gros fer » du moulin (Pactus legis Salicae, XXII, 2).
(1984, 1985), ont fourni un recensement des moulins hydrauliques connus en Angleterre, en Allemagne et en Suisse auquel on se reportera. L'Orient est certainement très riche. C'est dans le Pont que le premier moulin hydaulique est mentionné : Strabon (XII, 3,30) rapporte que, dans le palais de Mithridate à Cabire, se trouvait un moulin hydraulique. P. Roos (1996) a réexaminé le texte à la lumière des connaissances actuelles. La région de Cabire, aujourd'hui Niksar est parcourue par un torrent rapide qui depuis le $\mathrm{XVII}^{\mathrm{e}} \mathrm{s}$. au moins porte des moulins à tan et à grain. L'auteur pense qu'il faut le relier aux jardins et considérer qu'il fait partie d'un ensemble qui ne paraît pas être une nouveauté pour Strabon. P. Roos considère que Lucullus, qui introduisit d'autres nouveautés comme la cerise, aurait pu rapporter la technique des moulins hydrauliques en Italie. En Anatolie, plusieurs inscriptions font mention de moulins hydrauliques. Bien avant les nombreux moulins de l'inscription d'Orcistus, datée de 329-330 après J.-C. (Chastagnol, 1981), une inscription du $\mathrm{II}^{\mathrm{c}} \mathrm{s}$. trouvée à Hiérapolis de Phrygie mentionnait l'existence d'une corporation de meuniers à eau

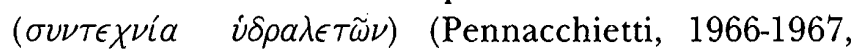
p. 297-298, n 7). H. W. Pleket (1988) en a tiré tous les enseignements quant à l'usage banal de l'énergie hydraulique dans cette région. Unc inscription trouvćc à Sardcs et datable des $\mathrm{IV}^{\mathrm{e}}-\mathrm{VI}^{\mathrm{e}} \mathrm{s}$. rapporte le nom d'Euchromius, constructeur de moulins hydrauliques (Foss, 1976, p. 110, $\mathrm{n}^{\circ} 10$ ). Ces témoignages épigraphiques sont désormais complétés par des vestiges archéologiques à Orkistos même (Alikel), à Kursunlu Selalesi près de Pergé en Pamphylie, à Lama en Cilicie (Roos, 1991) et à Éphèse (Schiøler, 1989, p. 141). Plus au sud, plusieurs meuneries hydrauliques sont signalées à Caesarea (IV e s., cf. Oleson, 1983 ; Schiøler, 1989) et en d'autres lieux de Palestine probablement datables du Bas-Empire (Avitsur, 1960 et 1969 ; Wikander, 1985, p. 161-162); il faut rappeler qu'une taxe sur les moulins à eau était levée à Antioche en 387 après J.-C. (Libanios, Or., IV, 29).

Si la mention d'un hydraletès dans un papyrus égyptien est fortement douteuse ${ }^{37}$, on compte toutefois en Afrique

37. Le papyrus Graec. Vindob 28415, trouvé au Fayoum et daté du Ve s. de notre ère, est fragmentaire et peu clair. Il s'agit d'une histoire incompréhensible de vinaigre jeté sur la meule à eau (?) et de pains à peser. Le terme $\dot{v} \delta \rho a \lambda \epsilon T h s$ est en fait une conjecture presque désespérée de l'éditeur et restituée à partir de $\dot{v} \rho 0[\ldots] \lambda \epsilon \tau a \nu$. (Gerstinger, 1952; Kiesling, 1958, $\left.n^{\circ} 9137\right)$. On ne peut donc en aucun cas utiliser ce document. 


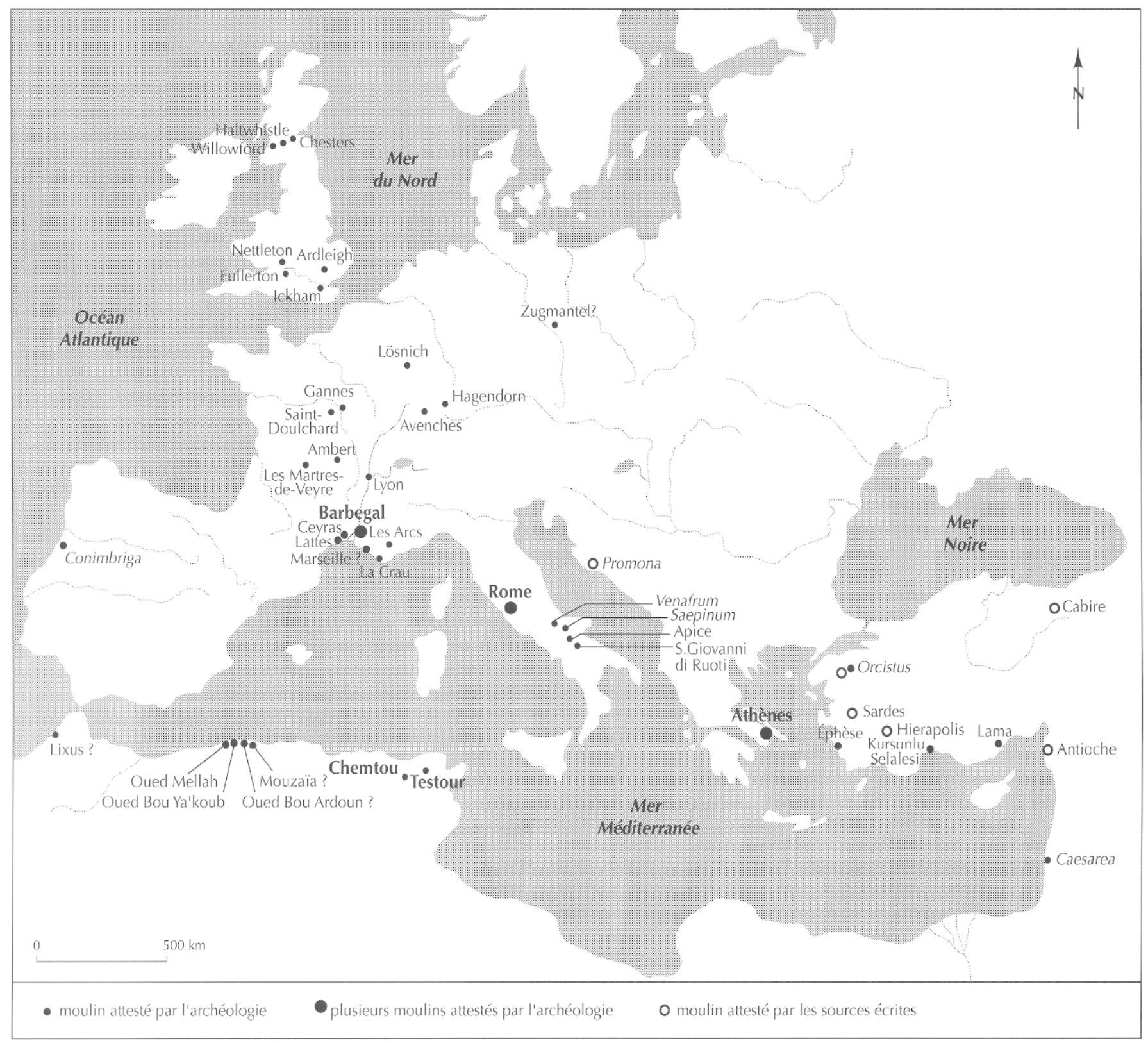

Fig. 35 - Carte de répartition des moulins hydrauliques dans l'Empire romain (J.-P. Brun).

Antioche : taxe sur les moulins à eau en 387 après J.-C. (Libanios, Or., IV, 29) ;

Ardleigh : moulin sur une rivière (Spain, 1984a);

Apice : meunerie à roue verticale sur une rivière du II's. (Johannowsky, 1994, fig. 1) ;

Athènes : moulin de la seconde moitié du V's. et de la première moitié du VI s. (Parsons, 1936);

Avenches: moulin du Ir s. (Castella, 1994);

Barbegal : meunerie comportant seize moulins des II'-IIT s. (Leveau, 1995);

Cabire : moulin dans le palais de Mithridate (Strabon, XII, 3, 30) ;

Caesarea de Palestine : moulin du $\Gamma^{e}$ s. (Oleson, 1983);

Ceyras, La Mouline : moulin des $I^{e}-I I^{e}$ s. après J.-C. (renseignement I). Garcia) ;

Chemtou : meunerie à turbines des $I I I^{e}-I V^{n} s$. (Röder, Röder, 1993);

Chesters Bridge : moulin du III's. (Spain, 1984a);

Conimbriga : moulin à roue verticale du Haul-Empire (observation de A. Alarcão et J.-P. Brun) ;

Conslantinople : mosaïque du grand palais représentant un moulin à eau ; 
Éphèse : plusieurs moulins (Schiøler, 1989, p. 141);

Fullerton : moulin (Spain, 1984a);

Gannes : roue à aubes moulée par des concrétions calcaires (Boisvillette, 1840);

Hagendorn: moulin de la fin du II" s.-débul du III's. (Gähwiver, Speck, 199I);

Hallwhistle Burn Head: moulin du III's. (Simpson, 1976);

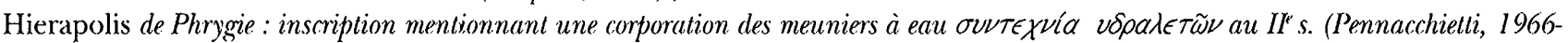

1967, p. 297-298, nº 7 ; Pleket, 1988);

Ickham : deux moulins des II'-IV's. (Spain, 1984b);

Kursunlu Selalesi près de Pergé en Pamphylie (Roos, 1991);

Lama en Cilicie (Roos, 1991);

Lixus (Oued-es-Soueïr) : moulin? (Wilson, 1995, p. 508, $\left.n^{\circ} 7\right)$;

Lösnich : deux moulins liés ì une villa (Neyses, 1983);

Iyon-Vaise : moulin du Ir s. après J.-C. (renseignement C. Bellon, 1998);

Les Martres-de-Veyre : deux moulins des Ir et IT s. (Romeuf, 1978);

Mouzaïa des Mines : barrage et moulin à turbine? (G.sell, 1911, fo. 13, $\left.n^{\circ} 21\right)$;

Nellleton: moulin du III's. (Spain, 1984a);

Orcistus : inscription mentionnant de nombreux moulins en 329-330 après J.-C. (CIL III, 352 ; Chastagnol, 1981, des vesliges de moulins

hydrauliques antiques sont mentionnés à Alikel [ancienne Orcistus] par Roos, 1991);

Oued Mellah : moulin à roue horizontale (Leveau, Paillet, 1976, p. 175; Wikander, 1990, p. 78);

Oued Bou Ya'koub: moulin à roue horizontale (Leveau, Paillet, 1976, p. 175, $n^{\circ} 173$ );

Oued Bou Ardoun : moulin à roue horizonlale? (I eveau, 1984, p. 381, $\left.n^{\circ} 211\right)$;

Promona : inscription mentionnant un moulin (CIL III, 14969, 2);

Rome, Janicule : meunerie comportant plus de cinq moulins (III-IVPs.) (Bell, 1994);

Rome, Thermes de Caracalla: moulin à deux roues des III'-V"s. (Schiøler, Wikander, 1984);

Saepinum : moulin du Haut-Lmpire (Cianfarani, 1958);

Saint-Doulchard (Cher) : pales de roue à aubes de la première moitié du $I^{\text {rr }}$ s. (Champagne et al., 1997);

San Giovanni di Ruoti : moulin à roue verticale du I Ir s. (Small, Buck, 1994, p. 44);

Sardes : inscription funéraire d'Euchromius, constructeur de moulins hydrauliques des $I V^{p}-V I^{p}$ s. (Foss, 1976, p. 110, $\left.n^{\circ} 10\right)$;

Testour : mennerie à turbines (Rakob, 1.99.3);

Venafrum : roue à aubes moulée par des concrétions calcaires (Jacono, 1938);

Willowford : moulin sur une rivière (Spain, 1984a).

près d'une dizaine de meuneries, à Chemtou (Röder, Röder, 1993), à Testour (Rakob, 1993), dans les alentours de Cherchell ${ }^{38}$ et peut-être de Lixus ${ }^{39}$. On ne connaît qu'un seul moulin hydraulique dans la Péninsule ibérique à Conimbriga, mais il s'agit certainement d'une lacune, car les aménagements hydrauliques sont nombreux ${ }^{40}$.

Pour la Gaule et l'Italie, nous avons tenté de compléter les données en dépouillant les "informations " de

38. Le cas le plus net est celui de l'oued Mellah signalé par Leveau et Paillet (1976, p. 175) et interprété par Th. Schiøler (1989, p. 140-141) et Ö. Wikander $(1990$, p. 78). Il faut y ajouter ceux de l'oued Bou Ya'koub (Leveau, Paillet, 1976, p. 175), de l'oued Bou Ardoun (Gsell, 1911, fol. 13, $\mathrm{n}^{\circ}$ 21) et de Mouzaïa des Mines (Gsell, 1911, fol. 13, $\left.\mathrm{n}^{\circ} 32\right)$.

39. Un moulin hydraulique a été anciennement signalé sur l'oued esSoueïr, au sud de Lixus au Maroc (cité par Wilson, 1995, p. 508, n ${ }^{\circ}$ ).

40. Toutes les conditions étaient réunies pour favoriser l'implantation
Gallia et les volumes parus de la Carte archéologique de la Gaule et de la Forma Italiae. Le bilan est encore maigre ; l'état de destruction des vestiges et le manque de description détaillée des meules trouvées dans les établissements ruraux occultent certainement une partie du phénomène. Deux exemples : au lieu-dit Logis de Pouillac à Mouterre-sur-Blourde (Vienne), François Eygun (1959, p. 484) publie la photographie d'une meule qui, com-

ouvrages hydrauliques (barrages, aqueducs, aménagements de cours d'eau), nombreuses agglomérations, bonne connaissance de la roue à augets utilisée pour épuiser l'eau dans les mines (comme celles de Vipasca par exemple). À Conimbriga (Portugal), on peut voir les traces d'une usure circulaire sur un mur appartenant à un aménagement hydraulique. Il s'agit des vestiges d'une roue à augets alimentée par en haut, qui appartenait à un moulin hydraulique urbain alimenté par l'aqueduc (Brun, 1997). Il faut souligner que la ville de Condeixa qui a pris la suite de celle de Conimbriga compte encore aujourd'hui plus d'une trentaine de moulins hydrauliques, certains encore en fonction. 
portant une anille, pourrait provenir d'un moulin hydraulique. Au lieu-dit Le Gros Hêtre, à Saint-Maximin (Oise), les fouilles d'un vicus ont mis au jour des metae très plates, rayonnées et, semble-t-il, percées de part en part (Piganiol, 1959). Mais toutes ces meules peuvent aussi bien provenir de moulins à bras car certains d'entre eux possèdent des metae perforées (par exemple aux Fontaines Salées : Lacroix, 1963). Par ailleurs, les prospections le long des cours d'eau sont encore insuffisantes. Les moulins découverts le long du mur d'Hadrien (Spain, 1984a) et les nombreux moulins médiévaux, comme ceux du Languedoc (Phalip, 1992), montrent que c'est le long des rivières que l'on a le plus de chance de mettre au jour de tels vestiges, mais les berges ont été très souvent érodées, ou au contraire alluvionnées, voire aménagées, ce qui rend toute prospection délicate. Enfin, une attention insuffisante a été portée aux structures liées à des aqueducs et notamment aux petits aqueducs qui alimentaient les villae et pouvaient être utilisés pour faire tourner des moulins.

$\mathrm{Au}$ total, les vestiges de moulins hydrauliques connus en Italie sont au nombre de six (Janicule et Thermes de Caracalla à Rome, Vénafre, Saepinum, Bénévent et San Giovanni di Ruoti) et en Gaule de douze (Lösnich, La Massc, Lcs Martres-de-Veyre, Saint-Doulchard, Gannes à Beaulieu, Vaise à Lyon, Lattes, Ceyras, La Bourse (?) à Marseille, Barbegal à Fontvieille, La Crau et Les Arcs). On peut ainsi compléter la carte de répartition des moulins hydrauliques en Méditerranée (fig. 35) ${ }^{41}$.

\section{L'ITALIE}

Les moulins du Janicule à Rome, entrevus par Lanciani, ont été partiellement fouillés en 1990 et 1991 par M. Bell (1992 et 1994). Construits au III ${ }^{e}$ s. et abandonnés avant la fin du $\mathrm{IV}^{\mathrm{e}} \mathrm{s}$., ils comprenaient au moins cinq unités de mouture dont les roues à aubes étaient implantées sur des dérivations de l'aqueduc de Trajan. Des moulins du même type ont été décelés en d'autres points de la colline du Janicule.

Un moulin hydraulique installé dans les sous-sols des thermes de Caracalla a été découvert en 1912 et étudié en

41. Il est évident que cette carte n'a d'autre ambition que de localiser les sites mentionnés dans le texte et qu'elle ne saurait refléter d'autre réalité que l'intensité des prospections archéologiques et de nos dépouillements bibliographiques.

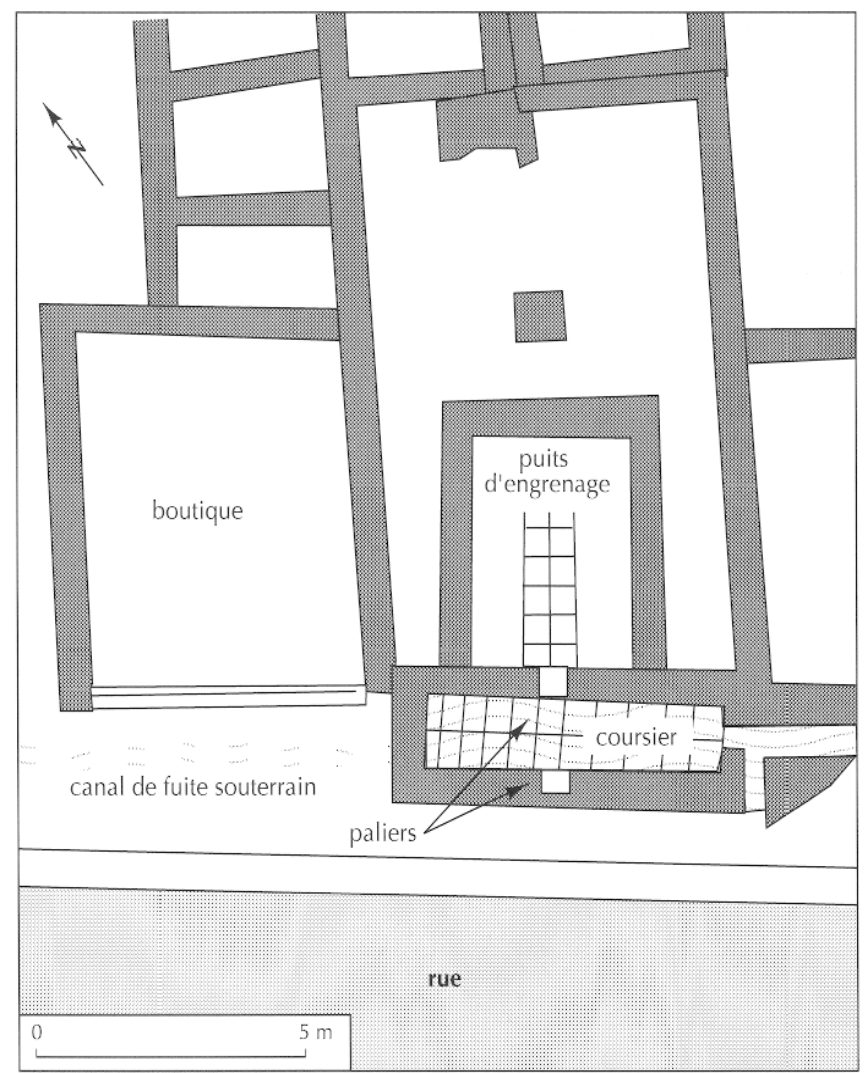

Fig. 36 - Moulin de Saepinum : plan (J.-P. Brun d'après Cianfarani, 1958).

détail par Th. Schiøler et Ö. Wikander en 1980 (Schiøler, Wikander, 1984). Construit en même temps que les thermes dans la période 212-235, il aurait fonctionné non sans vicissitudes (incendie, transformations) jusqu'en 537 après J.-C. L'emplacement des poutres, les paliers des roues et les traces de frottement sont conservés et permettent de reconstituer le fonctionnement du moulin qui comprenait deux roues verticales d'un diamètre moyen de $2 \mathrm{~m}$ alimentées par le dessus. Les rouets avaient un diamètre de l'ordre de $0,95 \mathrm{~m}$ pour une lanterne de $0,30 \mathrm{~m}$.

À Vénafre, en 1908, au lieu-dit Pozzili, des travaux agricoles ont attaqué un banc de tuf qui a livré deux meules mesurant $0,80 \mathrm{~m}$ de diamètre et $0,25 \mathrm{~m}$ d'épaisseur, ainsi que l'empreinte d'une roue à aubes en bois (Jacono, 1938). La roue, d'un diamètre de $1,85 \mathrm{~m}$ et d'une largeur de $0,29 \mathrm{~m}$, comportait 18 aubes fixées sur un axe d'un diamètre de $0,18 \mathrm{~m}$. D'après les calculs effectués par Luigi Jacono, cette roue pouvait avoir tourné à 46 tours/mn et donc avoir transmis une vitesse de rota- 


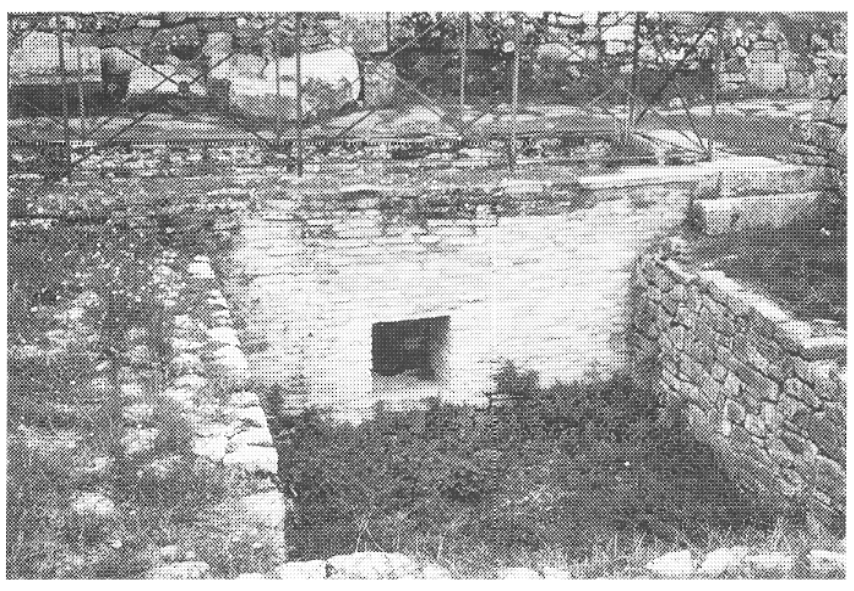

1

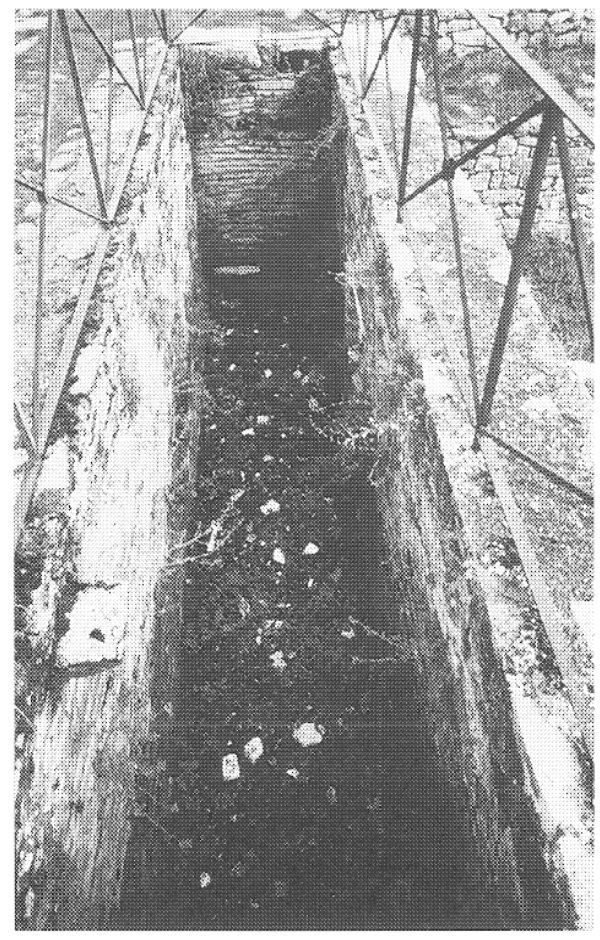

3

tion importante aux meules grâce au système d'engrenage. Étant donné les circonstances de découverte, le moulin n'est pas précisément daté.

À Saepinum, dans le Samnium, un bel exemple de moulin hydraulique a été dégagé le long du decumanus maximus, à proximité du forum dans un quartier de boutiques et d'ateliers d'artisans (fig. 36 et $37, n^{\circ} 1$ ). La publication, ancienne et très incomplète, n'a pas reçu toute l'atten-

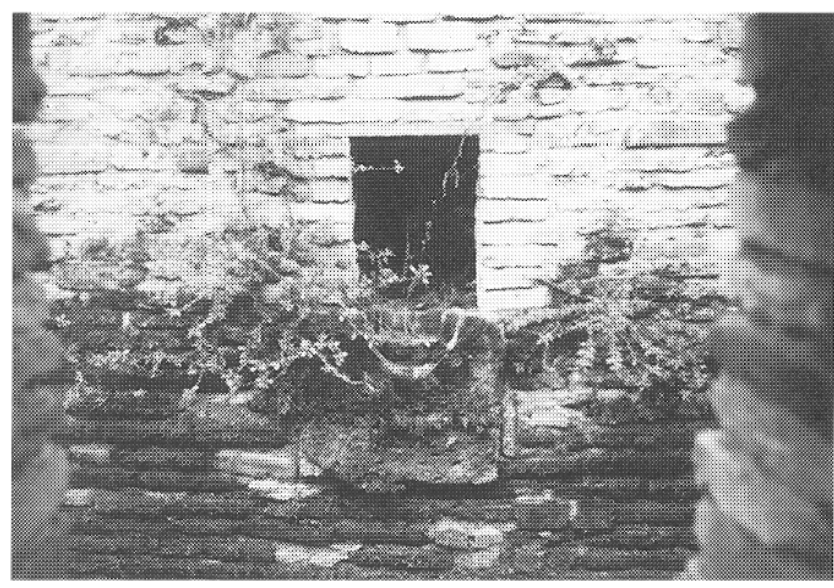

2

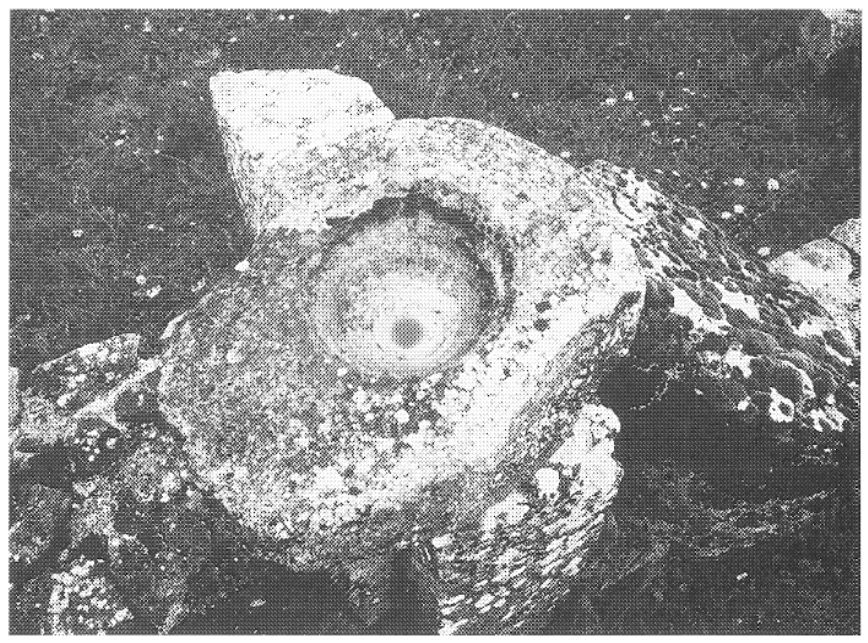

4

Fig. 37 - Moulin de Saepinum :

1, vue générale, au premier plan

le puits d'engrenage ;

2, le palier de l'axe de la roue;

3, le coursier ;

4, crapaudine du " gros fer»?(J.-P. Brun).

tion que la découverte méritait (Cianfarani, 1958, p. 45); c'est pourquoi nous publions ici quelques observations ${ }^{42}$. Le moulin est situé immédiatement à l'est d'une maison à atrium comportant deux boutiques en façade ; aucune donnée chronologique n'est fournie mais rien ne

42. Les vestiges ont été revus par J.-P. Brun en septembre 1996. 
s'oppose à une datation au cours du Haut-Empire. La meunerie comporte une pièce principale de $9,50 \mathrm{~m}$ par 6,20 m à laquelle est accolée un coursier creusé dans le trottoir de la rue (fig. $37, \mathrm{n}^{\circ} 3$ ). Le coursier, dallé en tuiles et bâti en briques originellement recouvertes d'un enduit de mortier de tuileau, mesure 5,50 m de longueur et $1,20 \mathrm{~m}$ de largeur. Il était alimenté par un canal aujourd'hui invisible, commandé par une martellière qui permettait d'envoyer l'eau dans un canal de dérivation se jetant dans les égouts. La hauteur de ce canal paraît indiquer que la roue était alimentée « à l'épaule », c'est-àdire à mi-hauteur. La bouche du canal de fuite est bien visible dans l'angle ouest du coursier : l'eau devait s'écouler par un canal souterrain vers le collecteur principal de la rue. Le palier sud est formé d'un bloc de calcaire portant les traces d'usure dues au frottement de l'axe de la roue (fig. $37, \mathrm{n}^{\circ} 2$ ). Le mur opposé est percé d'une fenêtre de $0,50 \mathrm{~m}$ de côté permettant le passage de l'arbre horizontal de la roue. Le puits d'engrenage mesure environ $4 \mathrm{~m} \times 3 \mathrm{~m}$, pour une profondeur conservée de l'ordre de $1,50 \mathrm{~m}$ (fig. $37, \mathrm{n}^{\circ} 1$ ). Aucun aménagement interne ne subsiste, sauf un dallage axial de tuiles. Les dimensions du puits sont anormalement élevées par rapport aux autres cas connus : faut-il imaginer que la roue entraînait deux couples de meules en parallèle par l'intermédiaire d'un rouet à deux couronnes d'aluchons ? Un bloc de calcaire déposé sur le mur du fond de l'atelier pourrait avoir servi de crapaudine pour un axe vertical du moulin ; il mesure $0,54 \mathrm{~m}$ de diamètre pour une hauteur de $0,25 \mathrm{~m}$ et comporte une cupule centrale de $22 \mathrm{~cm}$ de diamètre pour $13 \mathrm{~cm}$ de profondeur (fig. 37 , $\left.n^{\circ} 4\right)$. Le diamètre de la crapaudine implique que le " gros fer » ne portait pas directement sur la pierre, mais qu'il était fiché dans un axe de bois dont l'extrémité taillée en pointe et frettée tournait dans la crapaudine.

Il faut signaler qu'entre ces deux villes de Venafrum et de Saepinum, distantes de $70 \mathrm{~km}$ environ, la Table de Peutinger mentionne une étape dénommée Ad Rotas. Ce lieu, à proximité de Monteroduni, sur le fleuve Volturne, a dû être appelé ainsi à cause de la présence de moulins qui utilisaient probablement l'eau du fleuve.

À une quarantaine de kilomètres au sud de Saepinum, près de Bénévent, le Calore, affluent du Volturne, entraînait également des moulins hydrauliques. Au lieu-dit Ponte Rotto (commune d'Apice), sous l'une des arches du pont de la via Traiana, au niveau de la mutatio ad Calorem, un moulin hydraulique fut construit vers l'époque d'Hadrien (Johannowsky, 1994, p. 161-162 et fig. 1). Ses dispositions sont mal connues car il n'est pas fouillé ; on distingue une chambre de pression rectangulaire ouvrant à l'aval par trois coursiers où devaient tourner des roues à aubes verticales

À San Giovanni di Ruoti, les fouilles ont mis au jour un moulin hydraulique datable du premier état de la villa (début du $\mathrm{I}^{\mathrm{er}} \mathrm{s}$. de notre ère). Le coursier mesurait 0,30 m de largeur et un des paliers supportant l'axe de la roue était en place. Un fragment de meule d'un diamètre de 1,50 m a été également découvert (Small, Buck, 1994, p. 47-49).

\section{La GaUle}

Les moulins hydrauliques sont attestés dans les Trois Gaules et en Narbonnaise. L'exemple le plus nordique, en Gallia Belgica, est celui de Lösnich, une villa viticole située sur un affluent de la Moselle qui compte les vestiges de deux moulins implantés au flanc d'une colline au fil d'un torrent. Les aménagements, creusés dans une falaise d'ardoise, montrent des biefs et les ancrages de deux roues verticales dont une de grand diamètre (supérieur à $5 \mathrm{~m}$ ) appartenant à un premier moulin. Plus bas, un second moulin aurait également été doté de deux ensembles de roues et d'engrenages (une première de $5 \mathrm{~m}$ de diamètre et une seconde de $3 \mathrm{~m}$ ). Une meule a été retrouvée : elle présente un diamètre relativement large, mais on ne connaît pas son profil. La datation de ces moulins reste imprécise, le mobilier trouvé à leurs abords couvre un arc chronologique allant du $\mathrm{I}^{\mathrm{er}} \mathrm{au}$ $\mathrm{V}^{\mathrm{e}} \mathrm{s}$. de notre ère, soit toute la période d'occupation de la villa, mais il paraît probable que les moulins ont été construits un certain temps après la villa elle-même (Neyses, 1983).

Dans la Gallia Lugdunensis, le plus ancien moulin hydraulique a été trouvé au Pré des Avrillages (SaintDoulchard, Cher). Une fouille d'urgence exécutée en 1988-1989 sur la déviation de Bourges a dégagé un ensemble de structures (pieux de bois, empierrement) accompagné d'objets en bois (douelles de seaux, pales de roue à aubes) et en céramique (Rialland, 1989 ; Champage, 1990 ; Champagne et al., 1997). Bien que les meules n'aient pas été retrouvées, la présence des pales de roue à aubes indique qu'il s'agit d'un moulin hydraulique. Son plan n'est pas clair, mais la forme des pales montre qu'il était construit à fil d'eau et que la roue était 
alimentée par le bas (Rialland, 1989, fig. 1) (fig. 38). Les analyses dendrochronologiques datent la construction du moulin de la première décennie de notre ère, une part des pieux provenant de troncs récupérés, abattus vers 60 avant J.C. Le mobilier céramique montre que le moulin a été utilisé seulement au cours de la première moitié du $\mathrm{I}^{\mathrm{cr}} \mathrm{s}$. de notre ère.

Dans le Puy-de-Dôme, le vicus de La Masse (Ambert) a fait l'objet de fouilles qui, à la fin des années 1980, ont mis au jour des ateliers de métallurgistes et un réseau de canaux interprétés comme des biefs de moulins hydrauliques (Gagnaire et al., 1992). Dans la première moitié du $\mathrm{I}^{\mathrm{er}} \mathrm{s}$. de notre ère, un bief profond de $1,50 \mathrm{~m}$ et long de $57 \mathrm{~m}$ longeant la Dore, aboutissait à un bâtiment qui pourrait être un moulin. Le bief a été comblé dans le courant du $\mathrm{II}^{\mathrm{e}} \mathrm{s}$. de notre ère et remplacé par un autre, parallèle et consolidé avec des planches. Toutefois, le bâtiment de la meunerie supposée n'ayant pas encore été fouillé, on ne peut être assuré de l'interprétation.

Aux Martres-de-Veyre (Puy-de-Dôme), les fouilles d'A.-M. Romeuf ont mis au jour deux moulins hydrauliques. Un premier, daté du I ${ }^{\mathrm{er}}$ s. de notre ère, comprend une amenée d'eau débouchant sur un coursier au fond incurvé où devait tourner une roue à aubes (Poursat, 1983, p. 425-426; Provost, MennessicrJouannet, 1994, p. 175-176, fig. 79). Sur le côté une excavation quadrangulaire serait le logement du puits d'engrenage (fig. 39c). Cette installation fut détruite au II's. pour installer des fours de potiers. Le second moulin, mieux conservé, est daté du II $^{\mathrm{e}} \mathrm{s}$. (Romeuf, 1978 ; Poursat, 1981, p. 454-455) (fig. 39d). Il comportait un bief creusé dans la marne et une chute de $1,20 \mathrm{~m}$ environ, ce qui suppose une alimentation "à l'épaule ». Le coursier, large de $1,10 \mathrm{~m}$ (avec la banquette de circulation) et long de $2,50 \mathrm{~m}$, présentait un fond incurvé. La roue, assemblée avec des clous, devait avoir une largeur inférieure à $0,70 \mathrm{~m}$ et un diamètre de l'ordre de $1,80 \mathrm{~m}$; du côté sud, son moyeu reposait sur un palier taillé dans un bloc d'arkose. Le puits d'engrenage mesurait 1,80 m x 1,60 m. Onze meules en lave ont été découvertes : 6 metae perforées et 5 catilli dont les diamètres varient de 0,48 à $0,92 \mathrm{~m}$. Immédiatement au sud du moulin, se trouvait un hangar au sol bétonné comportant un bassin muni d'une évacuation. Il s'agirait d'un bassin de lavage du grain et d'une aire de séchage. Ce moulin a probablement été détruit par un incendie vers la fin du $\mathrm{II}^{\mathrm{e}}$ s. ou au $\mathrm{III}^{\mathrm{e}} \mathrm{s}$.
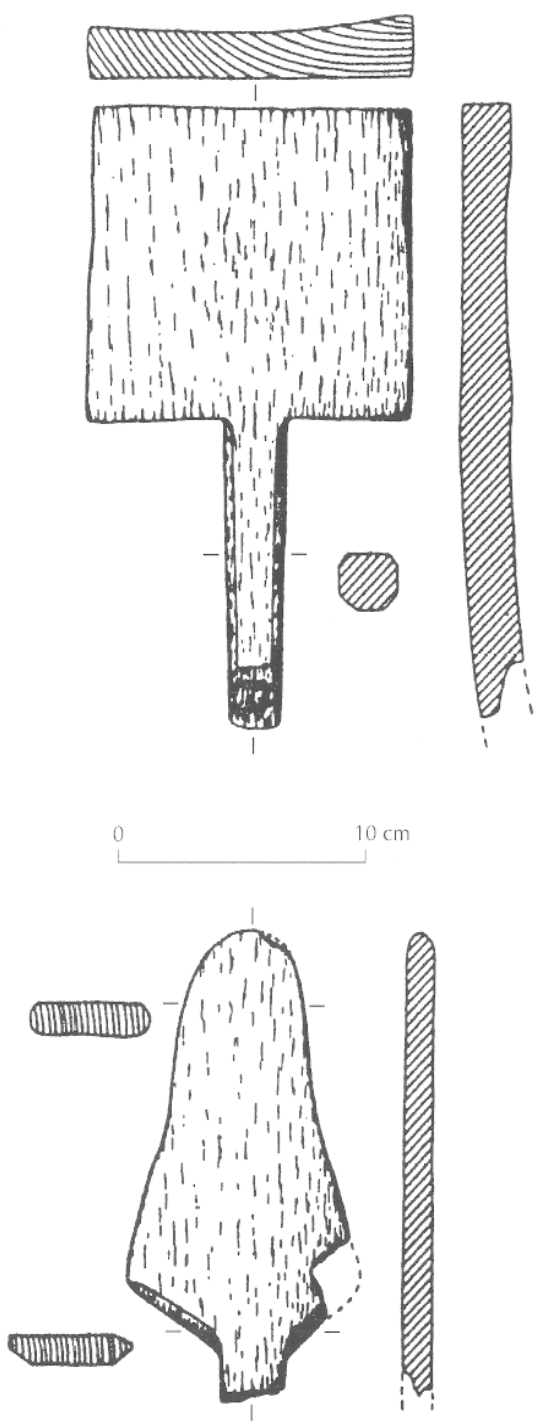

Fig. 38 - Moulin de Saint-Doulchard : pales de la roue à aubes (d'après Rialland, 1989, fig. 1).

À Gannes (commune de Beaulieu, Loiret), des fouilles du début du XIX ${ }^{\mathrm{c}} \mathrm{s}$., conduites à l'occasion du creusement du canal latéral de la Loire, ont découvert les vestiges d'une grande villa alimentée par un aqueduc dont une dérivation aboutissait à un "puisard " dans lequel on a trouvé « une large incrustation calcaire qui est venue se mouler sur la forme et se substituer à la place d'une portion de roue hydraulique [...]. La face supérieure de la pierre porte l'empreinte saillante et très apparente de petit rayons droits s'attachant au centre de l'arbre [...] de manière à présenter la trace pétrifiée d'une roue horizontale de $2,34 \mathrm{~m}$ de diamètre, de $0,56 \mathrm{~m}$ 

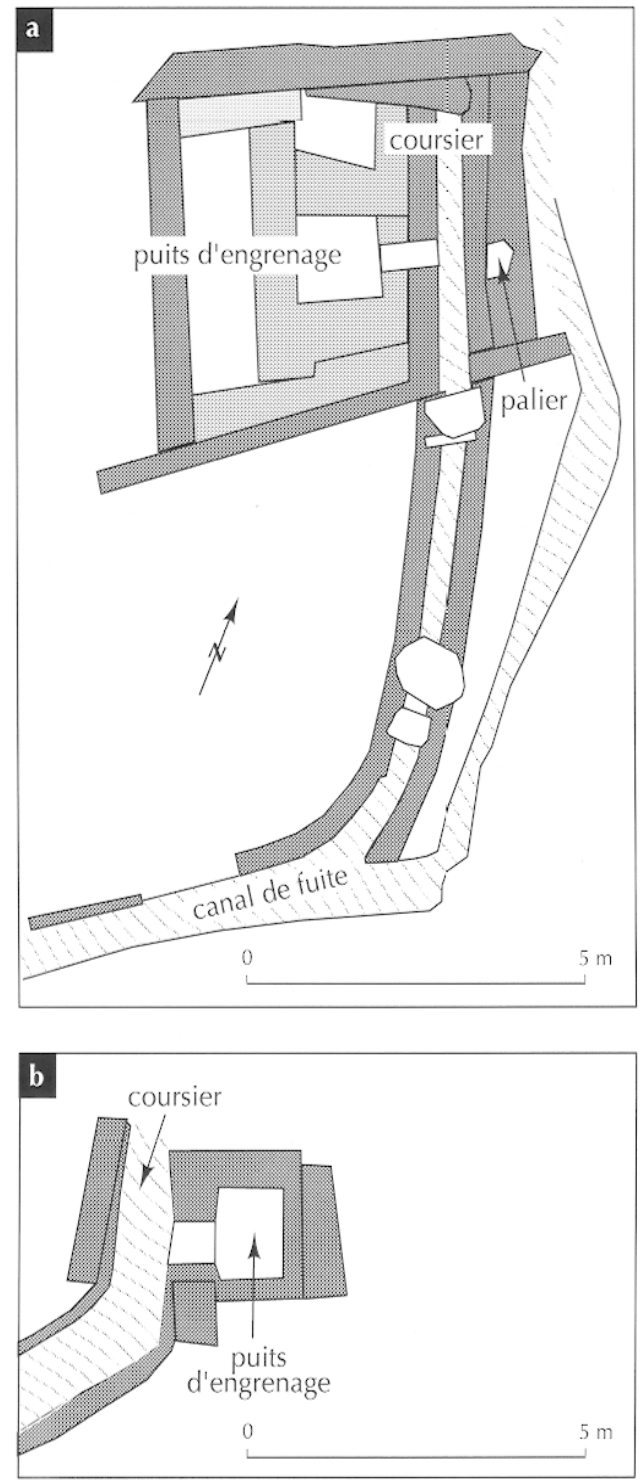

Fig. 39 - Plans comparés des moulins des Mesclans (a), des Laurons (b) et des Martres-deVeyre (c : Yrr s. ; $d: I T$ s. ; d'après Romeuf, 1978).
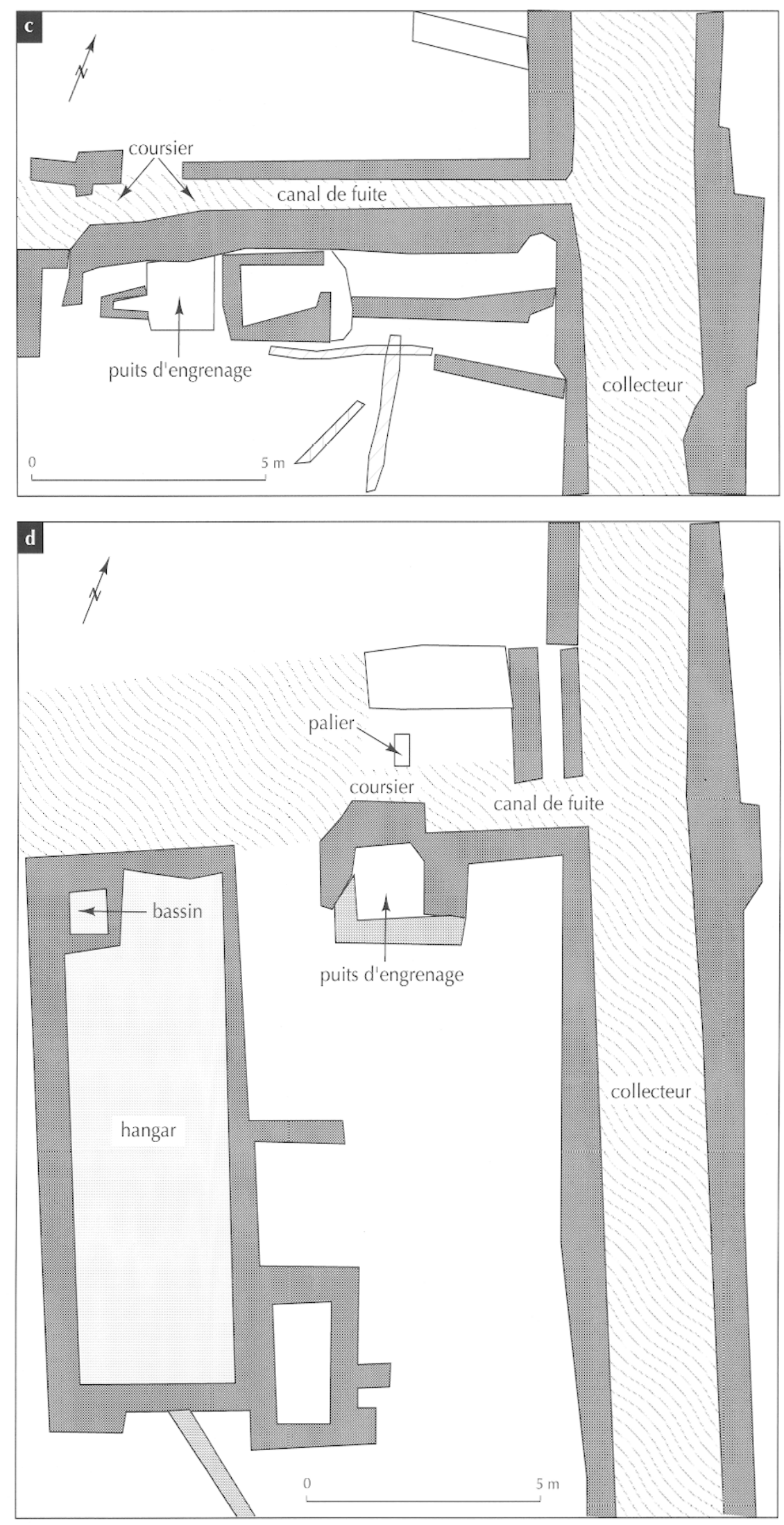


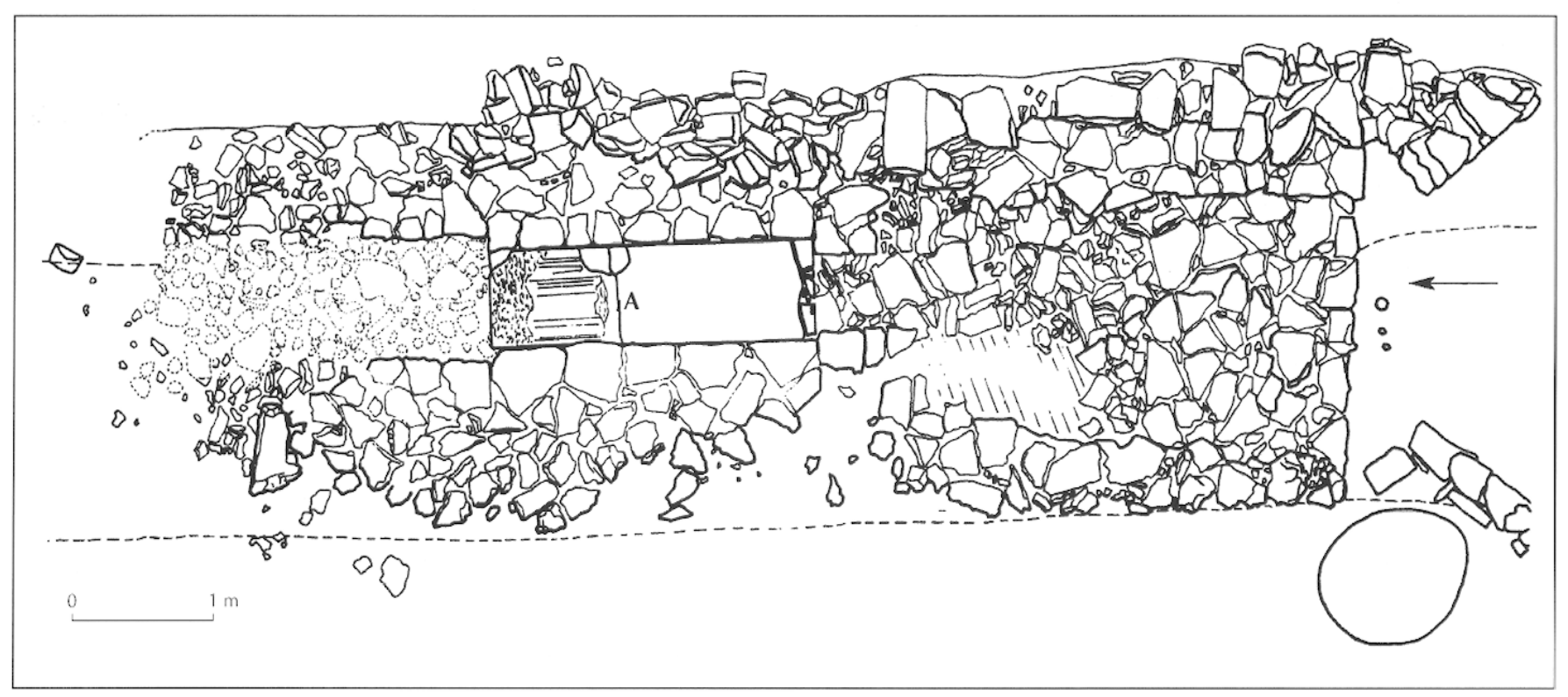

Fig. 40 - Coursier du moulin de Cougourlude à Lattes (d'après Amouric et al., 1989, fig. 1).

d'épaisseur, portant 26 rayons » (Boisvillette, 1840, p. 215-217) ${ }^{43}$. L'exemple presque identique de Vénafre en Italie incite à interpréter ces vestiges non comme ceux d'une roue horizontale mais d'une roue verticale qui serait tombée au fond d'un bief (Jacono, 1938).

À Lyon-Vaise, une fouille d'urgence conduite par Catherine Bellon en 1992, au 9, rue du $D^{r}$-Horand, a dégagé une partie de villa et, à proximité immédiate, les vestiges d'un moulin hydraulique qui semblait lui appartenir. Le moulin n'a été entrevu que dans des sondages en limite de la fouille : un sol en planches maintenues par des pieux était associé à plusieurs meules en basalte dont une meta percée de part en part et un catillus dont le diamètre s'élève à $0,84 \mathrm{~m}$. Le bief n'a pas été repéré, ni la roue à aubes, mais l'emplacement, dans un thalweg dont les eaux étaient canalisées par des canaux, et le type des meules ne laissent pas de doute sur la nature des vestiges. La construction du moulin n'est pas précisément datée mais son abandon intervient vers la fin $\mathrm{du} \mathrm{I}^{\mathrm{er}} \mathrm{s}$. après J.-C. (renseignements aimablement communiqués par C. Bellon).

43. Cette découverte a fait l'objet d'une autre mention dans Chaudru de Raynal, 1845-1847, p. 110 qui la situe sur la commune de Bellevillesur-Loire dans le Cher. Cette erreur de localisation s'est perpétuée dans la Carte Archéologique de la Gaule, 18, n¹29, p. 235.
En Gallia Narbonensis, on compte désormais au moins quatre et peut-être cinq moulins hydrauliques ${ }^{44}$. La meunerie « industrielle » de Barbegal (Fontvieille, Bouchesdu-Rhône) a fait l'objet d'études et de publications récentes (Amouretti, 1992 ; Leveau, 1995). Nous n'y revenons pas sinon pour souligner la datation haute qui est désormais proposée : construction sous les Antonins, peut-être sous Trajan ou Hadrien, cessation de l'activité de meunerie dans la seconde moitié du III ${ }^{e}$ s., abandon final au IVes.

À Lattes, des fouilles d'urgence, menées en 1987 par Henri Prades, ont mis au jour des vestiges de thermes et d'un coursier attribuables à une villa romaine établie en bordure d'une dérivation du Lez. Le coursier long de 2,32 m est aménagé dans un fossé régularisé par des empierrements latéraux restreignant le passage à $0,70 \mathrm{~m}$ (fig. 40). Au fond du coursier, une dalle de marbre porte des rainures provoquées par le frottement d'une roue dont le diamètre est estimé à $1,50 \mathrm{~m}$. Les structures bâties

44. Dans les fouilles du port romain de Toulon (Besagne-Dustasta), une meta en rhyolite (diamètre : $0,62 \mathrm{~m}$; épaisseur : $0,17 \mathrm{~m}$ ) présentant un trou cylindrique central (diamètre : $0,12 \mathrm{~m}$ ) a été trouvée à proximité d'un four de boulanger daté du $\operatorname{III}^{e} s$. de notre ère. Il pourrait s'agir d'une meule actionnée par l'eau (des installations hydrauliques peu claires ont été découvertes à proximité immédiate). 
montrent qu'il s'agit d'une roue alimentée par le bas, au fil de l'eau, ce qui explique sa largeur relativement importante. Cette roue pouvait éventuellement servir à l'irrigation mais il paraît plus probable qu'il s'agit des restes d'un moulin. La découverte ancienne d'une meule à proximité pourrait confirmer cette interprétation. La datation reste incertaine; le mobilier, rare, comprend des tessons d'amphores de Bétique et une monnaie de Maxence (Amouric et al., 1989).

Dans le Lodèvois à La Mouline, commune de Ceyras (Hérault), une fouille partielle des années $1960 \mathrm{a}$ mis au jour un coursier et des meules datés du Haut-Empire dont l'association fait penser à la présence d'un moulin hydraulique (à paraître dans la Carte archéologique de la Gaule, 34/1).

Le cas des fouilles de La Bourse à Marseille est plus complexe. Dans le secteur situé à l'est de la corne du port, un grand bassin en opus quadratum fut construit au début du II ${ }^{\mathrm{e}} \mathrm{s}$. après J.-C. Il devait servir de réservoir d'eau équipé semble-t-il dès le début d'une roue élévatrice de $3 \mathrm{~m}$ de diamètre dont il reste une mortaise de fixation dans le mur ouest. Au III ${ }^{e}$ s. (?), la première roue fut remplacée par une nouvelle dont le diamètre atteignait $4 \mathrm{~m}$. Plus tard, alors que le bassin était déjà en grande partie comblé par des alluvions, une troisième roue fut installée dans un coursier creusé perpendiculairement à l'axe des précédentes entre deux murets faits de blocs de remploi. Une portion notable de cette roue a été mise au jour : elle mesurait $3 \mathrm{~m}$ de diamètre et $0,2 \mathrm{~m}$ de largeur (fig. 41). Elle était accompagnée d'une gouttière incurvée en bois servant à canaliser l'eau. Les traces d'une quatrième roue ont été mises au jour à proximité immédiate. Le comblement total du bassin semble être intervenu vers les III -IV $^{\mathrm{e}}$ s. et, par la suite, un ruisseau traversait son emplacement pour se jeter dans le port. Vers le $V^{e}$ s., une chute fut aménagée et un coursier bâti en tegulae. Ces dernières portaient des traces de frottement circulaire qui permettent d'estimer le diamètre de la roue à 1,80 m. Les fouilleurs mettent en relation cet aménagement et la découverte connexe de scories de fer : ils imaginent que la roue motrice actionnait un soufflet de forge (Guéry, Hallier, 1987). La documentation publiée jusqu'ici n'est pas assez détaillée pour vérifier toutes ces hypothèses. Les deux premières roues sont visiblement liées à l'utilisation du bassin d'eau douce et leur emploi comme roues élévatrices paraît le plus probable. La troisième roue, en revanche, fonctionnait dans le bas-

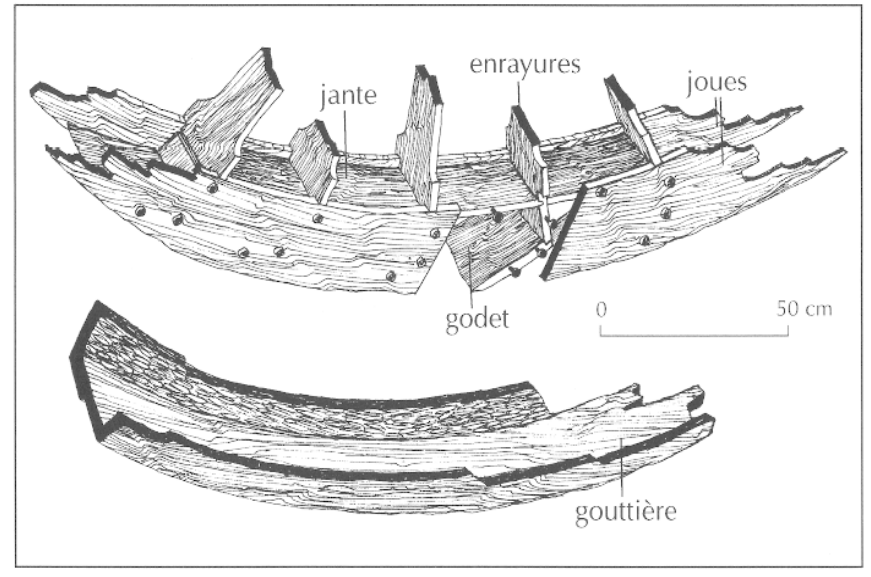

Fig. 41 - Roue à augets trouvée lors des fouilles de La Bourse à Marseille (d'après Euzennat, Salviat, 1968, p. 40).

sin en grande partie comblé et on peut se demander quelle était sa fonction exacte. Quant à la quatrième, il s'agit certainement d'une roue motrice verticale alimentée à l'épaule. Il est théoriquement possible qu'il s'agisse d'un appareil lié à une forge (soufflet, martinet?) puisque la transformation du mouvement circulaire en mouvement alternatif était connue au moins depuis le $\mathrm{IV}^{\mathrm{e}} \mathrm{s}{ }^{45}$, mais l'hypothèse la plus simple reste celle d'un moulin à farine. Toutefois les plans et les photos publiés ne permettent pas de savoir s'il y avait un puits d'engrenage accolé au coursier.

Ces exemples ne sont sûrement pas isolés et les recherches à venir permettront d'en découvrir d'autres. On est d'ores et déjà frappé par la diversité des contextes : la force hydraulique est utilisée aussi bien dans de grandes meuneries dépendant de cités à Barbegal et à Rome, dans des moulins artisanaux dans les villes de Saepinum et peut-être de Marseille, ainsi que dans les vici de Masse et des Martres-de-Veyre, que pour des moulins appartenant à de grands propriétaires à Gannes, aux Laurons, aux Mesclans, à Lösnich, à

45. I.e texte de La Moselle d'Ausone (v. 361-364) évoque les moulins à grain et les scies actionnés par la force hydraulique : "[..] nobilibus Celbis celelratus piscibus, ille praecipiti torquens cerealisa saxa rotatu stridentesque trahens per levia marmora serras audit perpetuos ripa ex utraque tumultus ". Selon Wikander (1981, p. 98-99), Grégoire de Nysse (In Ecclesiasten, 1II, 656A Migne, en 370-390) ferait également allusion à des scies hydrauliques pour le marbre, mais on n'a aucun texte qui évoque l'application de la force hydraulique au travail du fer avant le XII' $\mathrm{s}$. (si l'on excepte le texte douteux de la vita Sancti Romani cité par Wilson, 1995 , notc 17). 
Avenches et peut-être à Vénafre et à Lattes. On comprend bien quelle était la destination des meuneries dans les agglomérations : produire de grandes quantités de farines panifiables pour fournir les boulangeries. Mais dans les villae, la question se pose dans d'autres termes. Sauf dans le cas de Lösnich, la modestie des installations plaide pour une destination domestique : le moulin produisait de la farine pour l'alimentation du propriétaire et de sa familia. Il économisait ainsi de la main-d'œuvre que l'on pouvait employer ailleurs. Mais, pour cet usage seulement, la construction de tels moulins, même modestes, pouvait-elle se justifier? Ne doit-on pas imaginer qu'audelà des besoins domestiques, un moulin comme celui des Mesclans travaillait aussi pour des domaines voisins, pour des dépendants, voire pour des boulangers d'une agglomération proche - on pense à Olbia par exemple, distante d'une douzaine de kilomètres ${ }^{46}$ ?

La majorité des installations évoquées dans cet article sont datées du Haut-Empire : dès le $\mathrm{I}^{\text {er }} \mathrm{s}$. à SaintDoulchard, Vaise, Avenches, Les Martres-de-Veyre et La Masse; du II's. à Barbegal, Les Mesclans et probablement Les Laurons; de la fin du II s. à Ickham I, Hagendorn et Zugmantel ; du III ${ }^{\mathrm{e}} \mathrm{s}$. à Chesters Bridge, Nettleton, le Janicule, les Thermes de Caracalla, Lattes. Les cas plus tardifs sont encore rares : IVe s. pour Chemtou et Testour ; IV $\mathrm{IV}^{\mathrm{e}}$ s. pour Marseille et Césarée de Palestine ; $\mathrm{V}^{\mathrm{e}}-\mathrm{VI}^{\mathrm{e}} \mathrm{s}$. pour Athènes. Les deux exemples provençaux s'inscrivent dans le mouvement d'investissement agricole qui se manifeste en Narbonnaise à partir des Flaviens et durant la première moitié du II $^{c} \mathrm{~s}$. C'est l'époque où les exploitations agricoles, tant petites que grosses, s'équipent en pressoirs et cuves à huile et à vin dont la multiplication signifie certainement une extension des surfaces cultivées en oliviers et vignes, sans délaisser bien sûr les céréales. On croit déceler que ces domaines sont exploités en faire-valoir direct, probablement dans certains cas par l'intermédiaire d'un régisseur. Les résidences campagnardes sont souvent luxueuses, dotées de colonnades, de thermes, de bassins d'agrément et le propriétaire peut prendre plaisir à y séjourner. Quoi de plus normal dans ces conditions que l'on ait cherché à économiser la main-d'œuvre servile par l'emploi d'ap-

46. Aucune boulangerie n'a été formellement identifiée à Olbia, mais le "bassin monolithe ", trouvé par J. Coupry aux abords de la porte, doit être interprété comme la cuve d'un pétrin mécanique analogue à ceux des boulangeries de Pompéi. pareils performants : pressoirs à câbles, puis à vis, et moulins hydrauliques. Loin du « blocage des techniques», on assisterait donc à la diffusion et à la banalisation de techniques économisant la force de travail, y compris dans les domaines ruraux. Ces techniques ne se perdirent pas au Bas-Empire ni au cours de l'Antiquité tardive, époques où les vestiges archéologiques sont encore rares ${ }^{47}$ : les polyptiques carolingiens montrent que les domaines ecclésiastiques et très probablement laiques en étaient largement équipés (par exemple 84 moulins pour le domaine de l'abbaye de Saint-Germain-des-Prés vers 820). Certains de ces moulins avaient été construits par les moines, mais une proportion non négligeable d'entre eux avait été donnée aux abbayes au cours du siècle et donc remontait au VIII' s., voire plus haut (Champion, 1996, p. 54-55). On doit donc estimer que ce type d'équipement était largement diffusé dans les campagnes dès le Haut-Empire et que, selon les époques, la nature de nos sources privilégie tantôt les vestiges archéologiques tantôt les sources écrites, les unes comme les autres ne donnant qu'une image très atténuée de l'ampleur du phénomène.

\section{UNE MUTATION AGRICOLE DANS LA SECONDE MOITIÉ DU III ${ }^{e}$ S. : LA FIN DU FAIRE-VALOIR DIRECT ?}

Dans un article récent, nous avons fait le point sur la chronologie des villae provençales et sur la " crise du III ${ }^{e}$ siècle " (Brun, Congès, 1996). Il convient d'en reprendre partiellement les conclusions à la lumière de ces nouvelles recherches sur la villa des Mesclans et les moulins hydrauliques ruraux. En Provence, on décèle une vague d'abandon de petites et moyennes fermes vers la fin du II ${ }^{\mathrm{c}} \mathrm{s}$. et dans la première moitié du IIII ${ }^{\mathrm{e}} \mathrm{s}$. Les grandes villae toutefois ne semblent pas connaître de difficultés : les huileries du Candéou à Peymeinade et de Saint-Michel à La Garde, de La Pousaraque à Gignac, de Costebelle à Hyères, les chais à vin des Toulons à Rians, de Pardigon 2 et de la Rue du Port à Cavalaire-sur-Mer, des Mesclans à La Crau, de Notre-Dame d'Avinionet à Mandelieu-la-Napoule continuent de fonctionner jusque

47. Il faut toutefois signaler la découverte d'un moulin mérovingien à Paartal, Dasing, RFA (Czysz, 1994) et de deux moulins carolingiens à Audun-le-Tiche, Moselle (Rohmer, 1996) et à Belle-Église, Oise (Lorquet, 1994). 
dans la seconde moitié du III'e s., époque où l'on assiste à une mutation marquée par l'abandon des installations de production, mais non des bâtiments résidentiels. À SaintMichel, les anciennes cuves à huile sont transformées en dépotoirs et un cuveau de petites dimensions est construit : il doit servir alors à une production d'huile très réduite, peut-être seulement pour la consommation domaniale (Brun et al., 1989). Au Candéou, les huileries cessent de fonctionner au milieu du III ${ }^{\mathrm{e}} \mathrm{s}$. et le site luimême est abandonné une génération plus tard, dans le dernier quart du siècle (Vindry, 1981). Pour le vin, l'exemple des Toulons est frappant : vers la fin du siècle, le chai à vin est à l'abandon et une partie est transformée en pièces d'habitation (Brun, Congès, 1994). Dans la villa de la Rue du Port à Cavalaire, le chai est détruit à la même époque ou au début du IV ${ }^{\mathrm{e}} \mathrm{s}$. : les dolia sont arasés ou récupérés et un niveau d'habitation d'époque constantinienne les recouvrent (Brun, Oberti, 1993). À NotreDame d'Avinionet, l'entrepôt à dolia est détruit et recouvert par un lieu de culte à la même époque (Fixot, 1990).

Aux Mesclans, c'est tout à la fois la production du vin et de l'huile et l'utilisation du moulin hydraulique qui cessent. Aux Laurons, le moulin hydraulique est abandonné mais l'huilerie semble avoir fonctionné jusqu'au début du IVes.

Toutefois, plusieurs villae continuent de produire de l'huile jusqu'au IV' s. (Costebelle à Hyères, Saint-Martin à Taradeau, et au $\mathrm{V}^{\mathrm{c}} \mathrm{s}$. dans les cas de La Pousaraque à Gignac et de Saint-Pierre à Eyguières, $c f$. Pelletier, Poguet, 1993 et 1995). Pour le vin en revanche, nous n'avons aucune attestation de grande production datable de cette époque en Provence. Il est vrai que cette période correspond probablement à la généralisation de l'emploi des foudres et tonneaux, voire des pressoirs à vis en bois dans les installations viticoles, ce qui peut fausser notre appréciation. L'impression demeure malgré tout d'une quasi-disparition de la viticulture commerciale en Provence après la seconde moitié du III' $s$. On ne possède aujourd'hui aucun exemple de construction de pressoir et de chai au cours du IVe s. comme on en connaît désormais un grand nombre dans la vallée de la Moselle par exemple (Gilles, 1987, 1990 et 1994).

Un autre indice de diminution de la production de vin est donné par la progressive disparition des ateliers de potiers d'amphores vinaires. Peu ont été fouillés, notamment en Provence, mais les prospections de surface montrent qu'ils sont rares au III' $s$. et inexistants au
IV s. Celui du Collet-Long à La Crau ne livre que du matériel céramique datable du Haut-Empire. L'atelier de Portissol à Sanary-sur-Mer (Var) produit encore des amphores G4 à fond étroit dans la seconde moitié du III $^{c} s$., mais ne fonctionne plus après les premières décennies du IV ${ }^{\mathrm{c}} \mathrm{s}$. De même à Sallèles-d'Aude, la production d'amphores diminue au $\mathrm{III}^{\mathrm{e}} \mathrm{s}$. et cesse avant le $\mathrm{IV}^{\mathrm{e}} \mathrm{s}$. (Laubenheimer, 1989). Certes, là aussi, la cessation des activités potières est peut-être due au remplacement généralisé de l'amphore par le tonneau de transport, mais il n'en reste pas moins que bien des abandons de villae sont en partie liés à des désordres militaires et à un reflux démographique indéniables. La répression des Bagaudes par Maximien invite également à tenir compte du brigandage des paysans fuyant les dettes et l'impôt. Certes le phénomène n'était pas nouveau : on connaît en plusieurs endroits des praefecti ad latrocinium depuis le $\mathrm{I}^{\text {er }}$ s., mais il semble s'être considérablement accru à cette période ${ }^{48}$. Les désordres des temps, voire des épidémies, ont pu également aggraver une baisse démographique à long terme.

Mais cette explication globale rend-elle compte de la totalité du phénomène ? Bien des domaines petits et moyens ont été totalement abandonnés au III $^{e}$ s. et rachetés ou accaparés par les honestiores ${ }^{49}$. Mais de grandes villae qui comportaient de vastes chais, des huileries modèles et des moulins hydrauliques, ne l'ont pas été. Ce sont uniquement les moyens de production qui ont été délaissés. Il se pourrait que, étendant leurs possessions pour constituer de vastes biens-fonds, les grands propriétaires de la fin du $\mathrm{III}^{\mathrm{e}} \mathrm{s}$. aient abandonné le fairevaloir direct pour mettre en fermage leurs terres. Ils se déchargeaient ainsi des soucis de production et de commercialisation et n'avaient plus besoin d'investir dans du matériel agricole ou des innovations techniques ; les fermages perçus sur des propriétés de plus en plus vastes permettaient d'entretenir leur train de vie. Il suffisait de compenser la chute des rendements par l'extension progressive des biens accaparés et loués.

48. Des praefecti ad latrocinium sont connus à Nyon (Suisse), Eu (SeineMaritime) : en dernier lieu Mangard, 1982, p. 43.

49. Le phénomène est bien connu au niveau de l'Empire (Mazza, 1973, p. 157-216). Pour la Provence, nous pouvons citer au moins un cas archéologiquement attesté d'arrondissement de domaine au profit d'un grand propriétaire à Cavalaire-sur-Mer/La Croix-Valmer (Congès, Lecacheur, 1994). 


\section{ANNEXE}

\section{LES INCRUSTATIONS CALCAIRES DANS LES CANAUX}

\author{
Jean-Louis GUENDON ${ }^{50}$
}

\section{ÉCHANTILLONS ET MÉTHODES DE TRAVAII}

Dans la villa romaine des Mesclans, des concrétions calcaires sont visibles en trois points :

- sur les parois du canal de vidange du bassin 6 qui luimême ne comporte pas de dépôts,

- sur les parois d'un tronçon de l'aqueduc 7 situé à une vingtaine de mètres du bassin 6 , au même niveau altitudinal,

- en différents points des vestiges du moulin hydraulique, notamment dans le coursier.

Ces différents points sont isolés car des zones entières du site étaient détruites avant la fouille. Cependant on note entre l'aqueduc et le moulin une similitude de faciès des concrétions, une certaine proximité et un net dénivelé qui permettent de penser que l'aqueduc alimentait le moulin. De même, la relation entre l'aqueduc et le bassin est probable car ils sont situés au même niveau altitudinal, les dimensions de l'ouvrage concordent et les tronçons conservés sont alignés.

En revanche, certains éléments posent des problèmes : la quasi-absence de concrétions sur le tronçon d'aqueduc proche du bassin 6 et dans le bassin lui-même, la différence de faciès des concrétions au niveau de l'aqueduc et $d u$ bassin, enfin l'interprétation du sens d'écoulement des eaux étant donné l'absence de pente nette d'un point à l'autre.

L'analyse chimique des concrétions se heurte à plusieurs problèmes : contrairement aux sources captées pour l'aqueduc de Fréjus (Guendon et al., 1994), la différence de chimisme entre le Gapeau et le Réal-Martin, deux cours d'eau susceptibles d'avoir alimenté l'aqueduc, est sans doute trop peu significative pour servir de discriminant pour l'origine des eaux. Il faudrait de plus disposer d'analyses des concrétions formées dans ces

50. URA $903 \mathrm{du}$ CNRS, Centre aixois de géographie physique, Université de Provence, 19 avenue Robert-Schuman, F-13100 Aix-enProvence. deux rivières. Enfin, les échantillons pris dans l'aqueduc et dans le moulin, trop pollués par des argiles, donneraient des résultats difficiles à interpréter.

Les observations destinées à déterminer la direction du courant, par analyse des concrétions en lames minces, ne sont jamais aisées à interpréter ; elles sont rendues délicates ici par la structure grossière des incrustations.

Le comptage des lamines pour déterminer la durée de fonctionnement des installations, outre la difficulté pratique de la méthode (analyse par traitement d'images des lamines, trop fines et peu discernables pour être comptées à l'œil), se heurte ici à la faible lisibilité des échantillons prélevés dans l'aqueduc et le moulin. Quant à l'échantillon du bassin 6, pourtant le plus lisible, le risque est grand de rencontrer de nombreuses discontinuités car les concrétions provenant de fuites sont aléatoires, tardives et peu représentatives du fonctionnement originel et continu.

\section{L'ORIGINE DES EAUX}

Il est peu probable que l'alimentation en eau provienne de sources locales. D'une part, le massif environnant possède peu de sources (et aucune avec un débit suffisant); d'autre part, la nature schisteuse du substrat n'est pas apte à fournir des eaux suffisamment carbonatées pour donner des incrustations.

Les seules eaux proches, suffisamment abondantes et carbonatées, sont celles du Gapeau (issu de massifs calcaires et dans les gorges duquel existent de nombreux édifices en travertin prouvant sa capacité à donner des incrustations) et/ou du Réal-Martin (également issu de massifs calcaires et réputé avoir un pouvoir incrustant). Il faut noter qu'actuellement les deux rivières ne semblent pas montrer de traces de concrétionnement dans leur lit au niveau de la plaine de La Crau. Il est vrai que la saturation des eaux, et donc leur pouvoir incrustant, est renforcée par l'accélération de leur dégazage lors des écoulements turbulents, ce qui est rarement le cas en plaine. Par ailleurs, une certaine dilution des eaux carbonatées peut se produire à cet endroit par l'adjonction d'eaux issues des terrains cristallins traversés. Ces rivières présentent aussi une forte turbidité, ce qui ne favorise pas la conservation des éventuels dépôts carbonatés dans leur 
lit. Enfin, la pollution perturbant le processus de concrétionnement, il est probable que celui-ci soit réduit par rapport à des périodes anciennes.

Le site des Mesclans se trouvant entre ces deux rivières, sensiblement à égale distance des points permettant leur captage, il est difficile de déterminer laquelle des deux a été captée, même si le tronçon dégagé de l'aqueduc semble se diriger vers le Gapeau. L'état de destruction du site ne permet pas d'éliminer totalement l'hypothèse d'une amenée d'eau du RéalMartin aboutissant au bassin 6 et alimentant ensuite le moulin et d'autres installations situées à l'ouest.

\section{LFS CONCRÉTIONS : FACIÈS ET INTERPRÉTATION}

$\mathrm{Au}$ débouché du bassin 6 , les concrétions ne sont visibles que sur les parois du canal de vidange du bassin. Elles n'apparaissent qu'à une vingtaine de centimètres au-delà de la vanne et disparaissent rapidement vers l'aval après 1,50 m environ. Dans la partie où elles sont le plus épaisses, à leur point d'apparition, elles couvrent les parois sur 1 à $3 \mathrm{~cm}$ d'épaisseur et montrent nettement par leur structure et leur cassure en partie supérieure qu'elles remontaient plus haut. Ces dépôts ne proviendraient pas du point bas de vidangc, mais dc fuitcs, débordements, suintements issus de la partie supérieure du bassin aujourd'hui disparue. L'échantillon prélevé présente deux types de faciès.

- Un premier, au contact de la paroi, d'une épaisseur de 1 à $2 \mathrm{~cm}$, microfibreux, finement laminé, avec alternance irrégulière de couches blanches et rouille. Ce faciès ressemble à ceux que l'on observe classiquement sur les parois internes des aqueducs dans lesquels circulent des eaux claires et peu turbides.

- Un second, recouvrant le premier sur $1 \mathrm{~cm}$ environ, à structure feuilletée qui rappelle les dépôts de suintement visibles sous des arches ou des ponts et issus parfois simplement d'eaux de pluie percolant à travers la maçonnerie et lessivant les mortiers. Ce faciès pourrait donc correspondre à un dépôt postérieur au fonctionnement de l'ouvrage.

À hauteur du tronçon 7 de l'aqueduc, les concrétions épaisses de 2 à $3 \mathrm{~cm}$ recouvrent les parois internes de l'aqueduc. Les échantillons prélevés présentent un seul faciès, grossier, caverneux, au litage fruste. Des argiles brun-rouge encombrent la porosité. Ce faciès s'apparente à celui observé dans l'aqueduc de Nîmes, en fin de fonctionnement, et qui avait été interprété comme résultant de circulations d'eaux relativement turbides (Guendon, Vaudour, 1991 ; Blanc, 1991).

Dans le moulin hydraulique, les concrétions sont abondantes en divers points et présentent des intérêts divers. Celles qui recouvrent le coursier et le canal de fuite, abondantes ( 3 à $4 \mathrm{~cm}$ d'épaisseur au moins), sont évidemment liées au fort brassage des eaux par la roue à aubes. On note, comme au niveau du bassin 6 , une diminution rapide de l'épaisseur des dépôts en aval du coursier et leur quasi-disparition en quelques mètres. Un échantillon prélevé dans le canal de fuite présente un faciès comparable à celui du bassin 6 . Un second prélèvement vers le haut du coursier, à structure grossière, renferme moins d'argile dans ses pores. D'autres parois du moulin présentent des concrétions. Bien que moins épaisses, leur intérêt réside dans le fait qu'elles scellent des parois et aident à décrypter les phases de construction et de fonctionnement.

\section{COMPARAISON DES TROIS AFFLLUREMENTS : INTERPRÉTATIONS ET HYPOTHÈSES}

On constate une nette différence entre les concrétions au débouché du bassin 6 et les autres. En premier lieu, les concrétions sont claires, peu argileuses, fines, bien laminées. Les eaux devaient être claires, ce qui est logique pour des eaux s'écoulant de la partie supérieure d'un bassin de décantation. Ailleurs, en revanche, les dépôts grossiers et poreux traduiraient un écoulement plus turbulent et surtout par des eaux plus turbides. Cette observation est cohérente avec l'hypothèse d'une prise d'eau dans le Gapeau ou le Réal-Martin. La turbidité des eaux rendait nécessaire l'édification d'un bassin de décantation avant la distribution des eaux ménagères, mais après utilisation des eaux industrielles. Cet enchâ̂nement dans l'utilisation des eaux (usage industriel, décantation, usage ménager), logique quoique hypothétique, impliquerait un captage des seules eaux du Gapeau plutôt que du Réal-Martin, ce qui placerait la décantation avant l'usage industriel.

$\mathrm{Au}$ niveau du bassin 6 et du moulin, la disparition rapide des concrétions vers l'aval permet de penser que les eaux alimentant ces ouvrages devaient présenter un pouvoir incrustant relativement faible (ce qui est en accord avec le captage des eaux du Gapeau ou du RéalMartin). Les dépôts de carbonates se limitent aux seuls 
points où régnaient des conditions favorisant une saturation des eaux (dégazage par forte agitation du moulin, suintement cascadant et évaporation sur les flancs du bassin). À l'aval de ces lieux, lorsque cessent les conditions favorables, l'eau reprend rapidement son équilibre et perd progressivement son pouvoir incrustant. Dans cette logique, on comprend pourquoi le tronçon d'aqueduc se raccordant au bassin et le bassin lui-même sont quasiment dépourvus de concrétions (sauf localement de petits dépôts discontinus de moins de $1 \mathrm{~mm}$ d'épaisseur). En effet, ces points de l'ouvrage pouvaient présenter des écoulements laminaires ne perturbant pas l'équilibre physico-chimique de l'eau et n'entraînant que peu ou pas de concrétionnement. Bien sûr d'autres facteurs pourraient expliquer cette absence : concrétions enlevées lors des nettoyages du bassin, vases et argiles décantées dans le fond du bassin et de l'aqueduc empêchant le dépôt des concrétions.

Dans cette logique d'eaux peu incrustantes, les dépôts de l'aqueduc semblent en contradiction avec les autres car il présente des concrétions alors qu'il est horizontal et ne montre pas de cause pouvant favoriser le concré- tionnement. Certes, les parois sont parfois non enduites, ce qui peut provoquer des turbulences dans l'écoulement, mais le tronçon de l'aqueduc se raccordant au bas$\sin 6$ présente les mêmes caractéristiques, mais sans incrustation. Dans ces conditions, ces concrétions ne peuvent s'expliquer sans la présence, à proximité, d'une structure entrainant de fortes turbulences : chute, vanne, dérivation. Vers le sud-ouest, on ne décèle aucune trace d'une telle structure, mais vers l'est, au droit du moulin hydraulique, dans un secteur très arasé, il existe les traces d'une fondation semi-circulaire qui semble partiellement entraver l'aqueduc. Ce pourrait être la trace d'une dérivation ou d'une martellière permettant l'alimentation du moulin ${ }^{51}$.

51. Cette hypothèse repose le problème du sens d'écoulement des eaux. En effet, les concrétions se développent logiquement au point de turbulence et à son aval. Or, ici, le seul élément de maçonnerie susceptible d'être à l'origine des turbulences est situé au nord-est des concrétions, ce qui voudrait dire que l'eau serait venue de cette direction, donc du Réal-Martin, ce qui s'oppose à la logique de distribution des eaux évoquée plus haut 


\section{BIBLIOGRAPHIE}

AMOURETTI M.-C.

1986 : Le pain et l'huile dans la Grèce antique. Evolution des techniques agraires d'Hésiode à Théophraste, Centre de Recherche d'Histoire ancienne de Besançon, 67.

1987 : La diffusion du moulin à eau dans l'antiquité, un problème mal posé, in : De Réparaz A. (éd.), L'eau et les hommes en Méditerranée, Actes du Colloque du GIS 1984, Paris, CNRS, p. 13-23.

1992 : Barbegal, de l'histoire des fouilles à l'histoire des moulins, Provence Historique (Autour de Paul-Albert Février), 167-168, p. 135-150.

AMOURIC $\mathrm{H}$.

1983 : De la roue horizontale à la roue verticale dans les moulins à eau. Une révolution technologique en Provence?, Provence Historique, 134, p. 157-169.

1984 : Moulins et meuneries en BasseProvence occidentale du Moyen Âge à l'ère industrielle, Thèse de $3^{\mathrm{e}}$ cycle, Aix-enProvence.

1990 : Carrières de meules et approvisionnement de la Provence au Moyen Âge et à l'époque moderne, in: Actes du $115^{\circ}$ Congrès des Sociétés savantes, Avignon, p. 443-464.

1993 : Histoire d'un échec, la mouture économique en Provence à la fin du $\mathrm{XVIII}^{\mathrm{e}}$ siècle, in : Les céréales en Méditerranée, Actes de la Table ronde, Paris, CNRS, p. 52-68.

À paraître : Meules et matériaux de mouture en usage en Provence de l'Antiquité à l'époque moderne, in: Actes du Symposium de Schloss (Tyrol), 1993.

Amouric H., Prades H., Vayssettes J.-L. 1989 : Le moulin antique de Cougourlude à Lattes (Hérault), Archéologie en Languedoc, Hommages à H. Prades, p. 111-112.
AVITSUR S.

1960 : On the history of exploitation of water-power in Eretz Israel, Israel Exploration Journal, 10, p. 37-45.

1969 : Water-mills in Eretz. Israel and their contribution to water power technology, Transactions of the $2^{\text {nd }}$ International Symposium in Molinology, Danemark, p. 389-407.

BAATZ D.

1995 : Die Wassermühle bei Vitruv X 5,2. Ein archäologischer Kommentar, Saalburg Jahrbuch, 48, p. 5-18.

BELL M.

1992 : Mulini di acqua sul Gianicolo, Archeologia Laziale, 11, p. 67-74.

1994 : An Imperial Flour Mill on the Janiculum, in : Le ravitaillement en blé de Rome et des centres urbains des débuts de la République jusqu'au Haut-Empire, Naples-Rome, Centre J. Bérard, p. 7389.

BENOIT F.

1940 : L'usine de meunerie galloromaine de Barbegal (Arles), Revue Archéologique, 15, p. 19-80.

1955 : L'art primitif méditerranéen de la vallée $d u$ Rhône, Aix-en-Provence, Ophrys.

BÉrato J., Dugas Fr.

1990 : L'occupation protohistorique du territoire communal des Arcs-surArgens, Revue Archéologique de Narbonnaise, p. 13-31.

1993 : Avant l'histoire, du Paléolithique au Bas-Empire, in : Les Arcs-sur-Argens. Pages d'histoire d'un terroir provençal, Aix-en-Provence, Edisud, p. 28-47.

BÉRATO J., BorRÉANI M., LEGUILlouX M. 1990 : La villa gallo-romaine des Laurons (quartier Saint-Pierre) Les Arcs-surArgens, Var, Documents d'Archéologie Méridionale, 13, p. 221-247.
Bérato J., Codou Y., Dugas F.

1992 : Le Prieuré victorin de SaintPierre, Les Arcs-sur-Argens, Annales de la Société des Sciences Naturelles et d'Archéologie de Toulon et du Var, 44, p. 101-105.

Bérato J., Palfi G., Dugas Fr.

1996 : Sépultures rurales de l'époque gallo-romaine aux Arcs-sur-Argens, Bulletin Archéologique de Provence, 26, p. 3-28.

BERTUCCHI G.

1992 : Les amphores et le vin de Marseille, $V T^{e} s . a v . J .-C .-I I^{e}$ s. ap.J.-C., $25^{\mathrm{e}}$ suppl. à la Revue Archéologique de Narbonnaise, Paris, CNRS Éditions.

BLANC J.-J.

1991 : La séquence des laminae carbonatées de la tranchée du chemin de fer au Grès (Sernhac), in : L'aqueduc de Nîmes et le Pont du Gard, Paris, CNRSConseil Général du Gard, p. 191-204.

BLOCH M.

1935 : Avènement et conquête du moulin à eau, Annales d'Histoire économique et sociale, 36, p. 538-563. (rééd. Mélanges Historiques, Paris, EHESS, 1983, p. 800-821).

\section{BOISVILLETTE M. DE}

1840 : Notice sur les substructions antiques de la ville de Gannes (Loiret), Mémoires de la Société Royale des Antiquaires de France, 5, p. 212-225.

BOYER R., FÉVRIER P.-A.

1959 : Stations routières romaines de Provence, Revue d'Études Ligures, XXV, 3-4, p. 162-185.

Boyer R., Arnaud G., Arnaud S., REymondon A., Desse J.

1986 : Un groupe d'urnes cinéraires $\left(\mathrm{I}^{\mathrm{er}}-\mathrm{II}^{\mathrm{e}} \mathrm{s}\right.$.) découvert près des Arcs- 
sur-Argens (Var), Gallia, 44, 1, p. 91120.

BRUN J.-P.

1985 : L'installation de pressurage romaine de La Philippe (La Crau, Var), Bulletin Archéologique de Provence, 16, p. 21-24.

1986 : L'oléiculture antique en Provence, Les huileries du département du Var, $15^{\mathrm{c}}$ suppl. à la Revue Archéologique de Narbonnaise, Paris, éd. du CNRS.

1994 : Hyères, Saint-Michel de Valbonne, Bilan scientifique 1993 du Service régional de l'Archéologie de Provence-AlpesCôte d'Azur, p. 161-162.

1997 : Um primeiro moinho hidraulico romano na Peninsula iberica, em Conimbriga, in : Portugal romano. A exploraçao dos Recursos naturais, Lisboa, Museu nacional de Arqueologia, p. 30-31.

BRUN J.-P., CONGÈS G.

1994 : La villa viticole romaine des Toulons (Rians, Var), Annales de la Société des Sciences Naturelles et d'Archéologie de Toulon et du Var, p. 219241.

1996 : Une crise agraire en Provence au troisième siècle de notre ère ?, in : Fiches J.-L. (éd.), Le III' siècle en Gaule Narbonnaise. Données régionales sur la crise de l'Empire, Sophia-Antipolis, APDCA, p. 233-256.

BRUN J.-P., OBERTI G.

1993 : La villa viticole de la ruc du Port à Cavalaire (Var), Annales de la Société des Sciences Naturelles et d'Archéologie de Toulon et du Var, p. 191-212.

BRUn J.-P., CONGÈS G., JACOB J.-P.

1993-1994 : L'archéologie de sauvetage : valeur heuristique et évolution de la doctrine, in : Mélanges P.-A. Féruier, Revue d'Études Ligures, LIX-LX, p. 103131.

Brun J.-P., Congès G., Pasqualini M. (ÉDS.)

1993 : Les fouilles de Taradeau (Var) : Le Fort et L'Ormeau, $25^{\text {e }}$ suppl. à la Revue Archéologique de Narbonnaise, Paris, CINRS Éditions.
Brun J.-P., Congès G., GÉbara C., PASQUaLINI M.

1985 : L'habitat rural dans le Var à l'époque romaine, Provence Historique, 141 , p. 233-251.

Brun J.-P., Guimfili. P., Oberti G., QUIN G.

1984 : Les marques sur tuiles de la côte des Maures (Var), Bulletin Archéologique de Provence, 14, p. 13-19.

Brun J.P., Rogers G. B., Collmeal P., THINON M.

1989 : La villa gallo-romaine de SaintMichel à La Garde (Var), un domaine oléicole au Haut-Empire, Gallia, 46, p. 103-162.

Callebat L., Fleury Ph.

1986 : Vitruve, De l'architecture, Livre X, Paris, Les Belles Lettres.

CASEvitz M.

1986 : Les utilisations de l'eau dans les techniques en lisant Diodore de Sicile, Strabon et Pausanias, in : Louis P. (éd.), L'homme et l'eau en Méditerranée el au Proche-Orient -IIIL'eau dans les techniques, Lyon, Maison de l'Orient, p. 15-19.

CAstella D. (ÉD.)

1994 : Le moulin hydraulique gallo-romain d'Avenches "En Chaplix », Cahiers d'Archéologie Romande, 62.

\section{CENTRE ARCHÉOlOGIQUe dU VAR}

1990 : Travaux du Centre Archéologique du Var, Annales de la Société des Sciences Naturelles et d'Archéologie de Toulon et du Var, p. 209-236.

Champagne Fr.

1990 : Le site gallo-romain du Pré de Avrillages (commune de SaintDoulchard), Cahiers d'Archéologie et d'Histoire du Berry, 103, p. 13-20.

Champagne Fr., Ferdière A., Riallano Y. 1997 : Re-découverte d'un moulin à eau augustéen sur l'Yère (Cher), Rerrue Archéologique du Centre de la France, 36, p. 157-160.
Champion E.

1996 : Moulins et meuniers carolingiens dans les polyptiques entre Loire et Rhin, Paris, Association pour l'Édition et la Diffusion des Études Historiques.

Chastagnoi. A.

1981 : L'inscription constantinienne d'Orcistus, Mélanges des Écoles Franşaises de Rome el d'Athènes, 93, p. 381-416.

Chaudru de Raynal L..-H.

1845-1847 : Histoire du Berry depuis les temps les plus anciens jusqu'en 1789.

Chouguer G., Favory F.

1992 : Les arpenteurs romains, théorie et pratique, Paris, éd. Errance.

Cianfarani V.

1958 : Guida delle Antichità di Sepino, Milano.

COMET G.

1992 : Le paysan et son outil. Essai d'histoire technique des céréales (France, VIII-XV" siècles), Rome, École française de Rome.

Congìs G., Lecachfur P.

1994 : Exploitation et domaine sur la côte varoise à l'époque romaine : exemple de la plaine de Pardigon (Cavalaire, Croix-Valmer, Var), in : Favory F., Fiches J.-L.. (éds.), Les campagnes de la France méditerranéenne. dans l'Antiquilé el le Haut Moyen Âge, Documents d'Archéologie Française, Paris, MSH, 42, p. 279-287.

Coudert J.-P., PAsQualini M.

1982 : La Crau : inventaire archéologique de la commune et de ses environs immédiats, Annales de la Société des Sciences Naturelles et d'Archéologie de Toulon et du Var, 34, p. 39-45.

CZYSz.W.

1993 : Eine bajuwarische Wassermühle im Paartal bei Dasing, Das archäologische Jahr in Bayern, p. 124-1 39.

1994 : Eine bajuwarische Wassermühle im Paartal bei Dasing, Anlike Welt, 25. p. 152-154. 
Dechandol H., Feuillet M.-P., Oniot TH.

1983 : Le grand domaine viticole du Molard, Histoire et Archéologie, 78, p. 56-57.

DenIS A.

1882 (4éd.) : Hyères ancien et moderne, Hyères, Souchon.

Desbat A.

1980 : Les céramiques fines rhodaniennes à vernis argileux dites sigillées claires $B$ et luisantes, Thèse de $3^{\mathrm{c}}$ cycle, Lyon, $402 \mathrm{p}$.

DÉsIRAT G.

1980 : Bagnols-en-Forêt, Var, Draguignan, chez l'auteur.

DRAGENDORFF $\mathrm{H}$.

1895 : Terra sigillata, Bonner Jahrbücher, 96-97, p. 18-155.

\section{DRESSEL H.}

1895 : Corpus inscriptionum latinarum $X V$, Instrumentum domesticum urbis Romae, Berlin.

\section{Euzennat M., Salviat Fr.}

1968 : Les découvertes archéologiques de la Bourse à Marseille, Marseille, Centre régional de documentation pédagogique, $48 \mathrm{p}$.

EYGUN FR.

1959 : Informations archéologiques, circonscription de Poitiers, Gallia, XVII, 2, p. 475-489.

\section{FÉDIÈRE $\mathrm{G}$.}

1981 : Tuiles et briques romaines estampillées de Fréjus et de sa proche région (Puget-sur-Argens, SaintRaphaël), Annales du Sud-Est Varois, VI, p. 7-20.

\section{FEISSEL D.}

1987 : Inscriptions chrétiennes et byzantines, Bulletin Épigraphique, 421, p. 356 .

\section{FÉVRILR P.-A.}

1977 : Frójus (Forum Julii) et la basse vallée de l'Argens, Cuneo, Itinéraires Ligures, 13.
FL.EURY PH.

1993 : La mécanique de Vitruve, Caen, Presses Universitaires.

FIXOT M. (ÉD.)

1990 : Le site de Notre-Dame d'Avinionet à Mandelieu, Valbonne, Centre de Recherches Archéologiques, CNRS.

Foss CL.

1976 : Byzantine and Turkish Sardis, Cambridge, Harvard University Press.

Gagnaire J., Argant J., Boy M., Cardon D., Chobard A., DuprÉ G., HÉRILIER CH.

1992 : Ambert, vicus gallo-romain, Chroniques d'histoire d'Ambert, hors série, 19.

GÄHWILER A.

1984 : Römische Wasserräder aus Hagendorn, Helvetia Archaeologica, 5760, p. 145-168.

GÄHWILFR A., SPECK J.

1991 : Die römische Wassermühle von Hagendorn bei Cham ZG, Helvetia Archaeologica, 86, p. 34-75.

GARCIN E.

1835 : Dictionnaire historique et topographique de la Provence ancienne et moderne, Draguignan.

GASCOU J.

1982 : Quand la colonie de Fréjus fut-elle fondée ?, Latomus, XLI, I, p. 132-145.

1992 : Aux bornes du territoire de Fréjus? À propos d'une inscription dc Saint-Michcl dc Valbonne, Provence Historique (Autour de PaulAlbert Féurier), 167-168, p. 55-64.

GASCOU J., JANON M.

1985 : Inscriptions latines de Narbonnaise, Fréjus, XLIVe suppl. à Gallia, Paris, éd. du CNRS.

GÉbara C., Pasqualini M.

1993 : Sépultures et cimetières ruraux en Provence orientale à l'époque galloromaine, in : Monde des morts, monde des vivants en Gaule rurale, Actes du
Colloque ARCHEA/AGER, Orléans, 7-9 fév. 1992, Tours, p. 341-366.

\section{Gerstinger H.}

1952 : Prodomus corporis epistularum privatarum inter papyros Graecas Vindobonenses asservatarum edendi, Aegyptus, 32, p. 363-381.

Gilles K. J.

1987 : Die spätrömische Grosskelteranlage von Piesport, Kurtrierisches Jahrbuch, 19, p. 53-59.

1990 : Die neu entdeckte spätrömische Weinkelter von Brauneberg, Funde und Ausgrabungen im Bezirk Trier, 22, p. $33-45$

1994 : Die spätrömische Weinkelter in Erden, Funde und Ausgrabungen im Bezirk Trier, 26, p. 33-41.

\section{GRUEL K., LEBLANC J.}

1981 : Un exemple de prospection sur un atelier de fabrication d'amphores : la Crau d'Hyères, Histcire et Archéologie, Les dossiers, Côte d'Azur, 57, p. 84 .

\section{GSELL ST.}

1911 : Atlas archéologique de l'Algérie, Paris, Imprimerie nationale.

Guendon J.-L., Valdour J.

1991 : Les concrétions de l'aqueduc : génèse et intérêt pour la connaissance du monument, in: L'aqueduc de Nîmes et le Pont du Gard, Paris, CNRSConseil Général du Gard, p. 175-190.

Guendon J.-L., Parron C., Huon S., GÉbara C., Michel J.M.

1994 : Prcmicrs résultats sur l'étude géochimique des concrétions calcaires de l'aqueduc romain de Fréjus, Bulletin Archéologique de Provence, 23, p. 66-80.

GuÉRY R., Hallier G.

1987 : Réflexions sur les ouvrages hydrauliques de Marseille antique retrouvés sur le chantier de Ia Bourse, in : De Réparaz. A. (éd.), L'eau et les hommes en Méditerranée, Actes du Colloque du GIS 1984, Paris, CNRS, p. 265-282. 
HAYES J. W.

1972 : Late Roman Pottery, London, The British School at Rome.

JACOBI H.

1912 : Römische Getreidemühlen, Saalburg Jahrbuch, 3, p. 75-95.

JACONO L.

1938 : La ruota idraulica di Venafro, L'ingegnere, 12-15, p. 850-853.

JACQUES Fr.

1992 : Les moulins d'Orcistus, rhétorique et géographie au IV s. s., in : Institutions, société et vie politique dans l'Empire romain au IV' siècle ap. J.-C', Rome, École française de Rome, p. 431-446.

JOHANNOWSKY W.

1994 : Canali e fiumi per il trasporto del grano, in : Le ravitaillement en blé de Rome et des centres urbains des débuls de. la République jusqu'au Haut-Empire, Naples- Rome, Centre J. Bérard, p. $159-165$.

JOUVEN A.

1848 : Traité pratique des moulins à farine, Aix-en-Provence.

KIESIING E.

1958 : Sammel Buch Griechischer urkunden aus Ägypten, VI, Wiesbaden, Harrasowitz.

LACROIX B.

1963 : Les moulins domestiques du IV siècle des Fontaines Salées, SaintPère sous Vézelay, Yonne, Revue Archéologique du Centre de la France, 14, p. 301-314.

LALBENHEIMER F.

1985 : La production des amphores en Gaule Narbonnaise, Paris-Besançon, Les Belles Lettres.

1989 : Les amphores gauloises sous l'Empire. Recherches nouvelles sur leur production et leur chronologie, in : Amphores romaines el histoire économique, dix ans de recherche, Actes du Colloque de Sienne, Rome, École Française de Rome, p. 105-138.
Laubenheimer F., Béraud I., Gébara C.

1991 : Les vides sanitaires et les amphores de la Porte d'Orée à Fréjus (Var), Gallia, 48, p. 229-265.

LfFVFAU PH.

1984 : Caesarea de Maurétanie, une ville romaine el ses campagnes, Rome, École française de Rome.

1995 : Les moulins de Barbegal, les ponts-aqueducs du Vallon des Arcs et l'histoire naturelle de la Vallée des Baux, Bilan de six ans de fouilles programmées, Comptes rendus de l'Académie des Inscriptions et BellesLellres, p. 115-144.

Leveau Ph., PAIllet J.-L.

1976 : L'alimentation en eau de Caesarea de Maurétanie et l'aqueduc de Cherchell, Paris, L'Harmattan.

\section{LOHRMANN D.}

1990 : Travail manuel et machines hydrauliques avant l'An Mil, in : Hamesse J., Muraille-Samaran C. (éds.), Le travail au Moyen Âge, une approche interdisciplinaire, Louvain-laNeuve, Univ. de Louvain, p. 35-47.

IORQUET P.

1994 : Découverte d'un moulin carolingien à Belle-Église, Le Pré des Paillard (Oise), Revue Archéologique de Picardie, 3-4, p. 51.

MANGARD M.

1982 : L'inscription dédicatoire du Théâtre du Bois l'Abbé à Eu (SeineMaritime), Gallia, 40, 1, p. 35-51.

MAZLA M.

1973 : Lotte sociali e restaurazione autorilaria nel terzo secolo d.C., Roma-Bari, Laterza.

MORITZ L. A.

1958 : Grain Mills and Flour in classical Antiquity, Oxford, Clarendon Press.

Neyses A.

1983 : Die Getreidemülhen beim römischen Land- und Weingut von Lösnich, Trierer Zeitchrift, 46, p. 209221.
Oleson J. P.

1983 : A Roman Water-Mill on the Crocodilion River near Caesarea, Zeilschrift des deutschen Palästinavereins, 100 , p. 137-152.

Palausi G.

1965 : Les tailleries de meules anciennes dans la région de l'Estérel et lcur relation avec la géologie, Bulletin philologique et historique du Comité des Travaux scientifiques et historiques, 44, p. 707-714.

PARSONS A. W.

1936 : A Roman Water-Mill in the Athenian Agora, Hesperia, 5, p. 70-90.

Peiliktikr J.-P., Pogurt M.

1993 : Des prospections à la fouille : recherches à Eyguières (B.-d.-R.), Revue Archéologique de Narbonnaise, 26, p. 181-246.

1995 : Eyguières, Saint-Pierre de Vence, Bilan scientifique 1994 du Service régional de l'Archéologie de Provence-AlpesCôte d'Azur, p. 120-122.

Pennacchietri L. A.

1966-1967 : Nuove iscrizioni di Hierapolis Frigia, in : Atti dell'Academia di Scienze di Torino -IIClassa di Scienze Morali, 101, p. 287328.

Phalil' B.

1992 : Le moulin à eau médiéval, Problème et apport de la documentation languedocienne, Archéologie du Midi Médiéval, X, p. 63-96.

Picianiol. A.

1959 : Informations archéologiques, Circonscription de Paris, Gallia, XVII, 2, p. 267-292.

Pleket H. W.

1988 : Greek epigraphy and comparative ancient history : two cases studies, Epigraphica Anatolica, 12, p. 25-37.

POURSAT J.-C.

1981 : Informations archéologiques, Circonscription d'Auvergne, Gallia, 39,2 , p. 453-455. 
1983 : Informations archéologiques, Circonscription d'Auvergne, Gallia, 41, 2, p. 421-429.

Provost M., Mennessier-Jouannet Chr. 1994 : Carte archéologique de la Gaule, 63, 2, Le Puy-de-Dôme, Paris, Académie des Inscriptions et Belles-Lettres.

Py M.

1992 : Meules d'époque protohistorique et romaine provenant de Lattes, in : Py M. (éd.), Lattara 5, Recherches sur l'économie vivrière des Lattarenses, Lattes, p. 182-232.

RAKOB FR.

1993 : Der Neufund einer römischen Turbinenmülhe in Tunesien, Antike Welt, 24, 4, p. 286-287.

RAKOB Fr., RÖDER G.

1989 : Die Mühle am Medjerda-Fluss, High-tech vor 1700 Jahren, Bild der Wissenschaft, 12, p. 94-100.

RIALLAND Y.

1989 : La détection des sites en milieu alluvial : l'exemple de la Rocade ouest de Bourges, commune de Saint-Doulchard, Cahiers d'Archéologie. et d'Histoire du Berry, 98, p. 11-18.

RÖDER J., RÖDER G.

1993 : Die antike Turbinenmühle in Chemtou, in : Rakob Fr. (éd.), Simitthus -I- Die Steinbrücke und die antike Stadt, Mainz, von Zabern, p. 95102.

ROHMER P.

1996 : Le moulin carolingien d'Audunle-Tiche, L'Archéologue, 22, p. 6-8.

RoMfuF A.-M.

1978 : Un moulin à eau gallo-romain aux Martres-de-Veyre (Puy-de-Dôme), Revue d'Auvergne, 92, 2, p. 23-41.
Roos P.

1991 : $\mathrm{Zu}$ antiken Wassermülhen in Kleinasien, in : Basgelen N., Lugal M. (eds.), Festschrift für Jale Inan, Istanbul, p. 495-499.

1996 : Strabo and the water-mill at Cabira, Opuscula Romana, 20, p. 99103

ROUILLARD J.

1996 : Moulins hydrauliques du Moyen Âge. L'apport des comptes des chanoines de Sens, XV' siècle, Paris, Association pour l'édition et la diffusion des études historiques.

SAUZE E.

1993 : Les Arcs-sur-Argens, Pages d'histoire d'un terroir provençal, Les Arcs, Edisud.

SCHIøLLR TH.

1989 : The watermills at the Crocodile River : a turbine mill dated to $345-380$ A.D., Palestine Exploration Quarterly, 121 , p. $133-143$.

Schiøler Th., WiKander Ö.

1984 : A roman watermill in the Baths of Caracalla, Opuscula Romana, 14, p. 4764.

SCHWAB M. (ÉD.)

1977 : Le Talmud de Jérusalem, 3, Paris, Maisonneuve et Larose.

SIMPSON GR. (ED.)

1976 : Water-mills and military works on Hadrian's Wall. Excavations in Northumberland 1907-1913 by G. Simpson, Kendal, Titus Wilson \& Son.

Small A. M., Buck R. J.

1994 : The excavations of San Giovanni di Ruoti -I- The villas and their environment, Toronto, R.O.M.
SPAIN R. J.

1984a : Romano-british watermills, Archaeologia Cantiana, 100, p. 101128.

$1984 \mathrm{~b}$ : The second century romanobritish water-mill at Ickham, Kent, History of Technology, 9, p. 143180.

1987 : The roman water-mill in the Athenian Agora. A new view of the evidence, Hesperia, 56, p. 335-353.

TCHERNIA A.

1995 : Les dimensions de quelques vignobles romains, in : Du Latifundium au Latifondo, Bordeaux, CNRS Éditions, p. 383-394.

VINDRY G.

1981 : L'huilerie romaine du Candéou à Peymeinade, Histoire et Archéologie, Les dossiers, Côte d'Azur, 57, p. 71-74.

WIKANDER Ö.

1979 : Water-mills in ancient Rome, Opuscula Romana, 12, p. 13-36.

1981 : The use of water-power in classical Antiquity, Opuscula Romana, 13, p. 91104.

1984 : Exploitation of water-power of technological stagnation?, A reappraisal of the productive forces in the Roman Empire, Lund, Regiae Societatis Humaniorum Litterarum Lundensis.

1985 : Archaeological evidence for early watermills. An interim report, History of Technology, 10, p. 151-179.

1990 : Water-power and technical progress in classical antiquity, in: Ancient Technology, Actes du Symposium d'Helsinki, 1987, p. 68-84.

WILSON A.

1995 : Water-power in North Africa and the development of the horizontal water-wheel, Journal of Roman Archaeology, 8, p. 499-510. 